\title{
The Role of Art Education in the K-12 Curriculum in West Virginia A Comparative Case Study Using Ethnographic Methods
}

Helen G. Poffenbarger-Jordan

Follow this and additional works at: https://researchrepository.wvu.edu/etd

\section{Recommended Citation}

Poffenbarger-Jordan, Helen G., "The Role of Art Education in the K-12 Curriculum in West Virginia A Comparative Case Study Using Ethnographic Methods" (2016). Graduate Theses, Dissertations, and Problem Reports. 6428.

https://researchrepository.wvu.edu/etd/6428

This Thesis is protected by copyright and/or related rights. It has been brought to you by the The Research Repository @ WVU with permission from the rights-holder(s). You are free to use this Thesis in any way that is permitted by the copyright and related rights legislation that applies to your use. For other uses you must obtain permission from the rights-holder(s) directly, unless additional rights are indicated by a Creative Commons license in the record and/ or on the work itself. This Thesis has been accepted for inclusion in WVU Graduate Theses, Dissertations, and Problem Reports collection by an authorized administrator of The Research Repository @ WVU. For more information, please contact researchrepository@mail.wvu.edu. 
The Role of Art Education in the K-12 Curriculum in West Virginia A Comparative Case Study Using Ethnographic Methods

Helen G. Poffenbarger-Jordan

Thesis Submitted

To the College of Creative Arts

At West Virginia University

Masters of Arts

School of Art and Design

Art Education

Dr. Terese Giobbia

Professor Eve Faulkes

Dr. Erin McHenry-Sorber

Department of Art Education

Morgantown, West Virginia

2015

Keywords: art education, art educators, RESA, rural and urban West Virginia, CSOS.

Copyright 2016 Helen G. Poffenbarger-Jordan 


\section{ABSTRACT \\ The Role of Art Education in the K-12 Curriculum in West Virginia A Comparative Case Study Using Ethnographic Methods \\ Helen G. Poffenbarger-Jordan}

On the federal level, the visual arts are considered a core subject in the public school curriculum. However, the way in which visual arts curriculum is implemented in schools is largely left up to the individual states. This study focused on how art educators' design, direct, find support, and operate visual arts programs in the K-12 public school system in West Virginia using ethnographic research methods. 


\section{TABLE OF CONTENTS}

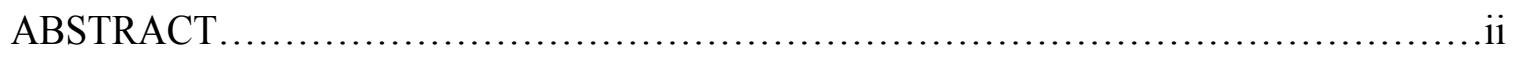

\section{CHAPTER 1}

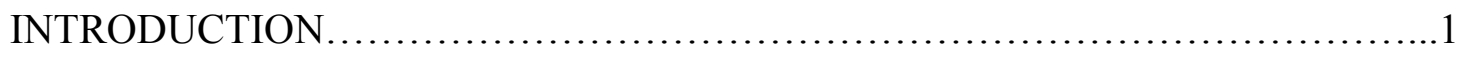

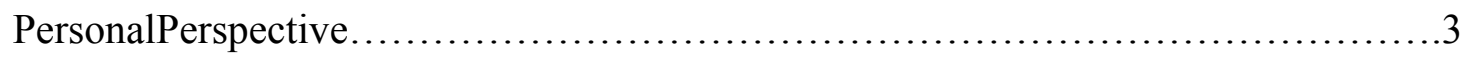

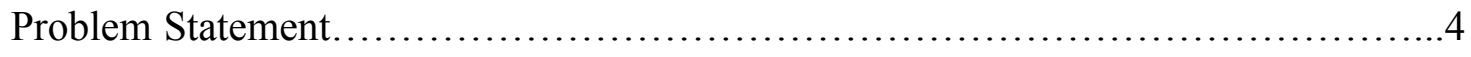

Conceptual Framework........................................................ 5

Research Questions............................................................

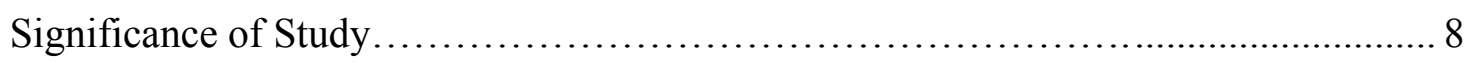

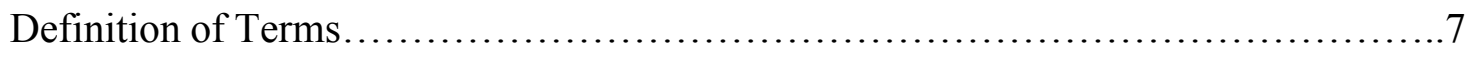

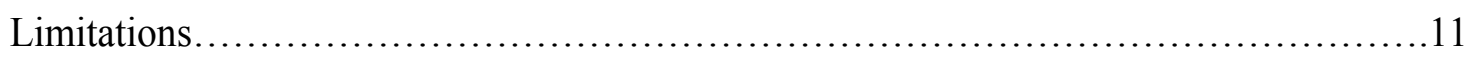

\section{CHAPTER 2}

LITERATURE REVIEW .................................................... 13

Art Education Policy Context...........................................13

Visual Arts Education Defined.............................................16

The History of Art Education as a Subject..................................16

Benefits of an Arts Education............................................ 18

Art Education and the Individual........................................ 22

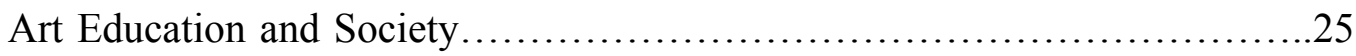

The Role of the Art Educator............................................28

Teaching and Learning in Appalachia; Pedagogy of Place.......................29

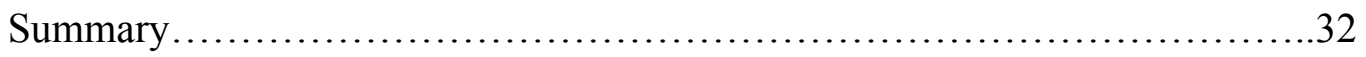

\section{CHAPTER 3}

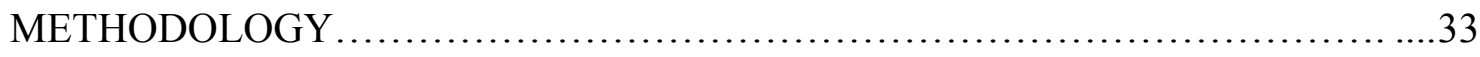

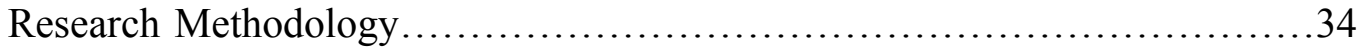

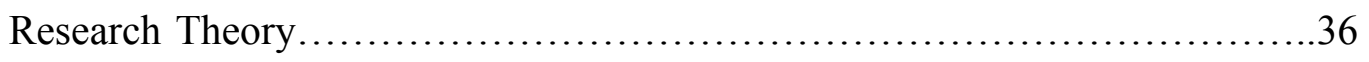

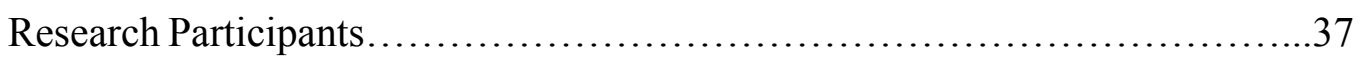




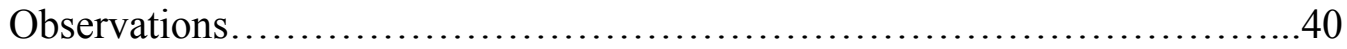

Documentation Review.................................................... 41

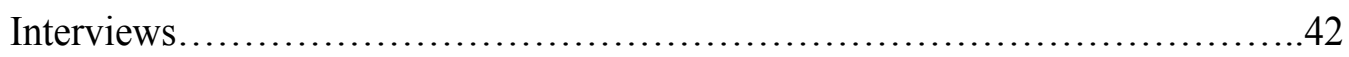

CHAPTER 4

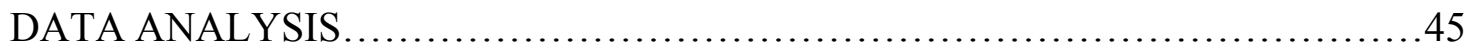

Participant 1.A........................................................ 45

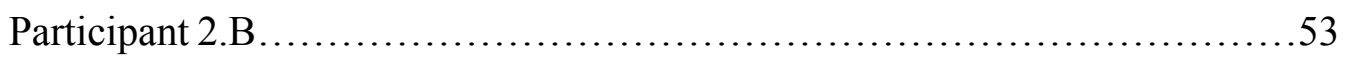

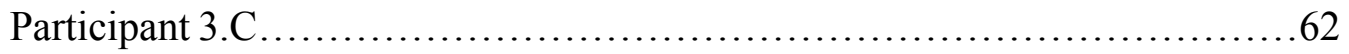

Participant 5.E..............................................................

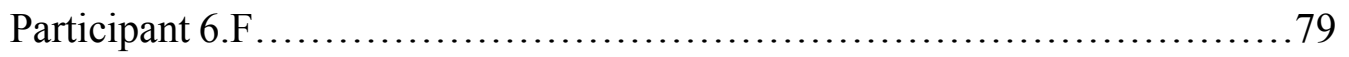

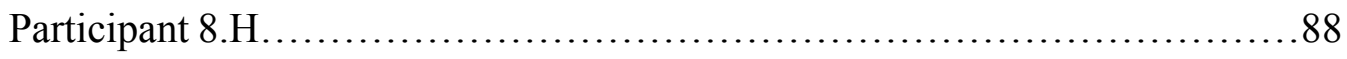

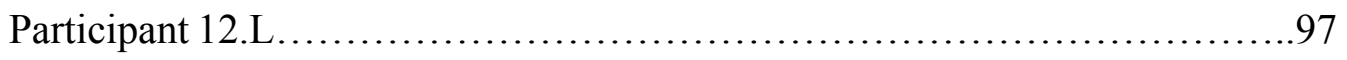

Participant 14.N..................................................... 106

Participant 17.Q...................................................... 116

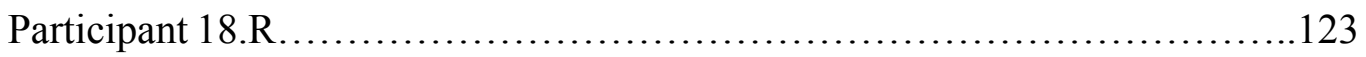

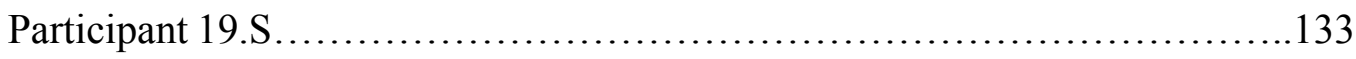

Participant 21.U................................................... 141

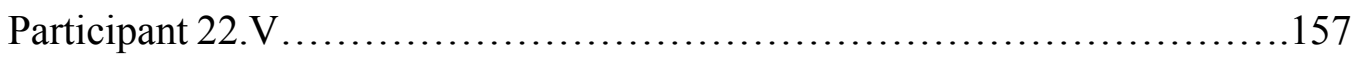

DATA ANALYSIS RESULTS...............................................

Methods of Instruction and Strategies........................................169

Support for Art Education Programs..........................................172

Art Education and Context............................................... 173

CHAPTER 5

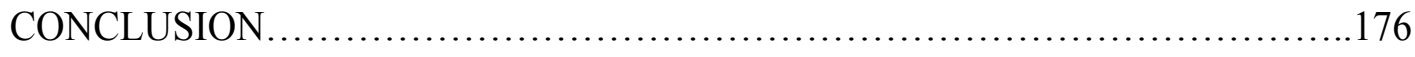

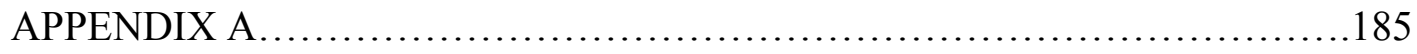

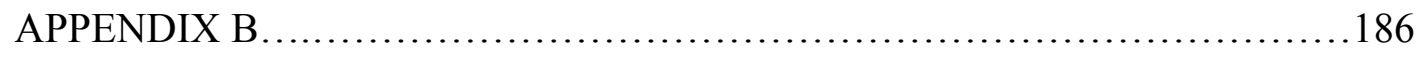

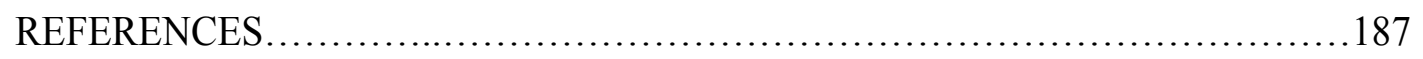




\section{CHAPTER 1}

\section{Introduction}

In 2015 the United States Senate passed the Elementary and Secondary Act (ESEA) reauthorization proposal, which defined art as a core subject in the K-12 curriculum (ESEA, 2010; Moran, 2015). While the arts are recognized as a subject that should be included in the K12 curricula, policies for Arts education programs are regulated and implemented through state governmental agencies and these policies vary greatly from state to state. While West Virginia affirms its commitment through its mission statement to provide its' students with 21 st century skills that include the visual arts there is nothing to indicate how these policies are being implemented throughout West Virginia. This research investigates the support and resources art education programs receive in West Virginia and the roles art educators play within these programs.

Visual arts are an important subject in the education curriculum and yet in this post-No Child Left Behind Act of 2001 (2002) era, the arts have decreased in content from the curriculum due to the increasing math content (Sabol, 2010). The West Virginia Board of Education recognizes the importance of art education, yet funding for the Arts are often vulnerable to cuts (Spohn, 2008; Zhao, 2014). Between the years 2010-2012, the U.S. national budget saw a 12\% drop in federal funding of the National Endowment for the Arts (Bohem, 2011). In the face of these cuts, many children only get minimal exposure to the visual arts in our public school systems (Walker, 2014).

In West Virginia arts education is a subject in the curriculum, but how these programs are being implemented can vary based on region. Arts education programs rely on tax monies. West 
Virginia is a state that has one of the lowest median incomes in the country (Noss, 2014; US

Census, 2010). This means there is a smaller tax base for education. West Virginia is a state that is losing population. This too, impacts monies for education.

The following research questions were investigated in this study:

1. Who is teaching art in rural and urban West Virginia; what education, background and experiences do they have?

2. What resources and support do they receive for their art programs?

3. What methodologies do selected art teachers follow in the planning, instruction, and assessment of art in the K-12 art classroom in rural and urban West Virginia;

4. How the art educators and their teaching methodologies influenced by the context of where they teach?

To answer these questions this study examined art educators who teach art in the state of West Virginia, and the support and resources these programs receive across the state. Attempts to learn about the backgrounds and experiences were conducted and answered through the interviews and the online survey.

The findings provided a detailed description of how art educators operate their programs in a state considered to be primarily rural, with higher than average levels of poverty affecting the students they teach. The data and descriptive information collected through this study can be shared with other art educators, administrators, new teachers in the field, and policy makers on the local, state, and national level. 


\section{Personal Perspective}

As part of my preparation to become an art teacher in the state of West Virginia I observed master art educators in their classrooms during the 2012-2013 calendar school year. The majority of my observations took place in art classrooms in public school systems of Harrison, Kanawha, Marion, and Monongalia Counties in West Virginia. It was during one of these observations at a high school in northern West Virginia that an English teacher came to the art classroom and asked for art supplies to complete a class project. The art teacher provided the necessary materials and after the teacher who borrowed the supplies left the classroom, the art teacher explained to me how she had devised a system with the assistance of school officials, to keep a running tally of all the paint, markers, tape and various other tools and materials for projects continually being "borrowed" from the art room. This information demonstrated to school officials how she was frequently called upon to give up some of her classroom supplies. Eventually through this information, the art teacher was able to make a case to the school administration to provide additional monies to purchase school community art supplies to be housed in a teacher workroom where everyone could use these supplies.. This way, the art budget was not being used for the entire school. 


\section{Problem Statement}

The art educator's contribution to a school community illuminates the essential role art education and the art educator fulfills in the state's education system. In West Virginia it is mandated that all children receive an arts education through the K-12 public educational system. Goals for incorporating the arts as a subject in West Virginia's curriculum are governed by the West Virginia Department of Education (WVDOE, 2015). The West Virginia Commission on the Arts extends support to the attainment of these goals for the arts education of the students of West Virginia through the Arts in Education Program. The mission of the Arts in Education Program is to advocate and support arts education for all students in the K-12 classroom in order to enhance learning and promote a life-long appreciation of the arts, including the visual arts, in the classroom through a "sequential, curriculum-based learning and hands-on instruction taught by qualified teachers with adequate resources" (WVDCH, 2015). One important role of the commission is to ensure that arts education be recognized as an important academic subject and student progress should be measured through assessment (WVDCH, 2015). Strategies on how each child is expected to acquire skills and knowledge in visual arts education from Kindergarten to the 12th grade are included, but it is not clear on how this should be, or are being implemented throughout the state.

The study also examined how this goal of including arts education in K-12 curricula is being implemented in classrooms across rural and urban settings in West Virginia. It explores how programs are impacted as art teachers, who are frequently called upon to support and supply materials for projects that are not part of their curriculum, deal with budget cuts to keep their programs operating. This study also provides a clearer picture of the roles art educators' play in providing the students of West Virginia with the skills and knowledge set needed to successfully 
complete their K-12 public education. The West Virginia Board of Education and the West Virginia Department of education provide $21^{\text {st }}$ century content standards and objectives emphasizing a rigorous, relevant, and challenging visual art curriculum to prepare students for the $21^{\text {st }}$ century (WVDOE, 2015). These standards and objectives are available for review through the West Virginia Department of Education website.

\section{Conceptual Framework}

This research study used Constructivist theory as its conceptual framework.

Constructivism is a theory developed through observation and scientific study about how people learn (Slavin, 2012). Its guiding principle contends humans construct their own understanding and knowledge of the world through experiencing things and reflecting on those experiences (Slavin, 2012). The views of art and art education as discussed by John Dewey (1934), a leading Constructivist, were examined as part of this research.

Constructivist theory demonstrates how knowledge is constructed through social interaction, such as that which can occur in an art education classroom (Crotty, 1998). Constructivist epistemology as research emphasizes the interactive process between the researcher and the participants (Crotty, 1998; Mertens, 2005). The constructivist approach acknowledges that the researcher brings constructed knowledge to the study (Mertens, 2005). 


\section{Research Questions}

The purpose of this research was to investigate the support and resources art education programs receive in West Virginia and the roles art educators played within these programs. The following research questions were investigated in this research:

1. Who is teaching art in rural and urban West Virginia; what education, backgrounds and experiences do they have?

2. What resources and support do they receive for their art programs?

3. What methodologies do selected art teachers follow in the planning, instruction, and assessment of art in the K-12 art classroom in rural and urban West Virginia;

4. How the art educators and their teaching methodologies influenced by the context what is being taught in art classrooms?

\section{Significance of the Study}

Little is known about the role an art educator provides in student achievement in West Virginia. At present, we do not have a cohesive or comprehensive body of information regarding who is teaching art in the state of West Virginia. After researching articles for my literature review and examining previous studies through West Virginia University's databases, I found research focusing on students, studies of art programs pertaining to rural schools and education, but I found no examples of a comparative-case study using ethnographic methods, of art educators West Virginia. 
This study seeks to investigate the important role art educators' play in the education system of the state of West Virginia. It is intended to provide a richly detailed description of how art educators operate their programs in a state considered primarily rural with higher than average levels of poverty (Noss, 2014). The data and descriptive information collected through this study can be shared with other art educators, administrators, new teachers in the field, and policy makers on the local, state, and national level. This proposed research seeks to provide an opportunity for colleges and universities in the state of West Virginia to better understand who is teaching the future students of their art programs. By creating a better understanding of the work of West Virginia art educators and the importance of the programs they lead, policy has the potential to create awareness of the benefits of art education for the students of West Virginia.

\section{Definition of Terms}

- Art Education

The history of art education in the public schools goes back as far as the 1870s when drawing was introduced as drafting courses (Efland, 1990; Bates, 2000). Visual art education traditionally includes mediums and materials such as drawing, painting and sculpture as well as ceramics, jewelry, textiles, and graphic design. Current trends in art education include computer technology, film, and installation art (Bates, 2000; Efland, 1990).

- Content Standards and Objectives (CSOs)

CSOs are course content descriptors that provide curriculum goals for educators. The CSOs are provided in the West Virginia Board of Education Policy 2520.12 and contain 
the $21^{\text {st }}$ century visual content standard and Objectives for West Virginia Schools. These content objectives are to be followed by art educators in West Virginia for the implementation of visual arts programs.

- Community:

A group of people who share common beliefs, a way of life, place or neighborhood, occupation, recreation, or some sense of purpose. Ordinarily, individuals in a community are drawn together through some kind of shared activity or interest (Congdon, 2004).

- Faculty Senate

West Virginia legislative code requires established at every public school West Virginia, a faculty senate which is comprised of all permanent, full-time professional educators employed at the school who shall all be voting members. Each faculty senate shall control funds allocated to the school from legislative appropriations and vote on spending according to mandated requirements and program needs. (WV Code 5, 2015).

- Rural

According to the current delineation by the US Census Bureau, released in 2010 and based on the 2010 decennial census, rural areas comprise open country and settlements with fewer than 2,500 residents (US Census, 2010). See Appendix B.

- S.T.E.A.M

STEAM is an acronym that stands for Science, Technology, Engineering, Art, and Math. It is a method of learning and assessment that ties all the subjects together in an 
interdisciplinary way that is applicable to the business and professional world. (Yakman, 2015).

- Urban

Urban or urbanized areas are developed areas that are comprised of residential commercial, and other non-residential urban land uses. Urban areas are areas comprised of 50,000 people or more. (US Census, 2010). See Appendix B.

- Urban Cluster

Urban Cluster regions must be comprised of more than 2,500 people to 50,000 (Census, 2010). See Appendix B.

- RESA

This acronym stands for Regional Education Support Agency and its purpose is to provide support and professional development for all teachers in the district. West Virginia has 55 counties that comprise the 8 RESA districts (WVDOE, 2015). See Appendix A.

\section{Limitations}

This research represented the following limitations:

a) Generalizations about the professional practice of art teachers are limited to the population investigated. 
b) Generalizations about the practice and qualifications of art teachers are limited to the population investigated. 


\section{CHAPTER 2}

\section{Literature Review}

The arts, and specifically, the visual arts provide a unique and distinctive role for providing students with a way to discover the self through an educational system (National Coalition for Core Arts Standards, 2014). The arts have been incorporated into every society and culture known to man, as far back as evidence of humans have been discovered (Efland, 2014; NCCAS, 2014). This study seeks to capture a glimpse of who implements these visual arts programs that provide a unique and distinctive way of learning in the West Virginia public school system.

\section{Art Education Policy Context}

The "arts" are currently listed as a core subject within the American education system but how the "arts" are defined and how they are implemented within the curriculum and regulated is left up to individual states to decide (Arts Education Partnership, 2014). The arts and visual art education are considered a part of the curriculum in West Virginia but how they are implemented from RESA to RESA, county to county, and educator to educator can vary given the context and setting.

The Elementary and Secondary Education Act (ESEA) regulates what subjects are to be covered in the classroom of the American public education system. Originally proposed and passed under the Lyndon B. Johnson Administration, ESEA attempted to provide an education reform bill intended to address education disparity (Brady, Thomas, 2005). ESEA has taken many forms in the last 40 years with the most recent being the Every Child Achieves Act, which

passed through the Senate in July of 2015 (Brady, Thomas, 2005; ESEA, 2015). The "arts" have 
been included as a core curriculum and therefore intended to be part of every student's public education experience. In the United States, education experts and policy makers continue to include the "arts" as a core subject that must be incorporated into the curriculum of all K-12 students, receiving a public education in the US in the 21 st century (NCAAS, 2014).

The National Coalition for Core Arts Standards (NCCAS) is an organization that is committed to defining and providing the standards for implementation of the arts in the education system as a core subject (NCCAS, 2014). Widely embraced since the 1990s, standards are published statements that define what students should know or be able to do in a certain subject area (AEP, 2014). Standards-based education continues to influence and shape the public education system in the United States. Individual states such as West Virginia, have been allowed to adopt and modify these standards as the conditions in which art education is taught in elementary and secondary schools is best understood at the state level (AEP, 2014). West Virginia has a system of laws and regulatory measures or policies that pertain to the teaching of visual arts in the $\mathrm{K}-12$ classroom.

Standards identify and promote the most effective pathways for students to develop the skills that enhance their abilities to be creative thinkers, makers and responders to the world in which they live (NCCAS, 2014). These standards, written by practicing art educators with the input of research specialists and professional artists, are intended to provide a clear framework for what students should be able to know and do in the artistic disciplines such as music, theatre, dance and the visual arts (NCCAS, 2014). This framework is accessible to West Virginia educators and all other educators across the country, to ensure consistency in the teaching of the arts as a core subject. 
With the exception of Iowa, every state has adopted a set of elementary and secondary arts education standards (NCAAS, 2014). State standards are designed to help arts educators provide the highest-quality curriculum guidelines, instructional methods recommendation, and assessment goals that provide students opportunity for success in school and eventually, career and these are supplemented with a set of newly revised national visual arts standards designed by the National Art Education Association (NCCAS, 2014). An important change to the revised standards was the inclusion of design and technology in the arts (NACCS, 2014).

West Virginia art educators, as well as administrators, policy makers and parents, are provided access to these 21st century standards through the Department of Education's website. Revised from the 1994 versions, the new standards emphasize development of what is called "Artistic Literacy" in all five art forms. The five art forms included are dance, media arts, theatre, music and the visual arts. The 21 st century standards are intended to empower students to carry out four shared Artistic Processes: Creating, Performing/Producing/Presenting, Responding, and Connecting (NCCAS, 2014). According to West Virginia's Department of Education, art education programs in West Virginia are to be designed and implemented in such a way that art educators are helping to prepare students for their futures both as individuals and as productive members of society in the 21 st century (WVDOE, 2008; WVDOE, 2015). This study sought to gain a better understanding of how art education policy is carried out by art educators in West Virginia. 


\section{Visual Arts Education Defined}

This term "visual arts" as it is implemented in this paper includes a great variety of visual media including more traditional media such as drawing, painting, printmaking, photography, and sculpture (NCCAS, 2014). As the definition has evolved to include the media arts such as film, graphic communications, animation and emerging technologies has been added (NCCAS, 2014). Other mediums included under the umbrella of visual arts by the NAEA also include architectural, environmental, and industrial arts such as urban, interior, product, and landscape design; folk arts; and works of art such as ceramics, fibers, jewelry, works in wood, paper, and other materials (NCCAS, 2014).

\section{The History of Art Education as a Subject in the Education System}

Historically, art education has been part of an academic curriculum since ancient Greek and Roman times (Efland, 1990). As a subject, art was first introduced to American public education through drafting classes in New England in the 1870s (Efland, 1990; Bates, 2000). By the 1950s art educators were directed to teach programs that were more child-centered. This back and forth of ideals and purpose of art education continued throughout the 1980s as Disciplinebased Art Education (DBAE) became the standard for curriculum development (Bates, 2000; Efland, 1990). This study seeks to examine how art educators define their education pedagogy based on current art education curriculum ideology.

The parallels between societal, cultural, and educational movements as they relate to the current state of education can be traced through the history of art education as a subject (Efland, 1990). Efland (1990) examined the origin of art education programs and how they developed and changed throughout the history of education. In his handbook, Efland (1990) provides a 
source for the foundations of art education as it functions today and discusses some of its current failings within the educational system. He gives an historical account of the failure of the British education system to provide artistic training to its subjects in the 1800 s specifically as reflected in their country's performance at the Crystal Palace World Exhibition (Efland, 1990). The products being exhibited were below the standards represented by other countries from around the world. He also provides a more a contemporary example when in the 1990's leading cinema producers found in they had to look overseas to find employees with better aesthetic and artistic training than those found in the United States (Efland, 2002). This type of historical knowledge serves as a platform for designing and implementing art education programs providing the most benefit to students. This idea takes careful consideration in examining the state of education and the place art education has within the American education system. Efland states:

"The arts themselves reflect the society in which they arise but so does the art education system that teaches the arts. Whether a system narrows access to the arts or makes the arts broadly available tells us something of the character of the society" (p.4).

His examples underscore the importance of visual arts education upon a society and its cultural artifacts. Sources of funding for the arts and arts education have declined over the last two decades and this underfunding may have some connection to the success or failures of the American education and economic system in general.

Art educators assert that the arts are unique to all other subjects in the curriculum in that they enrich, enliven and add meaning to the other subject areas and create avenues of knowledge for a variety of types of learners (Davis, 2008). Davis (2008) highlights the important role of imagination, representation and story telling that the arts and visual arts have, which give shape to the experiences of understanding and being human. 
Art Education scholar Viktor Lowenfeld (1903-1960) wrote the influential art education text Creative and Mental Growth It is in this text he states, "Art is often considered one of the highest forms of human expression"(Lowenfeld, 1987, p.20). Art can have multiple uses and meanings within societies and stands as a reflection of the society that creates it (Lowenfeld, 1987). He felt as art held an important role in the development of the person, it increased a child's "capacity for action, experience, redefinition, and stability" in a changing society filled with tension and uncertainty (Lowenfeld, 1987, p.22).

Lowenfeld (1987) examines both product and processes and asserts the visual arts as more than a pastime. He identifies children's art is meaningful communication (Lowenfeld, 1987). Children construct and organize knowledge through art making processes. Lowenfeld cited evidence of visual arts education's influence on aesthetic, social, physical, intellectual and emotional growth of children. Art education provides an important avenue of construction of knowledge and sense-making in the education system for the child learner.

\section{Benefits of an Arts Education}

Studies show visual arts is an important subject in the education curriculum and supports the cognitive and social development of a child. The implementation of the No Child Left Behind Act (2001) created an atmosphere of teaching to standards that were based primarily on literacy and numeracy while marginalizing the arts even though they are a mandated subject (Hetland, Winner, Veema, and Sheridan, 2007). NCLB (2001) has resulted in even further reduction for support of the arts (Hetland, et al. 2007). However, art education scholars, classroom teachers, and academic studies continue to point toward the multiple benefits of art education. 
Jessica Hoffman Davis (2008) maintains the status of the arts are unique to all other subjects in the curriculum in that they enrich, enliven and add meaning to the other subject areas and creates avenues of knowledge for a variety of types of learners (Davis, 2008). She highlights the important role of imagination, representation and story telling that the arts and visual arts have that give shape to the experiences of understanding and being human (Davis, 2008).

Eliot Eisner (2002) advocated the arts and their distinctive contribution as a critical part of a child's education and wrote about the cognitive importance experiences of viewing, interpreting and creating art has in the growth and development of the child. Eisner felt that arts could transform consciousness through the biological processes of the sense. He contends the senses allow the individual to experience and respond to the qualitative world but it is through the processes of learning and discerning that the individual grows. Eisner felt the arts had an important role to play in refining the senses and the cultivation of the imagination (Eisner, 2002). Eisner also describes the function of art where the role of cognition makes concrete the abstract. He explains that ideas and images are quite difficult to hold on to unless they are inscribed into a material that gives them some kind of semi-permanence (Eisner, 2002). Art processes, like writing, makes ideas more tangible. The visual arts have an important role in the classroom to provide a lens through which students can process their world.

Art education has the ability to stimulate this cognitive flexibility by presenting problems, or art projects with multiple solutions. Efland provides a cognitive account of the roles metaphor, imagination and narrative provide in the production and interpretation of artworks (Efland, 2002). It is through cognitive flexibility that Efland believes learners can use their knowledge in relevant and real-world situations (2002). He says that through this flexibility, learners can exercise the capacity to represent knowledge achieved, concepts and ideas through 
multiple methods that can take learning into many directions and can foster the formation of multiple perspectives (Efland, 2002). Efland asserts that within general education, the purpose of art education is not to induct individuals into the professional work and world of the fine arts community but rather, the purpose of art education is to give individuals ways to find meaning in the world of art for connections to their own lives and the lives of others in the everyday world (Efland, 2002).

One way the arts have been given a greater role in education is by integrating them, or intertwining them with other subjects (Davis, 2008). Art programs have the opportunity to provide learners with opportunities to examine multiple perspectives through the examination and production of art. This type of teaching, connecting the subjects, has the possibilities of new outcomes for learning and cognition (Davis, 2008). This implies that art education is a subject that can enhance fuller understanding and transfer between subjects.

Furthering the idea that art can be a critical component for integrations of subjects in the general curriculum, Efland explains the nature of interpretation of a work of art and how it frequently draws upon knowledge domains of other subjects. He believes the examination and study of artworks can be the foundation of an integrated model of general education (Efland, 2002). Efland argues,

If the aim of education is to fully activate the cognitive potential of the learner, ways have to be found to integrate knowledge from many subjects to achieve a fuller understanding than would be provided by content treated in isolation" (p. 104).

This emphasizes art education as a subject that enhances greater knowledge transfer between subjects within the curriculum. Efland asserts the nature of interpretation of a work of art and how it frequently draws upon knowledge domains of other subjects. He believes the 
examination and study of artworks can be the foundation of an integrated model of general education (Efland, 2002). By integrating art with other subject areas, art educators have greater capabilities to enhance the learning capacity of students.

Categorization and metaphor are two more cognitive processes that occur in many realms of learning within art education. Art educators believe imaginative cognitive operations like metaphor and categorization engage higher thinking, skills and performance (Davis, 2008; Efland, 2002). Efland also believes education should have as its ultimate goal, to expand the cognitive potential of the learner (Efland, 2002). This requires the recognition of the importance of the realm of imagination and the cognitive tools, like categorization and metaphor that make cognition operation possible, in all subject areas. Efland believes it is the visual arts are quintessentially the highpoint of cognitive operations (Efland, 2002). This perspective recognizes the benefits of complex thinking and knowledge acquisition that can occur through the processes of art making in the elementary and secondary art education classroom.

In order to better understand art education and its role in the education of a child, it is also important to understand the challenges that can affect the field. Efland identifies three problems that affect the arts as a subject in the general education system. First he says that there is a tendency for the arts to be regarded as frivolous entertainment and as a "nice" supplement for a student's cultural experience but only when time and resources allow (Efland, 2002). Davis refers to this attitude as "nice but not necessary" (Davis, 2008, p. 25).

The second challenge Efland identifies is a lack of understanding of the important role the arts can play in cognitive development, personal growth and knowledge acquisition (Efland, 2002). And the third problem he highlights is a lack of understanding by educators as how to 
utilize the arts for cognitive development or how to assess development fostered by the arts (Efland, 2002). By ignoring and downplaying art education and its role in public education, an important mode of learning is lost. It is important for public school administrators, teachers, parents and students to have a better understanding of the benefits of visual arts education specifically in the West Virginia public education system.

\section{Art Education and the Individual}

Studies show how organized education impacts the experiences a student may have in school helping to shape the individual person they eventually become (Eisner, 2002). Arts and specifically the art classroom have the potential for creating an environment that fosters individual development with the art educator serving as a guide to creative and cultural experiences. This highlights the importance of visual arts educators and their programs as they foster a vehicle for learning and shared knowledge that other courses may not.

Eisner saw transformation as the key aim of education and the role of the arts as a pathway to the refinement of the senses present in the individual learner, ultimately enlarging imagination (Eisner, 2002). According to Eisner, art education gave the student a chance to explore themselves and the world around them. As art educators and art education programs provided ways for students to express concepts and ideas of the imagination in concrete and expressive forms, art became a way of making the intangible tangible (Eisner)

The cognitive function of art is to help us notice and learn about the world and this in turn can provide the conditions for an awakening of the self to the world around us or "another way of knowing" (Eisner 2002). This increased knowledge and awareness can liberate the individual to a better understanding of the self and others and this increased understanding becomes a 
vehicle for cultural development (Eisner 2002). Art educators and their programs have the ability to awaken awareness of the self and others through the process of making art. In West Virginia, geography can limit a child's exposure to lives and cultures of faraway people. Art education can bring the world to them through exploration of the art of others and this in turn, can lead to a greater understanding of the self and fosters empathy toward others.

Davis (2008) advocated for art education as a means to get to know more about our self, and one another through a collaborative. Davis believes as we examine, interpret, make and share art in the classroom, we are opened to many points of view. This kind of thinking is critical to learners in the increasingly global economy where societies and cultures intersect.

Eisner, like Dewey, felt that experience was essential to growth and that arts education provided experience for performance and production, enhanced the expanding consciousness of the young mind, helped to shape dispositions and attitudes, and aids in the quest for meaning (Eisner, 2002; Dewey, 1934). Both Eisner and Dewey saw practical life skills as crucial to a child's development (Dewey, 1934). Visual arts education can provide learning opportunities in problem-solving, production, aesthetics and design that are essential components of life skills required for an individual living and working in the $21^{\text {st }}$ century.

Increasingly case studies on art education and the literature surrounding the effectiveness of arts education illustrate the positive benefits of arts education in our pubic schools (Brens, 2001; Clark, 2000; Hetland, 2007; Moorefield-Lang 2010, Newman, 2003). Students participating in art education effectiveness studies demonstrated how their art classes were an inspiration to them and helped to increase student motivation to perform well in other subjects (Brens, 2012; Moorefield-Lang, 2010). Many researchers and art educators emphasize that while 
more research needs to be done, it appears arts education is beneficial in the development of selfefficacy among adolescents (Newman, 2003).

The study of the role of arts education on the self-efficacy of middle school students in rural schools of North Carolina presented positive reports from the participants (MoorefieldLang, 2010). In conducting research for her Ed. D., Heather Moorefield-Lang observed, interviewed, and surveyed middle school students regarding the students' perceived relationships of arts to their motivation and self-efficacy. The majority of her findings reported that the students did indeed feel their arts education classes were an inspiration to them and increased their motivation to perform well in other subjects (Moorefield-Lang, 2010).

Studies like Moorefield-Lang's offer insight into the benefits of art education on the performance of students. Surely this kind of positive arts education engagement is just as important to the self-efficacy of middle school students across West Virginia as those in North Carolina. What this study implies for my research is that art education and the role of the art educator is important in the general growth, education, and development of our youth in West Virginia. A strong arts program led by a dedicated art educator can provide an infinite number of benefits to the education and development of our youth (Brens, 2012).

An approach to art education that is gaining momentum is a holistic and transformative alternative to the development of the student learner (this gained traction in the 90s). This approach takes into account all the facets of an individual while relating the person to society (Campbell, 2011). Addressing outdated models of teaching, a holistic approach recognizes the wholeness of the student. In this way, the art teacher takes each individual student into consideration as they create meaning and connection with themselves and to their world through 
art making processes (Campbell, 2011). This approach applied to art education begins with the present behaviors and demeanor, or presence of the art educator themselves (Campbell, 2011). The holistic approach also takes into account educational concerns of the post-modern era such as diversity, multiculturalism, environmentalism and critical thinking skills with respect for the individual learner as the educator guides the students into interaction with visual images, products and processes (Campbell, 2011). It is important to understand art educators in West Virginia may already be applying some aspects of this type of transformational learning in their art classes.

\section{Art Education and Society}

Art education has been a subject in the public school system since the late half of the 19th century. Art education scholars have often described art education under two categories: art for the benefit of society and art for the enhancement of the self (Bates, 2000). Eisner expressed the importance of arts education for a number of reasons including the visual arts as enhancing cognitive development, is supported by visual culture, fosters creative problem-solving, is supported by integrating other areas of academics, provides design education, allows creative self-expression and prepares a learner for the work world (Eisner, 2002).

Education philosopher, teacher, lecturer and author and proponent of education reform, John Dewey (1859-1952) saw the arts as fundamental process. He felt that through the compartmentalization by museums and the wealthy, the arts had lost connection with human learning. Dewey's philosophy of art and education took a naturalistic approach that viewed knowledge as arising from interaction of the human organism to its environment (Dewey, 
1958/1934). How art educators are connecting their programs and students with their environment and the society in which they live in West Virginia is largely unknown.

John Dewey expressed the importance of the role of art and art-making in the life of the individual and the collective community (Dewey, 1958/1934). He concluded that art is a product and a process that separates us from the animals (Dewey, 1958/1934). Dewey states that "every culture has its own collective individuality" and art is reflection of the individual as a part of collective humanity (Dewey, 1958/1934). He wanted to advocate on behalf of the arts by writing about them with the intention of emphasizing the connections between the art object and processes, the individual and society as a whole.

Current research supports the essential role of art and art education in the elementary and secondary education curriculum. Studies on creativity, innovation, and arts learning highlight the important policy makers and government agencies emphasizing that "creativity" is the genesis of innovation and the cornerstone of entrepreneurship (Ruppert, 2010). The author goes on to stress that creativity a key component for the design and development of new products and services (Ruppert, 2010). The information provided in this article emphasizes creative problem solving skills as one of the two main components to keeping the United States workforce competitive in a dynamic global economy (Ruppert, 2010). The driving idea or concept behind Ruppert's work is that by fostering creativity, imagination, and innovative thinking in our education system, we are developing a workforce capable of implementing new ideas that critical to the economic growth of the United States (Ruppert, 2010). As West Virginia faces changes in its economy and population, it is ever important to educate its students in ways that will keep them competitive in the global market. The creative and problem-solving aspects of visual arts education have the 
potential of preparing students for their future and for the advancement of the economic climate of West Virginia.

The author notes that the arts are also defined in federal legislation as a core academic subject and an important component of a complete and competitive education (Ruppert, 2010). She further discusses that states are redesigning their K-12 educational systems in ways that are attempting to meet the challenge of preparing students for a 21 st century education in a competitive global market. West Virginia was mentioned by the author as a state that is prescribing "changes to the curricula and standards to reflect the knowledge and skills young people need in the increasingly globalized, technology-rich future" (Ruppert, 2010, p. 3). This provides a strong argument for the important role of art educators and their programs in the education system and it also underscores West Virginia's commitment to provide its citizens with a 21 st century education.

Bates (2000) states two reasons that give rise to art education movements over time: art to support society and art to enhance the individual child (Bates, 2000). Art to support society tends to deal with design and skills based art education and its relationship to industry and the economy. Within this approach, art education courses have the potential to grow the individual learner but also grow and expand the learner's relationship to the society in which he or she lives.

A list of rationales for the teaching of art to enhance society, provided by author, Jane K. Bates (2000) includes:

to ensure economic security by developing creative and innovative thinkers for the workforce, to develop connections and enrich communication and 
understanding among people, develop and enhance trade and technical skills and to promote aesthetic appreciation (Bates, 2000 p. 9).

The examples provided are some of the ways that visual arts can enhance and promote growth of society in West Virginia.

To revisit the example of how the lack of art education and basic aesthetic skills is affecting the American workforce Efland (2008) highlighted the importance of art education to society when he shared how the movie industry in California had to look outside the United States to find qualified employees with training in the arts and basic aesthetics. This example is a reflection of the state of arts education in the United States. It is evident that the skills and knowledge attained in arts education is a critical component to a well-educated and well-trained workforce (Efland, 1990). Art education is important to the growth and development of the self, but also society as a whole.

\section{The Role of the Art Educator}

The quality of teaching and the quality of the curriculum are important factors affecting a child's development (Eisner, 2002). It is the educator, or in this instance, the art educator, and their program and classroom that holds an important place in a child's learning journey (Eisner 2002). Eisner asserts that the art educator's role is not to merely transmit knowledge but to find ways to enhance the students' thinking. Art educators, in best practice, are capable of guiding their students through active and engaging art processes that can be both challenging and illuminating.

The role of the art educator, as described by Eisner, is not one where the teacher merely transmits information, but rather where the teacher has an opportunity to be an environmental designer for the learner (Eisner, 2002). In this way the art educator has an opportunity to create 
an environment or situation that can stimulate a student's appetite to learn (Eisner 2002, p. 47). The art educator in West Virginia has the capability to create a situation and environment where students' creativity is ignited and their capacity to learn can be enhanced. It is the art educator who has the ability to shape the potential for creative learning in the visual arts classroom. Davis emphasizes this by suggesting the art educator has the important role of reflecting and modeling attitudes toward the arts (Davis, 2008). She asserts that the teacher's ability to positively encourage interest in artistic expression has direct impact on how a child views art (Davis, 2008).

Eisner also felt that the educator must know what skills or ideas the students have the capacity to learn and how they, the educator, will impart these skills to their audience. It is here the art educator can build upon what the students already know (Eisner 2002). When given a dedicated guide, art education has the capacity to invite the child into a whole new realm of learning. It is this kind of guide in art education that can transform a child's education experiences and worldview in the West Virginia public education system.

\section{Teaching and Learning in Appalachia; Pedagogy of Place}

West Virginia, the only state situated entirely within the boundaries of Appalachia, is in need of maintaining a workforce prepared to meet the challenges of a global economy. The learning environment in Appalachia can be challenging given its geography and demographics. There is great disparity of income between the wealthy and the poor (Eller, 2008). This disparity changes drastically between urban and rural West Virginia. With a lower than average graduation rate as well as one of the lowest income medians in the country the tax base to support education continues to shrink (US Census, 2012). Population loss in West Virginia also 
continues to be a concern as it affects tax bases that fund education. Loss of tax revenue means loss of monies for education as West Virginia remains one of two states to continue to lose population in 2014 (Gutman, 2015).

When the financial support for education is unavailable or lacking, programs like art can be affected and lose priority for available monies. This study is important in that it can shed light on how art educators manage their programs in the face of such challenges within the specific Appalachian region of the state of West Virginia.

Securing support and funding for visual art education has the potential to be challenging in a state with a struggling economy and a primarily rural population. Budget cuts in financial support for public arts programs is the current trend. The National Endowment for the Arts (NEA) saw a 12\% drop in federal funding between 2010-2012 (Bohmen, 2011). This kind of drop in funding can potentially have an impact on arts programs in West Virginia.

Education finance is often based on income tax formulas (Mathias, 2010). Therefore a correlation between income and monies earmarked for education exists. West Virginia ranked 47th in income for the year 2012 (US Census, 2012). The US census Bureau (2010) ranked West Virginia as 8 th in the top 10 states with the highest child poverty rates with $30.4 \%$ of children between the ages of 0-4 living in poverty and $23.4 \%$ of children from the ages of 5-17 living in poverty (Crouch, 2010; US Census, 2012). These are the challenges facing every educator in West Virginia, not just art educators.

In spite of obstacles for many West Virginians in attaining a high school diploma in the past, currently our state and federal government, along with improved road systems, have changed the range of opportunities for most West Virginians and education through high school 
is available to every child student age. Even though the number of Appalachians getting their high school diplomas rose to $77 \%$ in 2000 the Appalachian region, including West Virginia, lags behind the $81 \%$ for the rest of the nation (Eller, 2008). Fine arts requirements are a part of the coursework every high school student in West Virginia must take. However, implementation of visual arts programs may vary from county to county. This study was to examine the degrees of variation between the educators, their support, and their programs in West Virginia.

The geography of West Virginia and its close kinship ties has always played a part in the shaping of its' education and economics (Eller, 2008). With the varying and rural terrain of West Virginia, school consolidation has had an impact on schools and communities. School consolidation was considered a solution to budget shortfalls and local schools are closed to create larger regional schools (DeYoung, Howley,1990). Critics argue it has taken a toll on rural communities (DeYoung, 1990). Students potentially spend long hours commuting to school from their rural communities. This distance can make it more difficult for students and their parents to participate in school programs. Through consolidation many rural communities lose a center for community life (DeYoung,1990; Eller, 2008). The issue of consolidation and changes in community life and culture has the possibility of impacting art educators and their programs. How this is impacting visual arts programs is not entirely known.

In these times when funding for the visual arts is a lower priority, community art resources and programs have the opportunity to take on a greater role of education and expose school children to the visual arts in their service areas. Unlike sparsely populated geographical areas, art education programs in more densely populated regions have access to better public transportation. Students and residents of metropolitan areas have shorter distances to travel to art centers such as museums and public art spaces. Urban communities are homes to centers of 
business and governments where funding and support may be more readily available (Clark, 2002). It is the varying geography of West Virginia that has the potential to shape and affect art educators and how they operate their programs.

\section{Summary}

Art education has an important role in the cognitive and social development of all children. Keeping visual arts programs in the schools and communities is of great importance to the West Virginia's public education system. With budget cuts due to declining populations and tax revenue bases and the assessment-based system that has been at the forefront of public education, arts education and namely visual arts programs can be vulnerable to budget cuts and marginalization.

West Virginia is a state that is on the lower income level of the spectrum due to economic uncertainty and population loss. Therefore, its public education system can be subject to budget deficits, which can in turn affect visual arts programs. It is up to the art educator to find ways to keep their programs current and thriving in spite of these obstacles and how they are able to operate their programs may vary from RESA to RESA, county to county and educator to educator.

At this time, there is a gap in the literature regarding who is teaching art in West Virginia. No research is available that addresses what art educators specifically do to operate visual arts programs nor is there information on how art educators address their needs and the needs of their students. How are these needs are being addressed can potentially change given the context, such as geography, location and population. This study seeks to gain a greater understanding of the role of art educators and their programs in West Virginia. 


\section{CHAPTER 3}

\section{Methodology}

The purpose of this research is to describe the role the art educator provides in the West Virginia public school system. The goal of this study is aligned with the constructivist research paradigm in that it is intended to create a greater awareness and understanding of their role to other educators, to administrators and policy-makers, and can be empowering to art educators themselves. This chapter 1) describes the research methodology used in this study; 2) explains the sample group selection; 3) describes the procedures used for collecting the data, and 4) provides an explanation of the procedures and instrumentation used to analyze this data. The purpose of this study is to examine:

1. Who is teaching art in rural and urban West Virginia; what education, background and experiences do they have?

2. What resources and support do they receive for their art programs?

3. What methodologies do selected art teachers follow in the planning, instruction, and assessment of art in the K-12 art classroom in rural and urban West Virginia;

4. How the art educators and their teaching methodologies influence the context of what is being taught in art classrooms? 


\section{Research Methodology}

This methodology will employ a comparative case study using ethnographic methods. Ethnography is a method of research and study that focuses on a natural form of inquiry by participant observation and interviewing (Kvale, 1996). Case studies, ethnographies, and phenomenological studies have all been proven to be useful and effective research methodologies for studying inquiry within a "modernist phase" (Denzin \& Lincoln, 1998, p. 16).

Robert K.Yin (2010) describes qualitative research as being diverse in that a researcher can apply these methods in a myriad of ways, as it is adapted to a particular area of study. Qualitative research methods encompass as many as five particular characteristics (Yin, 2010). A characteristic highlighted by Yin, describes the importance of qualitative methods in the study of meaning in people's lives (Yin, 2010). Studying the work of educators, namely art educators requires the researcher to examine the role of the art educator encounters in the real world conditions of the geography, culture and economic climate of West Virginia. Another feature of qualitative research is its role in representing the perspective of the people in a study (Yin, 2010).

This research project employed a qualitative, comparative, multiple case study of art educators from the eight RESA districts in West Virginia using ethnographic methods. RESA stands for Regional Education Support Agencies. With a focus on individual art educator's perspectives, insights and interpretation of their practice, their program's support and setting, this study's primary methodology is a comparative, multiple-case study using ethnographic methods. Ethnographic methods require the researcher to delve deeply into the descriptive (Miles, Hubterman, Saldana, 2014). As is often the case for qualitative research, the researcher is the essential and main instrument for conducting the study (Miles, Huberman, Saldana, 2014). The 
researcher's main goal is to give words to, or rather descriptions and accounts of the ways people in particular settings come to understand, interpret and interact within their daily lives. While time and location provided boundaries and constraints, which limited time with each art educator, the interview method provided a glimpse into the daily work of the art educator in West Virginia.

It is through what Miles, Huberman, and Saldana (2014) call generalizability, which is the purpose of seeing processes and outcomes across many cases and contexts (Miles, Huberman, Saldana, 2014). This aspect of qualitative research can help this study develop richer descriptions and stronger explanations of art educators and their programs. The strength of studying multiple cases and how as each case is understood provides data for which "we hunger for understanding that comparative analysis can bring" (Miles et al, 2014, p. 101). The study of art educators in West Virginia as they vary from practice to practice and program to program under different contexts can deepen our understanding of the role the play and the service they and their art education programs provide to the students of West Virginia.

The intension behind cross-case analysis is to deepen understanding and explanation. Two specific reasons for using cross-case or comparative-case analysis is to enhance the relevance of general understandings among cases as well as the opportunity to apply understandings as they transfer from case to case (Miles et al, 2014). By examining a variety of art educators, their programs and their systems of support, a greater understanding of their role in the public education system in West Virginia can be more thoroughly understood. 


\section{Research Theory}

Researching and studying the role of art educators in the West Virginia school system requires a research paradigm under which to operate. For this thesis, the Constructivist research paradigm was implemented. Constructivist theory demonstrates how knowledge can be constructed through social interaction and that the research and data obtained must be interpreted within the context in which it was gathered (Mertens, 2005). In constructivist research, multiple perspectives are sought through qualitative methods such as interviews, observations and document analysis (Mertens, 2005). Interviewing and observing educators from both rural and urban West Virginia can provide the variety of perspective necessary to conduct a study that is rich in its data sources.

Constructivism is a theory developed through observation and scientific study about how people learn. Its guiding principle is: humans construct their own understanding and knowledge of the world, through experiencing things and reflecting on those experiences. Donna Mertens (2005) describes Constructivist epistemology as research emphasizes the interactive process between the researcher and the participants. The constructivist approach acknowledges that the researcher brings constructed knowledge to the study (Mertens, 2005). This relates to the research goals of this study as the participants (art educators) are being observed in their work environment, their opinions and ideas are sought through interactive interviews, and as the observer, I bring prior knowledge an experience as an art educator to the research. Research done through systematic inquiry with carefully executed data collection, analysis and interpretation can be used for a variety of reasons (Mertens, 2005). 


\section{Research Participants}

The units of analysis for this research are elementary and secondary public school art educators from all eight of West Virginia's RESA districts. As it would not be possible to interview every art educator in the state, a survey was included in this study and attempt were made through both RESA and county board offices throughout the state to extend the survey to every art educator in West Virginia. The survey portion was to identify the art educators who may have been most receptive to a face-to-face interview. Participants in the study were identified by invitation to contact me if interested in the interview portion. Participants were also recruited through recommendations by art educators who were receptive to the interview process.

RESAs are multiple county regions and they provide technical and professional development for the teachers working in the districts (WVDOE, 2015). Each RESA has a director and attempts were made at the outset of this study to contact each RESA director to collect a list of all art educators in the district for conducting surveys and the selection of the interview participants. Of the eight RESA districts that were contacted, only four responded and none were able to provide a list of art educators for their RESA.

After receiving a limited response from the RESA directors, each county superintendent in the state was approached by email letter, asking for information or suggestions about how the art educators in their region could be contacted for participation. With nearly one quarter of superintendents responding, several interviews were secured. Another method of recruitment for survey and interview participation was by professional acquaintance and word of mouth. 
The sample of educators was chosen based on the division of counties of the state of West Virginia through the RESAs. These multiple county regions each serve their particular geographic region. By comparing the cases between the RESAs, the research can show similarities and differences between educators and their programs.

For example, the eastern panhandle, RESA IIIV, of the state is situated between Maryland and Virginia. It has seen a population growth in the last few decades from the D.C. metropolitan area expanding into areas that were previously and historically rural farmland. This area's economy is driven by very different forces in comparison to that of RESAs I and II where mineral extraction industry have had a different type of impact on the landscape and the people. By purposefully choosing to study a minimum of two art educators from each RESA, this study can provide a range of contexts in which we find art educators working.

The study started in the fall of 2014 and continued through the 2014-15 academic school year. The sampling techniques chosen for this research are 1) convenience sampling because the researcher lives in Morgantown, WV and has limited funds for traveling to and spending time in the areas in which the participants live or work and 2) criterion sampling, which identifies specific criteria for why the participants were selected for this research (Mertens, 2005). Therefore, this study does not represent all teachers in West Virginia who are teaching art during the 2014-2015 school. Instead it represents a small percentage of the identified teachers who teach art in West Virginia.

This research collected from a select group of art teachers in West Virginia. Since the primary goal of this research was to discover who teaches art in the state of West Virginia and what kind of resources teachers have to teach art in their programs, data on the backgrounds and 
experiences of art teachers in West Virginia and their creative processes of these teachers as well as the creative processes of the students who are taught by these teachers will be collected. from multiple sources in multiple ways, including qualitative methods of direct observations, one-onone interviews, and documentation review in an effort to provide rich descriptions of the participants' perspectives and interpretations of their role as art educator in the schools and communities in which they serve. Specifically, this study sought to discover what informed art educators do to keep their programs relevant supported in the context of teaching in West Virginia. This study sought to gain knowledge as to who is teaching art in West Virginia and what are their backgrounds and educations. Information about who is teaching art programs in West Virginia can provide evidence of the important role the art educator has in the curriculum of the West Virginia public school system.

In an effort to determine the best practices of art educators data was collected from multiple sources in multiple ways, including direct observation of teachers within art programs, curricula documents, student activities, completed projects, assessments, field notes and personal artifacts (Bogdan \& Biklen, 2003; Denzin \& Lincoln, 1998; Glaser \& Strauss, 2011; Hoyle, Harris \& Judd, 2002; Mertens, 2005; Robson, 2002).

The survey portion of the research was intended to collect more information over a greater number of teachers, as well as recruit participants for the more formal face-to-face interview and/or classroom observations. While there are some indications that surveys have issues with reliability, the survey utilized as a broad platform to begin the research. The survey potentially gathers some basic information about art educators in West Virginia and the types of support systems they have in their schools, communities, and at the state level. It was also 
intended to provide in less, detail but over a greater number of teachers, important data as to what these educators and their programs have in common as well as the differences.

\section{Observations}

There is great potential in gathering data by being in the classroom to directly observe the teachers working within their environment and at their natural pace. Classroom observations can provide the opportunity to observe the way art educators support and manage their programs. There are many aspects of the classroom dynamics with which I chose to familiarize myself. I sought to gain a clearer understanding of how art educators in West Virginia are connecting their lessons to the daily lives of their art students.

I observed the instructional strategies art educators used to teach art within their classrooms. These teachers allowed me some access to their curriculum and most, their student product. Art educators in most cases met with me in their schools during the school day. Three participants met with me during the school day and invited me to stay for observations. Two participants met with me and told me they had put in their notification to retire somewhat unexpectedly. This provided a somewhat different dynamic than expected as they no longer had a classroom or current student work to provide as artifact. I met with both of those educators outside the school setting. Two currently teaching educators drove to meet me as it fit better into their schedule and the remaining educators met with me on their lunch or prep periods.

Each visit to a school provided me with permission and access to photograph art work and classroom set-up. When observing in the school setting, I was able to take note of the physical environment of the art room and its location within that particular school. Access to the classroom and school building also allowed for observation of general school procedures and a 
glimpse of the art educator's daily routines which most often included observing them fulfilling classroom duties other than those specifically designated for art instruction. With each observation and interview, field notes were gathered noting on key phrases expressed by the art educators as well as notes on physical surroundings and any data that appeared relevant to the study.

\section{Documentation Review}

Document analysis, a method for constructivist research, provided an opportunity to examine the art educator's curriculum to learn what art educators are teaching, from region to region. Teachers had an opportunity to share with me the types of lessons they are using with their students. It was illuminating to see which teachers are relying more on technology in the classroom and which teachers are using culture, current events or social issues in their lessons. Lesson expectations and design may be different from one school to another.

I collected physical evidence to further support my observations and interviews through documentation review. Very few teachers allowed me access to their physical lesson plans, instead describing lessons to me as they shared their students' work. One art educator did provide me with a few brief lesson plans that are included in the appendix. Two provided examples of rubrics but most were unable to provide the lesson plan documents due to time constraints. Each educator was offered the option of emailing me lesson examples later but only one art educator emailed information after our interview. This educator provided me with written insights and accounts of what it meant to them to serve the public education system in West Virginia. 


\section{Interviews}

Interviews are considered to be one of the most powerful sources of information for obtaining "meaning of the central themes in the life" of the participant (Kvale, 1996, p. 30).

Interviews, as described by Dr. Tony L. Whitehead (2005) fall under the two categories of informal/unstructured, conversational, and descriptive. Whitehead explains that it is through these conversational beginnings that a semi-structured and structured interview begins to develop (Whitehead, 2005). My intention is to open the "conversation" through the survey and, as data emerges, the selection of participants for the semi-structured interview and direct observation portions of my research will emerge.

In The Enlightened Eye, Elliot Eisner describes conversation as being close to teaching (Eisner, 1991). He asserts education is to be understood as a part of a system. Through the semistructured interview method comprised of a few of questions and prompts, I collected data and information regarding how art is taught in West Virginia, information on who teaches it, and how the art education programs are fitting into the school system as a whole. In these interviews or conversations, the art educator had the opportunity to teach me about their work and the visual arts programs of West Virginia.

Every interview was recorded for accuracy. Each of these interviews was transcribed through NVivo and then hand color coded based on the relevance to the thesis question it addressed. All recordings were successful except two. One was accidentally erased and another had poor audio quality that left some ambiguity in the transcription. The interviews gave the art teacher an opportunity to clearly express their ideas about their work, their programs, and the contexts in which they teach. 
Another productive aspect of the semi-structured interview method is to gain a better understanding through a detailed account of how their art programs are supported at the state, local, and school level. It is my intention to gain more specific information about how art educators acquire support (i.e. school budgets, donations, grants, supply donations, fundraisers etc.) and what support comes from the community outside of the school building.

As a researcher studying art educators, this study is to present the perspective of educators who have the important task of bringing the visual arts to students of West Virginia. A third feature applicable to this study, Yin describes as studying the context and conditions in which people live (Yin, 2010). This feature of qualitative research connects to the first feature wherein the conditions, contexts and constraints in which art educators live and work are to be studied and shared. This study also emphasizes the use of multiple sources of evidence, yet another feature highlighted by Yin (2010). This study strives to include many art educators from the different RESAs of West Virginia in order to provide many perspectives. This is intended to enrich our understanding of the role of art educators in our states educations system across a variety of settings.

The decision to conduct a thesis project as a comparative case study is important because of the diversity of population and geography in the state of West Virginia. West Virginia is one of the most sparsely populated states in America but it also has urban and suburban regions (US Census, 2012). Comparing the resources and support for art educators in rural areas of West Virginia to those of urban areas can provide a complete description of the practice and support for art educators and how this can vary from region to region. 
The field of ethnographic research is described as research that involves some immersion into people's everyday lives (Emerson, Fretz, Shaw, 1995). In traditional anthropological ethnography, the field researcher might know little about the group they intend to study and therefore immerse themselves in their subjects' daily lives, experiences, and culture (Emerson, et al, 1995). Having taught art as an uncertified art educator in elementary and secondary private school settings, there is a certain amount of art classroom experience that I bring to this study as a researcher. The intent as a student researcher was to report on the ordinary events, the unique successes, as well as the pressures and constraints affecting art educators in the West Virginia public school system and the programs they teach. 


\title{
CHAPTER 4
}

\author{
Data Analysis
}

\section{Participant 1.A}

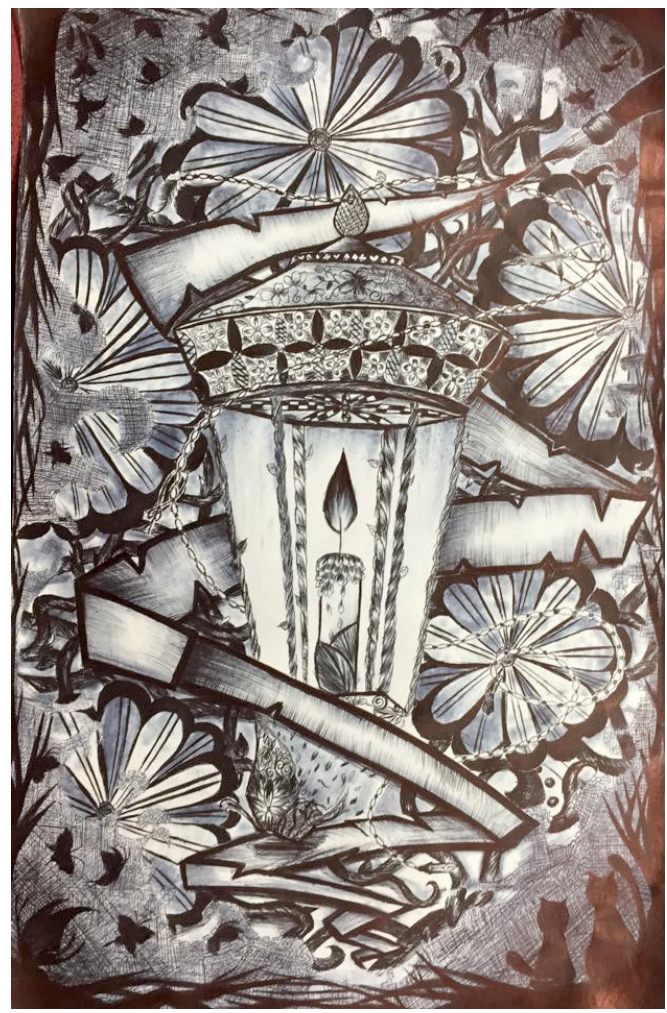

Figure 1; "Kill the Pen Project"; High School student work; pen and ink; RESA I, 2015.

The trip to the secondary school where educator 1.A taught brought me to a small city in the mountains of RESA I. The interview with 1.A took place at the school where they teach on September 8, 2015.

The area where this educator and school are located is marked by some growth and has a history with mineral extraction industries. In recent years, this part of West Virginia has seen a growth in the recreation and tourism industries. The county has four high schools and two technical schools total. The high school where this educator teaches has approximately 1400 
students. The campus was large with multiple buildings. The art room was located in a building separate from the main building. Ann said at one time the building housed all of the arts courses, including music and dance. Now it houses the arts and humanities courses. Teachers at all schools are required to stand in the halls during class transitions.

To answer the first question; "Who is teaching art in rural and urban West Virginia; what education, background and experiences do they have?"

Author: Have you always been an art teacher? Did you always know you would teach?

1.A: Always. I didn't know I was going to be an art teacher. I didn't have art in school. My first art class was at Concord University.

Author: Are you from the area?

1.A: I'm from Southern West Virginia. Pineville, Wyoming County. [RESA I]

For thesis question number two; "What resources and support do you receive for your art program?" I asked the question, "Do you have support for your program?

1.A: Yes, even though some administration doesn't understand what we do, we've got great support at this school.

Author: And community support?

1.A: Yes. I've got a really good relationship with the local art group. And so we have our art shows there. This community is very supportive of the arts. 
For the third question: "What methodologies do selected art teachers follow in the planning, instruction, and assessment of art in the K-12 art classroom in rural and urban West Virginia?

Author: $\quad$ How do you situate your practice as an art educator in the public school system?

1.A: Mostly it becomes a safe haven. I see the art room as a place where students get to know themselves and gain the confidence to go out and do well in other classes. I think in...on all levels that is our goal. On the higher level, when they get to ART III, IV, and AP, they get to know themselves as artists. They are the ones that continue to make art. But until you get that to that level. Art will always be part of their life, because we're humans. They will always need to understand good design.

1.A: Our charge in the school system today is so much different than it used to be when we were kids or even 10 or 15 years ago. That the whole thing that we teach art is not enough, we have to teach the whole child. If that means having a conversation about what happened in their life last night, while there working. If that means teaching them how to measure because they lost it in elementary school... whatever it takes to get the child to be successful, that's what we have to do.

1.A: I really like the ideas of learning communities the way the schools are going right now. I see us, as art educators...we're the ones that can reach our students at a level that other teachers are not able to reach them. All of 
the arts. Music, dance, theatre...choir, any of the arts. We reach kids in ways that no other teachers reach them. We pull things out of kids. We see things emerge...

For the fourth question: "How does the context of teaching art in West Virginia influence the work of art educators?"

Author: This is a big school.

1.A: People don't realize how big this school is. We've got 1400 students. It's a small town, and that in and of itself creates its own problems and situations. At one point...[announcement on intercom: 1.A, "we're getting iPads today"] At one point we were on the books as being the most diverse school in the state. I wouldn't have thought we would have more diversity than the more urban areas in West Virginia. But we have a student population that is $25-30 \%$ Black. We've got maybe $5-10 \%$ students who are Muslim. There is a diverse population as we have a lot of doctors in the area. We have the very, very wealthy to the very, very poor. I think our poverty rate is higher than average, somewhere around $50 \%$

Author: I want to understand how you teach art when you have kids coming to school hungry or homeless. How does that impact your work as an art educator? Is it a challenge?

1.A: It's definitely a challenge and that's what $\mathrm{I} /$ we have to... that's why what we teach has to transcend the material. It has to. We have to make these kids want to be here. We have to make them feel safe. In many cases, the 
only meals they get are at school. The only hugs they get are at school. The only peace they get is at school. And you know with iPads and social media the way it is today, the drawings have to mean something.

Author: Do they art education in the elementary schools in this county?

1.A: They need to have art education in every elementary school. They only have it in two schools in this county. The principals at those schools got it in there. Every school has one "support staff". Some schools hiring reading some schools...these particular schools decided to hire an art teacher as their support staff.

1.A: I can tell from the quality of work I get from the students, compared to those that never had art. It impacts their willingness to even try something new. The elementary teachers are so regimented because they've piled so much on them that the kids don't even get 15 minutes on the playground anymore. And so there's no creativity that goes on in the elementary schools. None. It's really scary.

1.A: In middle school they just have 6-9 weeks. So you when they come to high school many have had at the most, six weeks of art. When they come to me in high school, they're still drawing the sun in the corner. And the little box house.

1.A: So when we come in the art room, sometimes I just hand them a ball of clay and just say simply play with this, see what you come up with. 
Its really, nearly impossible to get them into that frame of mind, but if you can get them to do that. If you can get them there, they come to know that and then they start developing that and it becomes a need for them just like water and air. They realize that art takes them to a place where they don't have to worry about what's going on outside.

1.A: Then they are looking at these devices which already have other peoples' images. So, when we get them in the classroom and say, "Okay, you're going to create this picture." These children are so crippled they cannot use their creative minds. They cannot use their imagination. We've done that to these kids. These kids are still born with souls and with a creative spirit but they have never had a chance to use it.

\section{Case Analysis}

Art educator 1.A brings 35 years of experience to their practice which provides students with a curriculum and program that is consistent. There were numerous awards on this art educator's walls including one naming them "County Educator of the Year" and "West Virginia Art Educator of the Year". This art educator indicated intentions to retire within the next five years. It will be important for the school to maintain a consistent program after their veteran art educator leaves.

At this RESA I secondary school, the financial support for the program was available and the art educator had a proven record of student success which lent itself to receiving consistent support. Art educator 1.A reported a positive rapport with peers and with the community. This support led to successful community art shows and positive representations of the program 
throughout the service area. Due to state requirements for an arts credit and the size of the school, educator 1.A felt that the program would remain a solid and supported part of the curriculum even in the face of budget cuts.

Through the interview process 1.A described a variety of aspects of their methods, and art education philosophy as it pertains to the school, community, and students in their service area. This perspective offers a description of these young people and where they come from each day as they walk into the art education classroom room. It appears without the opportunity to work on art, which provides open-ended problem solving, students have difficulty do not know working creatively and without explicit instruction. This educator used constructivist principals within their lessons acting as a guide with students while they worked from drawing exercises for improving skills to more complex open-ended projects that incorporated personal expression.

Art educator 1.A described the technical, social, and cognitive benefits of their art education program as it pertained to student learning. Educator 1.A allowed for observations in the classroom. I saw multiple levels and a variety of learners working within the same classes. This educator balanced lessons between 3 levels of students during a single class. Students worked in small groups and there was a great deal of support from the educator through demonstrations and individual feedback and support.

\section{Figure 1 Analysis}

"Kill the Pen" is the title of the art projects. Upper level students create large scale drawings (18" x 24") using pen and ink as their solitary medium. They create their image and utilize a variety of line and texture to create dramatic light and shadow until the literally run out of ink or "kill the pen". This work exemplifies open-ended problem solving allowing the student 
to "find their voice" by choosing original imagery. They refine their drawing skills by rendering their images and completing them by maximizing the effects of light and shadow using a variety of line.

\section{Word Frequency Analysis}

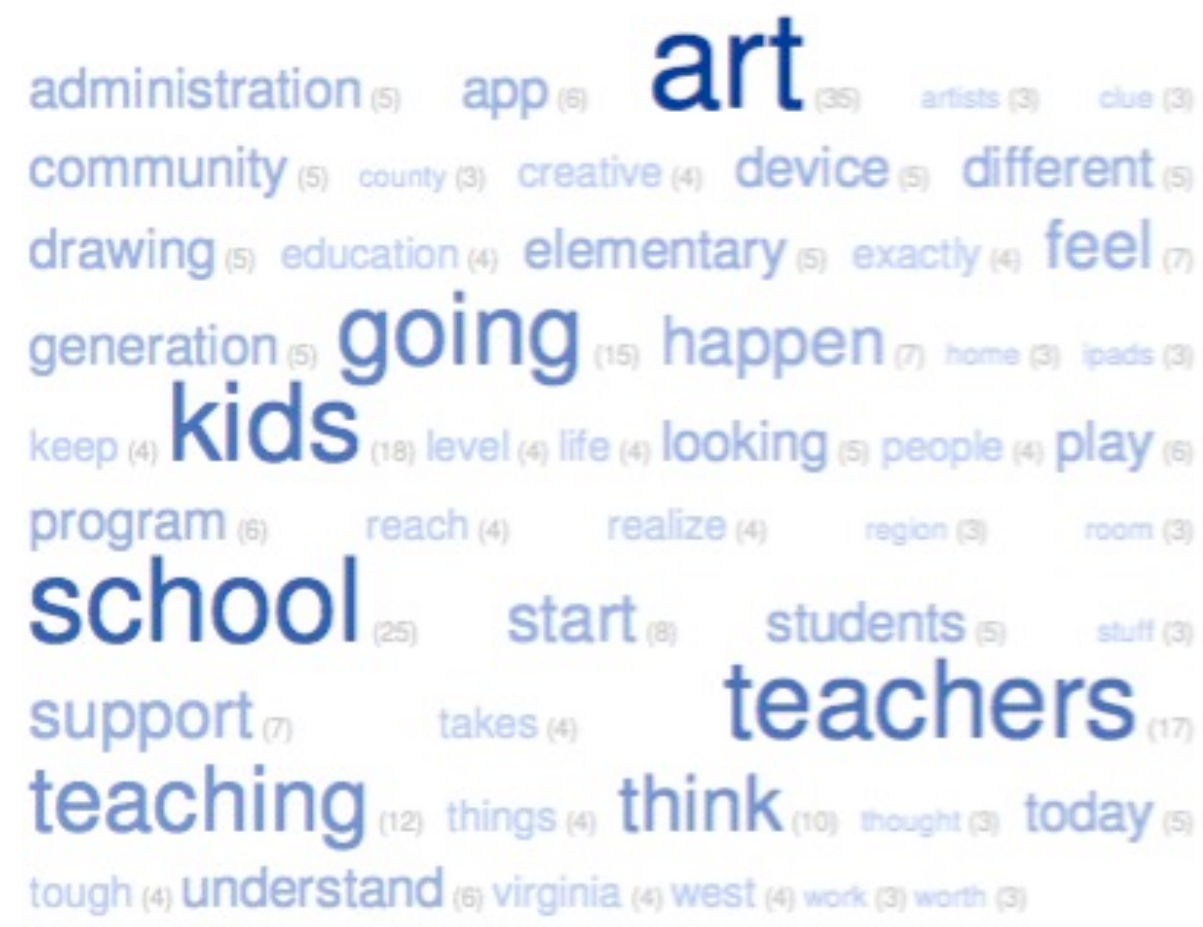

Figure 2; Word Frequency analysis from educator 1.A's interview transcription, 2015. 


\section{Participant 2.B}

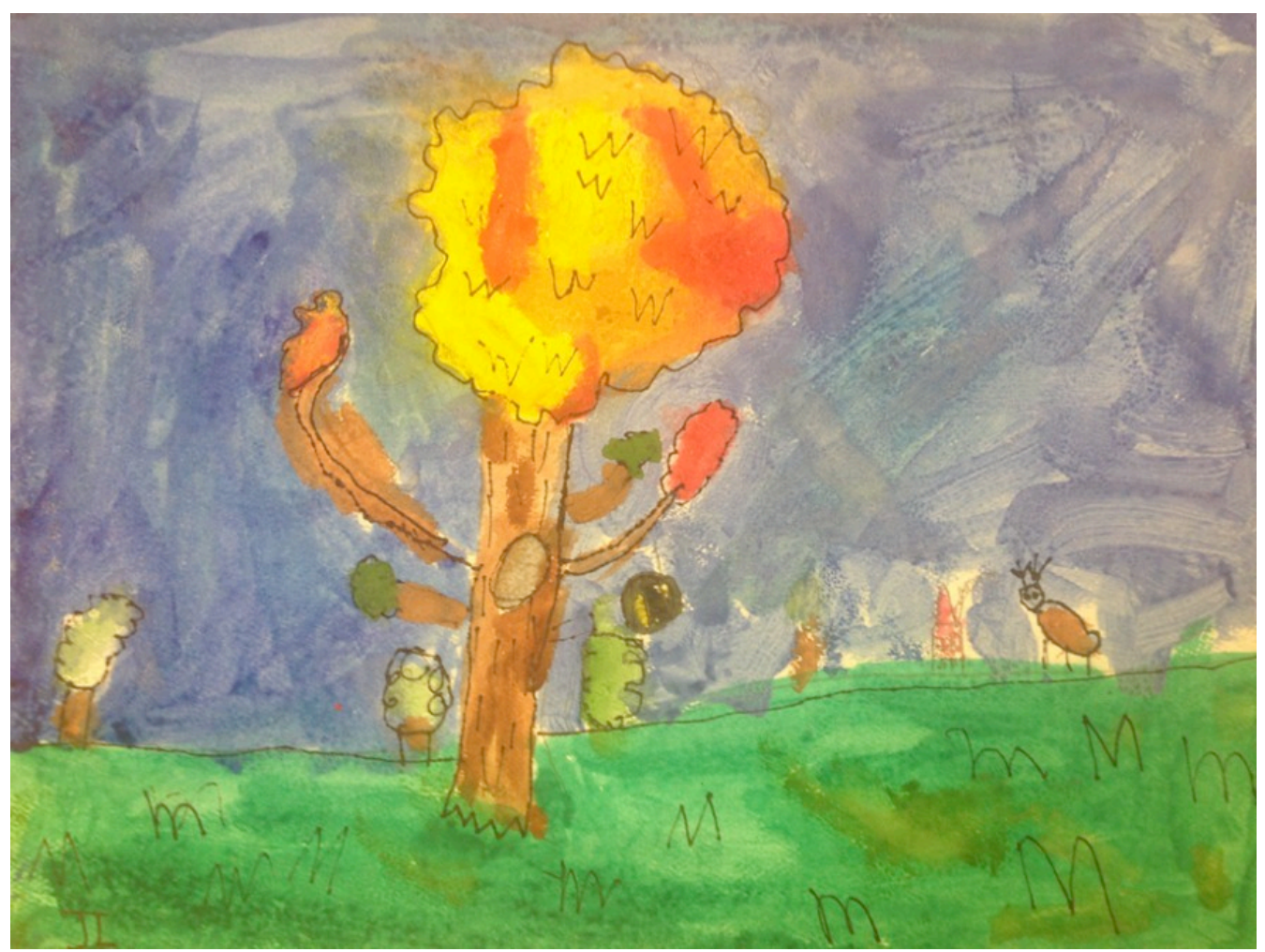

Figure 3; Fall Landscape; "Warm and Cool Colors-based Project"; watercolor; Elementary student RESA I, 2015.

Educator 2.B is a RESA I elementary art educator in a county that serves nineteen

elementary schools. There are only 2 full time art educators in the county. The elementary where this educator teaches is rural but on the outskirts of an urban cluster region. The majority of the county is Title I funded, but this elementary is not as it is located near a high-income gated community. The interview took place on September 24, 2015.

To answer the first thesis question; "Who are the West Virginia art educators? What are their backgrounds and experiences?" art educator, B.2 brings to their practice as an art teacher, previous experience as a special education teacher. Special education teachers require 
certification and extra course work on working with student of greatly varying abilities and needs. When asked if they felt this added to their practice as an art educator;

Author: What led you to teach art?

2.B: I've always loved art, I've always been interested in art. It's something I've enjoyed all my life. I had art in elementary school. And I kind of attribute that to my love of art. My whole family is kind of creative and artistic. Crafty. Originally I was going into commercial art. Quickly I realized that I would have to live in a bigger city to make any kind of money doing that. I went into art education. Left that field for a while and went into special education.

Author: Do you feel teaching special education lends itself to your practice as an art educator?

2.B: I don't see how it couldn't. Because I know that there are so many different levels and so many different ways that kids need to express themselves. There is a need and special education really opened my eyes. For one thing, we at this school some of the kids have discipline issues that are maybe special needs as well. They thrive in my art class. They thrive in here. I don't have problems with them.

For the second thesis question, "What kinds of resources and support do they receive for their program?" art educator 2.B talked about how they designed their program and garnered support. 
2.B: So I am supported here by the staff and by the administrator in our mission to bring visual arts education to the students. The kids love it. They love art. It can happen. Just like the other art teacher [in the county] is supported by another type of funding.

2.B: The money is not out there but you find it. It is out there. I was just pulling up the application date for an available grant. There are all kinds grants available through the of West Virginia Division of Culture and History.

For the third question; "What methodologies do selected art teachers follow in the planning, instruction, and assessment of art in the K-12 art classroom in rural and urban West Virginia?"

Author: What are some of the benefits art education brings to your students?

B.2: Critical thinking skills. Problem solving. Communication. Creativity. All the things they need for 21 st century learning. Art is a total different ballgame when it comes to standards. I use the West Virginia Standards when it comes to my lessons. And try to fit all of the CSOs in. I want to really try to make sure they understand those basic elements of art. I also want them just learning to love and enjoy it.

2.B: I think It's important. I think that a lot of the kids are lacking are problem solving skills. I think they don't know how to solve problems. They don't know how to think something creatively. It's all about the electronics. It's all about study for this and this and this. They might have general 
knowledge about something but when you give them the opportunity to really think about it, they don't know how to do that sometimes. And I think it's important they have the opportunity to express creativity, and to have an outlet to do it.

2.B: Even though they don't realize this is doing it, art education is giving them an option to think differently. Especially when they have to think a certain way so much these days, with all the computerized testing...

Author: How would you describe your practice, your art education program?

2.B: I'd like to do the same that my art teacher did for me in elementary school which was to give me a love of art. I give them a love of art. The kids come up and tell me "oh! My mom's getting me an art kit for home”. Or, “I drew you a picture! Look what I did!". That's my role. And not just to teach them a love of art but also teach them the actual elements of art an principles of design. So when they go up through the school system, they'll have a better knowledge of it and be able to create a beautiful work all their own.

Author: Is your program well supported? As I understand it, you're one of two art educators in the county? Were you brought in by local entities?

2.B: Last year, or year before, they passed the law that we had to have a 40 minute planning period. And our school only had a 30 minute planning period. SO we had to create another position to allow for the teachers to get a planning period. The principals had the choice of what [support staff] 
to hire. It could have been a technology person, it could have been an interventionist...we have music and physical education.

2.B: I was a first grade teacher who loved art. So I started an art club that was after school. We did some really wonderful things and I had some great kids. I did that twice a week so when my principal had the opportunity to hire somebody, she thought an art teacher would be a great person to have here.

2.B: The position is with the school system but it is not funded. I don't get any monies. However, we do fundraisers and we do the box tops for education and the music teacher does that and he shares the monies with me. So I am supported here by the staff and by the administrator. And the kids love it. They love art. It can happen.

Author: What are some of the challenges you and your program face?

2.B: Money. Of course that's always an issue for a lot of things like getting the kind of supplies you want to use. And time. 40 minutes is not a lot of time. We make a huge mess so when we talk about. We have a rotation. I see the kids every three days and when they rotate in they have the 40 minutes. We have to set things up. Like last year, we did clay and ceramics. So every grade level did it so I didn't have to try and clean up the mess. So it stayed a mess the entire time we did the project. 
In reflections and response to the fourth thesis question, "How the art educators and their teaching methodologies influenced the context?" art educator 2.B talked about designing and implementing lessons in a way that would save on time and materials.

2.B: I try to stick with the same materials even though I'm doing different projects so I can keep the same materials out, most of the time. But the time frame is a big challenge. When it's all said and done, we only get about 25 minutes to work, factoring in transitions, set-up and clean up. But we've got some good stuff going on.

Author: Do you find you have to work on ways to keep your projects going?

2.B: I'm working on a way to get a kiln. There's got to be a way. We've got to find a place. I'm always working an angle. I'm working on a grant right now. A STEAM grant. Because what I would like to order. I do community theatre as well. So I want to do a science is magic show.

Author: $\quad$ Are you a Title I school?

2.B: No. We are not a title one. We have about 550 students and we do have some low income instances but we also have a wealthier community that feeds into this school.

\section{Case Analysis}

The first thesis question addressed the question; "Who are our art educators and what are their educations and backgrounds. Art educator 2.B was born, raised, and educated within the RESA of their current teaching position. They have a background that includes graphic design 
and special education. This educator did leave the region in pursuit of another career but returned from a large city in the Northeast to go back to their teaching roots. 2.B worked as a general classroom teacher but continued to pursue art education endeavors outside of class time by teaching in the community and forming an active after-school art club while completing a certification in art education at a local state institution.

This art educator employment is a county funded [salaried] position, but the program itself, is not supported with any funds. This positon was created in order for general classroom teachers to receive the appropriate amount of planning time, 40 minutes, as required by law. The school community could have hired any number of support staff but chose to hire an art educator to augment their school's curriculum. When an art educator position was created, art educator 1.A was ready to direct the program. Choosing an art educator as support staff shows the level of commitment and interest the school, administration, and the community has in providing their elementary students with the valuable learning experiences attained in visual arts classes.

In this particular county within RESA I, there are only two art education programs in operation out of nineteen public elementary schools served. Even though this position is salaried, this art educator has to raise funds for supplies and materials, which include box tops for education, as well as grant writing, and donations. 2.B also described a local foundation from which has provided approval and funding for grants. Educator 2.B said the school has gotten several including one that has helped the school develop an outdoor classroom. Without grants like these, this art educator would not have glue, paint, paper, scissors and all of the other supplies an art teacher needs to provide students with beneficial cognitive experiences in the art classroom. The school does not have kiln so 2 .B transported 500 ceramics projects home to their own kiln at home for firing. This translates to the art educator transported the 500 projects from 
school to home and back again and also paid the electric bill to fire them. This art educator goes above and beyond the classroom hours and a budget to provide students with the best of materials and instruction.

Art Educator 2.B discussed the context of their teaching practice and reported methods they used to stay prepared and maximize student class time. As reported by all elementary art educators represented in this study, time constraints are a factor in the context of teaching in an elementary school setting. An art educator must consider materials, space, and storage. Transitions are what teachers refer to as the time it takes for children to come into a classroom and settle in their seats to work. Elementary children can require a little extra assistance in this matter depending on age and circumstances. "Set-up" is a term art teachers use to describe activities such as the passing out of tools and supplies to redistribution of artwork from an ongoing lesson. Setting up a lesson might mean the teacher has to supply all students with glue, paint, brushes or drawing supplies. It might also include putting on smocks to protect clothing. A well-prepared teacher has a system in place for these procedures and the students understand the procedures and know what is expected.

A number of art educators express art education classes as having the ability to reach students who have learning issues or difficulty with assimilation into their other classes. They cite examples of students who have emotional, developmental, and cognitive needs, able to be successful with projects and lessons in visual arts classes. Art educator 2.B shared specific examples of how art lessons conducted in their classroom were able to reach students with special needs, including an incidence of a particular non-verbal student who became more verbal by using their artwork as a platform for communication. This educator provided concrete 
evidence of visual arts education programs success in assisting in the growth and cognitive development of all types of learners.

This interview revealed an increasing concern by art educators surrounding digital learning and assessment-based education as it impacts creative and open-ended problem solving. Art educators like 2.B feel that visual arts classes provide learning for across a great number of learners. Citing the testing atmosphere of the current education system, this educator felt visual arts classes provided students with a different way of thinking. They also felt art education classes provided a necessary avenue of expression for students. This provides insight to the multiple ways children can learn through art education.

This elementary art educator knows the current standards and uses them in lesson planning. 2.B also wants to promote the benefits of appreciating and creating art as something, both activity and artifact, that can bring joy.

\section{Analysis of Figure 3}

Art educator 2.B was particularly proud of this example as the student who created it requires special instruction and is general non-verbal in communication. The artwork, dedicated the technical lessons of color and drawing, provided the student with the skills to open a conversation with the teacher. This educator feels that art education is imperative for the development of young minds and can reach students who may have difficulty in the general education classroom. 


\section{Word Frequency Analysis}

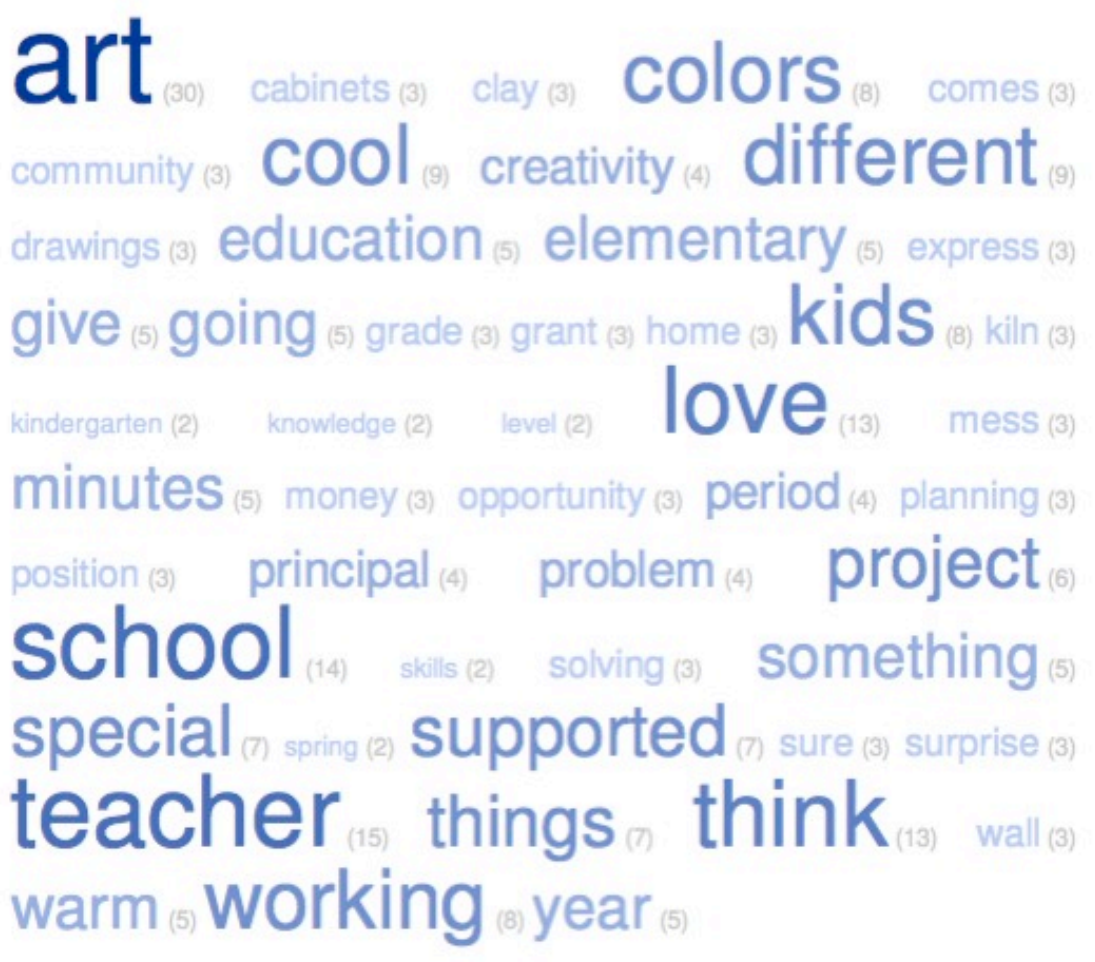

Figure 4; Word frequency analysis from interview transcripts with educator 2.B, 2015.

\section{Participant 3.C}

A rural school situated in historic farmland in RESA II not too far from the Ohio river, 3.C teaches at a combined middle and high school. This art educator teaches the 9-12 art courses. Currently the school is not set up to have art education in the middle school. 3.C's interview was conducted off-site on August 30, 2015. 
In reference to the first thesis question; "Who is teaching art in rural and urban West Virginia; what education, background and experiences do they have?" the participant discussed their education.

Author: And your master's is in?

3.C: It's in teaching and art education. I have 2 bachelor's degrees. One in graphic design and the other in 2D art.

Author: How long have you taught? When did you start teaching?

3.C: 2002. I took a small break.

3.C: I went back to it by 2004 and I knew I was hooked. I started back at the school where I graduated. I commuted every day for a semester. Then I found this job in the county where I teach. Next to the county where I live.

To answer the second thesis question, "What resources and support do they receive for their art programs?"

3.C: Well, we don't have a whole lot of money. We do a lot of drawing and painting. We don't really do ceramics. Ceramics is expensive. We'll do a papier-mache project instead.

3.C: My principal is very supportive and if there is extra money, she tosses it my way.

3.C: Of course, you still provide money out of your own pocket. You see materials and you know 'they would love this'. My spouse is great about 
it. Invariably when we're looking for something in the house, say, pencils, or tape...teaching is the one thing where you steal from your house. You see the good. They [students] need so much.

3.C: We have some benefactors and they graduated from the county schools. They came back to the area and they fund trips every year. The eighth grade gets to go to the Huntington Museum of art and make a pot, and tour and we have lunch there. There is also a high school trip. We can only afford one bus so I have to kind of pick and choose who goes. But if we didn't have that, I don't know what they would do. They love it. They look forward to it every single year.

In response to thesis question, "What methodologies do selected art teachers follow in the planning, instruction, and assessment of art in the K-12 art classroom in rural and urban West Virginia?" the interview question let to an elaboration of the benefits of the visual arts to middle and high school students. Participant 3.C stated business leaders say they want foster in their students what one would foster in productive employees:

3.C: I think the arts foster. Thinking outside of the box. Creativity. Interrelation. The list of art education benefits is...ongoing. We're teaching you to think critically. And everybody is all about project based learning and that is what we have always been. Name it and art. Even if it just appreciating aesthetics. Being more sensitive. Being more confident. In my art classes, you have to get up and show your work. That scares some people. We make it really accepting and safe 
because. I know how scary it can be. They say, "well I'm not going to be a speaker.

In addition to their role as an art teacher, 3.C as an educator utilizes the impact of reading as methodological tool for learning in their art classes.

3.C: I like to do writing and reading. Every day I read for 6 minutes and they are required to write three complete sentences in response to the reading. It sounds easy but it's not. They can summarize. They can think of something. It's a free-write. Students can critique the reading. I'm not grading for content, just mechanics. A lot of studies I've read indicate children, who are read to, are more interested in reading and can become better readers. So in my class, we pick a book. I read to them for six minutes. We do that every day.

3.C incorporates a second writing component for their class to enhance learning:

3.C: Each nine weeks the students are required to write a paper about an artist of interest.

For the fourth thesis question; "How the art educators and their teaching methodologies influenced by context?" 3.C replied to my assessment of the region as beautiful:

3.C: Go driving through there. Ah. Some of the best people, the salt of the earth. They appreciate everything...Because you know everybody. It's like a big family. The parents work closely with me. 
In reflection to the thesis question, "How the art educators and their teaching methodologies influenced by the context of where they teach?" art educator 3.C talked about their program in respect to the community in which they teach.

Author: How do you see your role and your program's role in the school where you teach?

3.C: We're an underserved population. It's a Title I school. A lot of times I do a lot of things that you would think stereotypically a parent would do. There is a saying that I believe so much, 'children who are loved at home come to school to learn. Children who aren't, come to school to be loved.' So a lot of my job is about looking after those kids. Sometimes I'm exhausted but I think we're learning. And maybe it's not just about art. I mean we do a lot of work with art, don't get me wrong, but at the end of the day, if I helped you be a better person. Helped you through sometime really negative then that is just as, if not more, important.

Author: What particular challenges do you and your program face?

3.C: It's not that those kids (kids from disadvantaged backgrounds) don't want to do art. They do. But when you're brain... some of these kids are in survival mode. A lot of these kids they don't even have power and running water. They don't know where they're going to sleep at night. Of course the parent in me comes out through my teaching. Sometimes I will just sit with them. I am authentic. I care about all of my students. 
Author: Are there any other challenges you face in your school setting?

3.C: The biggest challenge? The access to art is not equal.

3.C: Nobody in the county has an art degree ...or understanding of what art teachers do. I'm looking at CSOs how are my kids going to talk about the elements of art and principals of design. They don't even know those things exist. I have to go back and revisit their fifth grade CSOs. My principal has asked, 'why are you using a fourth grade CSO?' and I tell him, 'that's what I'm having to teach'.

3.C: It sets the tone for the state. The equal access part. Some parts of the state have arts education from kindergarten up, and others do not. Unless your grade school teacher did some crafts with you, you don't get anything. It's really sobering that some of these outlying areas...We took kids to the Clay Center and I thought they were going to die!

\section{Case Analysis}

Art educator brings to their practice two art degrees plus a MA in administration. They live in a rural county next to the county where they teach. 3.C's school is one of several joined middle and high school that serve rural communities in West Virginia. A small community school means that an educator is going to know students in a potentially more closely-knit environment. In 3.C's case, even if they don't have art in middle school, they start seeing the students in the building beginning in the seventh grade. This facilitates a familiarity that cannot be duplicated in a 9-12 high school where the student body is a thousand. Art educator 3.C 
teaches all of the visual arts courses for the school and also teaches dance. This educator has the opportunity to know their students in multiple contexts.

3.C says because the school community recognizes the dedication to their children, the families of students try to provide assistance at events and monies for needed materials as they can. Art educator 3.C said when unable to cover supplies with the budget, other people inside their friends and family network assist the program with monetary donations. 3.C, stated, "if I need money, there are a few who will help if they have it. My neighbors up on the farm are really good to help. They've given hundreds of dollars." In other words, if an art educator cannot find the support within their school community or if grants are unattainable or feasible, they sometimes choose to ask from benefactors who simply believe in the mission of visual arts education.

With respect to the third thesis question, "What methodologies do selected art teachers follow in the planning, instruction, and assessment of art programs in the K-12 art classroom?" 3.C felt there were too many inconsistencies in the implementation of programs therefore not all students in the state were receiving equal access to arts education. They also felt leadership didn't have a particular connection to arts programs. Because of the inconsistencies in the implementation of art education in the elementary and middle schools, art educators in the high schools, find themselves having to backtrack or teach concepts that should have been covered in the elementary schools. In this instance some students have never had an art class until high school. Educator 3.C reported having to re-teach concepts that were goals in the CSOs for elementary and middle school visual arts programs. 
Art educator 3.C integrates reading and writing into their visual arts program. This example of multiple-methods of teaching within the class structure proves art teachers not only have students producing traditional works of art, they are finding ways of teaching students to articulate the meaning and method behind their work or the work of other artists, cultures, and histories through reading and writing exercises. Also, in respect to classroom methodology and pedagogy, 3.C expresses a theme that implies art teachers are aware the majority of their students will not pursue a career in the visual arts. However, even though the course may not lead to a career in the arts, arts classes do provides necessary tools and skills that enrich the cognitive, social, and emotional development of students in their education.

\section{Figure Analysis}

Art educator 3.C met off-site for the interview. Several attempts have been made to share a photo of a particular lesson but nothing has been sent thus far.

\section{Word Frequency Analysis}


access (5) appreciate (4) 2 (27) asked (4) book (6) brain (6) bus (5) children (5) class ${ }_{(6)} \quad$ comes (6) community $(8)$ confidence (6) $_{\text {COUnty }}$ (10) course $_{(7)}$ creative (4) $\operatorname{csos}(5)$ culture (5) dance (6) education (7) everybody (7) getting (5) going garde help hars $\mathrm{kids}$ learning is listm looking love money parent people progaram read School somethings sometimes (6) student (5) Supportive (8) talk (4) teacher $_{(11)}$ teaching ${ }_{(10)}$ things think work

Figure 5; Word Frequency chart from interview transcripts of educator 3.C, 2015. 


\section{Participant 5.E}

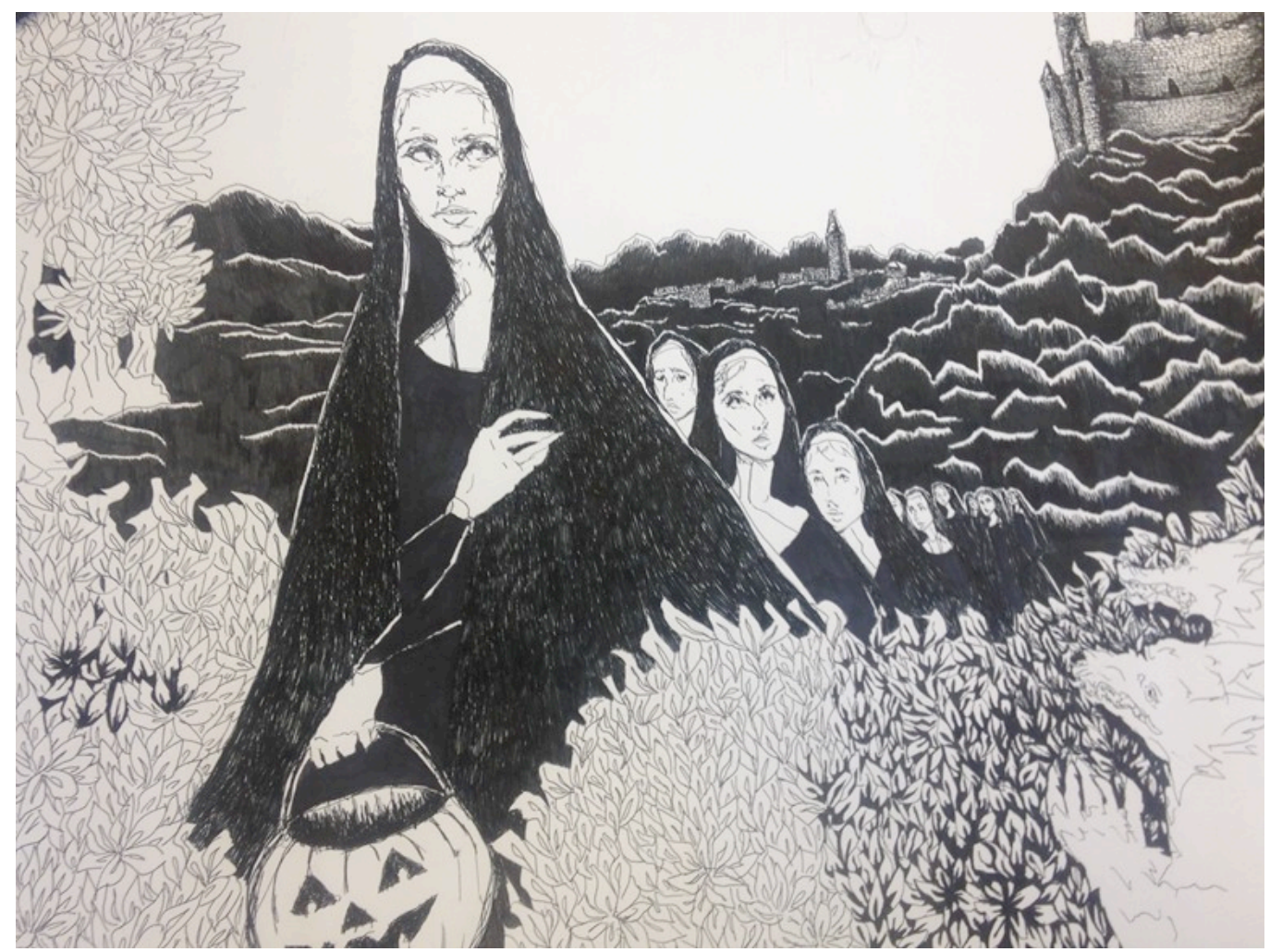

Figure 6; Untitled, Sketchbook Project; High School Student work; pen and ink; RESA III, 2015.

RESA III, art educator 5.E works at a high school in a region that by the US Census definition would be labeled Urban-cluster on the outskirts of an urban area. The high school educates a student body of approximately 1,000 students. E. 5 brings to their practice a certification in art education as well as gifted education. This educator has taught an age range from elementary age students to students in a high school program that is designed for students with special needs to earn a diploma by the age of 21 . This interview took place in school on October 4, 2015.

In response to the thesis question; "Who is teaching art in rural and urban West Virginia; what education, background and experiences do they have?" 
Through the interview it was discovered, as a West Virginia native, E.5 teaches in the RESA where raised and educated. E.5 started out studying graphic design and commercial art in a school in southern West Virginia but for tragic and personal reasons, transferred to a state college in central West Virginia to earn a bachelor's degree and teaching certification in Art.

5.E: $\quad$ Because my generation of graduates were always double major like art and science or art and English. You could even double major in Art and Physical Education (PE). I chose to double major in art and art. All my electives were art and similar to what you do now at West Virginia University.

5.E: I started out teaching elementary gifted. And I taught for nearly 10 years. I started subbing there and they hired me under contract. The main reason was there weren't elementary art jobs in the region. They had very few art jobs in the county.

For thesis question; "What methodologies do selected art teachers follow in the planning, instruction, and assessment of art in the K-12 art classroom in rural and urban West Virginia?” A veteran educator, 5.E describes the IB program at the heart of the program but they have a wide range of duties to provide an art education to a great variety of learners in a bustling, suburban high school.

5.E: I've only been here three years in this building. And I'm slowly starting to build up the art program to the point that this year, they have me teaching all 8 periods of the day. Every other teacher in the building has 2 prep-periods to do collaborative prep and regular prep. I gave 
up both of those. It's for some extra pay, but it works out to like minimum wage.

5.E: There are so many children that want to take art we are at the point where we really need a second art teacher. It's really growing since I've been here.

Author: Do you feel that your students come into high school art with the background that they need?

5.E: This county there is not an art teacher in every elementary school, but there is one assigned to every elementary school. Some of our elementary art teachers have as many as 6 different schools they are assigned to so they are traveling and they are there for a 6-week period.

Author: Do you think elementary art education gives students an advantage in high school?

5.E: It probably helps that they have had it, but I still have to teach high school kids color wheels, and everything else. You start from ground zero regardless." It appears E doesn't seem sure there is a significant difference in what is perceived as prior knowledge when students take Art I in high school.

5.E talked about the role of art education programs in preparing students to become productive members of society: 
5.E: We did a training a few years ago where all the area businesses came in and told us as teachers, not just art teachers, what we need to do to fix their problems in the work force and communicate with each other. Kids today don't know how to communicate with each other. They don't know how to work together or work in groups together. They've spent their whole lives looking into a computer screen.

5.E: can still do and express and feel like they're accomplishing something in the high school and they are being integrated into regular classrooms and art classes like this.

5.E: I just tried to get them as well rounded in the arts as possible. I realize the majority of the students that I have in class are not going to be art majors. They are not going on to art school. But I want to give them an appreciation for art and some knowledge of what's out there. I'd like this so they can walk into an art museum and see abstract art and have an appreciation of the really hard work that goes into a piece, and the really hard mental-work that goes into that piece.

In response to thesis question: "What resources and support do they receive for their art programs?" this educator reported both school-wide and financial support for the visual arts program they direct.

Author: Do you feel supported? Is your program well supported?

5.E: My community is more supportive than any other community that I've been in. 
5.E shared the supplemental benefits acquired for their school's visual arts program through grant opportunities provided by the local Chamber of Commerce;

5.E: any teacher in this area can apply grants and that are reasonably attainable. That is how I ended up with a kiln last year. They have a limit to the amount they can give for grants, but they gave the full limit to me. The art education association awarded me some money too. We were able to get the kiln and now starting we're starting to get it underway.

In reflection to the fourth question; "How the art educators and their teaching methodologies influenced by the context of where they teach?" the art educator talked about the communication skills of today's learners in the digital age.

5.E: They don't know how to talk to someone in an interview and talk to you. They don't know leadership. So in the art room, I try to give them some freedom to work in small groups. To talk and have interaction going on to spur their creativity. Because I am one of the few electives where you can take them in. This is why my numbers are probably growing here. I end up with a lot of special education students. In Art I, especially. Most of those kids are the ones that are on the 21 year plan for high school. They can still do in here and express and feel like they're accomplishing in the high school. They are being integrated into reglular classrooms or classes like this. I think that's really good for those students as 
well. I've got a high percentage of those students right now because I'm offering as many classes as possible.

\section{Case Analysis}

Through the interview and classroom observations, educator 5.E shared information about their background and training as an art educator. This educator is teaching in the RESA where they were raised and educated. 5.E received their degree and certification through a West Virginia institution of higher learning. They reported a scarcity of art teaching jobs when they first began to teach in the early 1980s so they spent the first half of their career teaching in gifted education in elementary and middle schools in their county. This is their third year at this particular school.

Educator 5. E reported having a high percentage of special needs learners because so many sections of Art I are being offered in the school's curriculum. Educator 5.E feels the visual arts education provides an environment that fosters productive communication between a variety of learners in the visual arts classroom as students are required to spend some of their time collaborating. 5.E also said that because they teach Art I and the school has a 21 year high school plan for students with IEPs and special needs, their visual arts program is providing for differentiation in instruction and learning for a wide range of learners.

The high school where 5.E teaches is West Virginia's first International Baccalaureate (IB) School. Authorized in 1999, this school is one of 2,401 IB schools in 139 countries. 5.E described the IB program as carrying greater weight as a course of study because it is recognized internationally whereas Advanced Placement (AP) is recognized in the US only. An IB program requires students to spend two years on the course, as the projects require intensive 
documentation, both written and through creative visual methods in a sketchbook, where the student documents the development processes and courses of action.

In this instance, art educator 5.E is teaching, Art I, Art II, Art III, and Art IV, IB, and AP. Each of these courses requires a prepared lesson plan and each plan must show the ways in which the art educator will accommodate every kind of learner. At E.5's school, every student is required to have one credit of art. Options for this art credit include theatre and chorus but students find art classes less pressure since they are not required to perform in front of an audience singing, dancing or speaking on stage. This is in part, why educator 5.E does not have a planning period and why this educator thinks it is likely time to hire a second art educator for the school's growing program. Educator 5.E is an example of an art educator accommodating learners at every level.

\section{Figure Analysis}

The visit to this RESA III High school afforded the opportunity to observe many classes. This particular drawing was a work in progress by an IB student. Students design artwork and record the creative art processes in a journal. This student was working with a series of drawings with the same or similar themes and this rendering is part of a collection. The dimensions were approximately 18 " x 24 " and the photograph loses some of the detail. 


\section{Word Frequency Analysis}

almost. (5) ap (6) area (7) classes (4) community (5) concord (5) county (4) craft (4) different (4) tone (1) educator (12) elementary (12) else (4) end (5) feel(s) gave (s) gifted (10) going (4) groups (5) hired (3) international (5) job (10) kids (5) leave (3) level(5) $\operatorname{lot}($ (5) major (3) mother (6) person (4) position (10) principal (x) program (1) really (5) $\mathbf{S C h O O}_{(20)}$ someone (3)

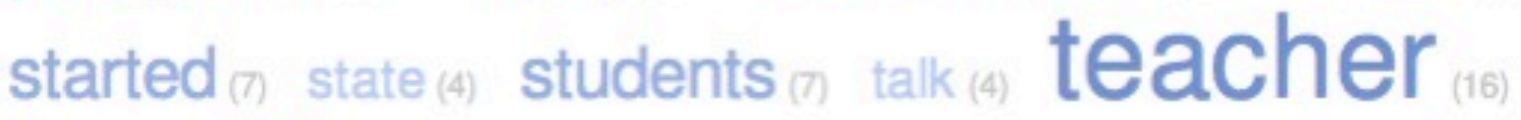

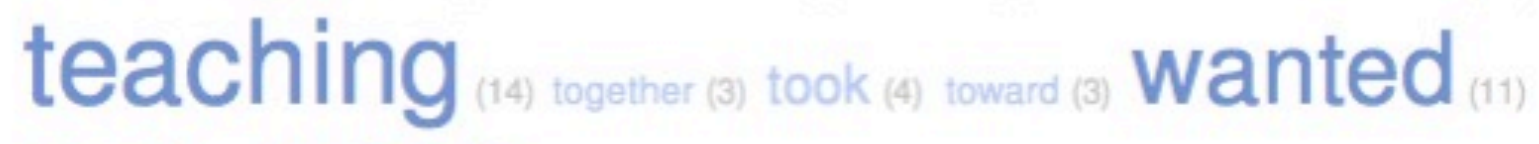
work $_{(\bullet)}$ year $_{(\mathfrak{)})}$

Figure 7; Word frequency chart from interview with educator 5.E, 2015. 


\section{Participant 6.F}

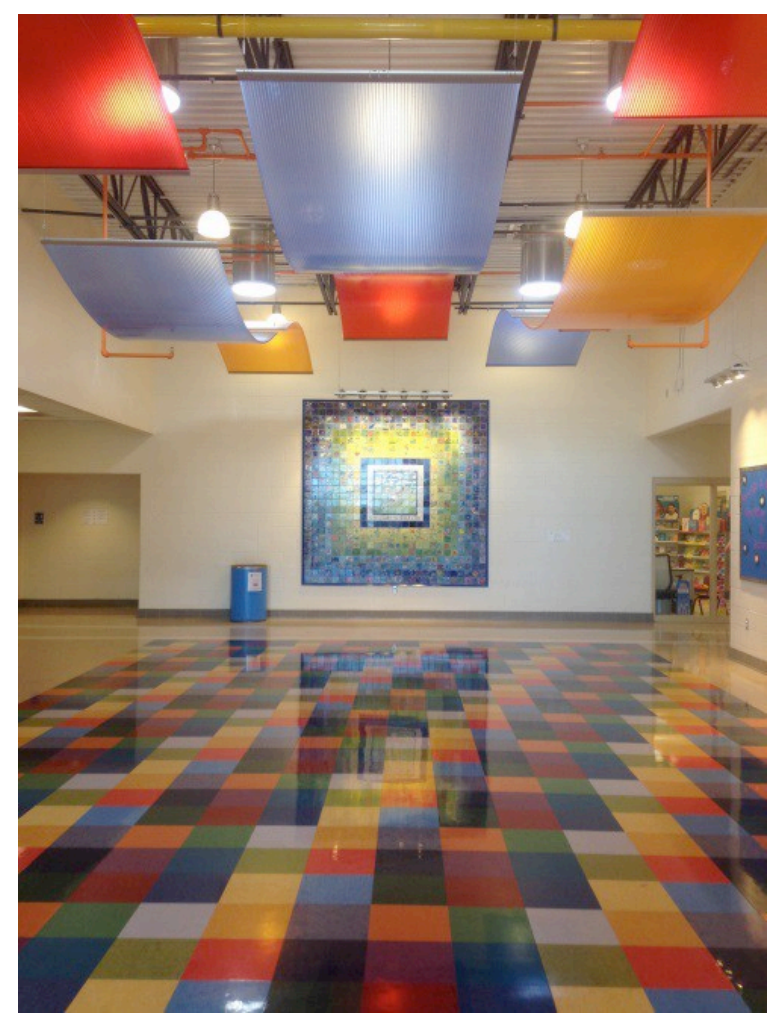

Figure 8; Entryway to elementary school, RESA III; Fall 2015.

This interview with educator 6.F of RESA III took place at a new suburban elementary school on October 5, 2015.

Figure to represent educator 6.F, was chosen based on the powerful statement the use of color imparts as it was used in the entrance and throughout a brand new elementary school in an urban area of West Virginia. These primary colors were used for aesthetics and coding.

In reflection to the thesis question; "What methodologies do selected art teachers follow in the planning, instruction, and assessment of art in the K-12 art classroom in rural and urban West Virginia" art educator 6.F talked about their practice. 
Author: $\quad$ Tell me about your practice as an art educator.

6.F: At this school, they get art for 40 minutes every other week. At my two other schools. I have 10 or 11, depending on the school, 30-minutes classes. The schedule allows for one class right after the other, with no transition time in between classes. So really, that comes out to be about 20 minutes of actual activity time for the students.

6.F: I have really well-crafted lessons and I build upon the STEAM standards. I go, and I look at those standards and build lessons from there and yet I get such little time in the classes.

Author: Do you follow a particular education pedagogy?

6.F: I'm kind of a 'mutt'. I learned on DBAE. I'm a really a fan of 'tab choice'. I'm starting to do a little more of that because it allows me to do selfdirected learning is something that these kids really need. Like when we talked about the Exploratorium. Kids really need time to make choices and to choose what want to learn, choose how they want to learn about it and how they want to express what they've learned to people.

6.F is an educator who believes in the interrelation of subjects in the curriculum:

6.F: Art and science are very similar. They are connected. Look at the scientific method, they are very parallel. If you take all of the steps of the artistic process and the scientific method and you put them side by side, it 
is the same thing. It is exactly the same thing. With science you start with a hypothesis, with art you do the same thing, you start with a sketch.

6.F: I've only been in this arrangement [of schools] for two years. There are more initiatives this year than I've ever seen before. It is all data driven education.

6.F: I have a lot of the kids who do not have the skills of just using scissors. I can't tell you how many times I have to teach even the older kids, how to use scissors. It's ridiculous and it's depressing.

In response to the thesis question; "What resources and support do they receive for their art programs?

Author: What about administrative support?

F.6: My administrator is helpful and tries to see we get help if we need extra. He does what he can. I've never really had to go without, but I have to be that one teacher who says "you get one piece of paper" and that's it. You have to make that piece of paper work.

Author: Do you have to modify your lesson due to money issues?

F.6: Yeah you really do... at this school, we have an active parent-teacher group. and they raise money for my program so I haven't had to ask for anything here. Some things I can get through supply funding, some things I can get through the PTA. Some things I really can't buy. I can't buy tech. There are rules about what I can spend my money on. If I want to buy 
technology, even if it just for a new cord for my iPad, I have to get a grant to buy it. Or I have to go to my boss and ask. And they are spread so thin.

There was an air of frustration surrounding all the complexities involved in acquiring even the smallest piece of equipment.

F.6: I have to keep three sets of lesson plans. They are three very different schools. I can't do the same things in all three schools. I don't have the same resources in all three schools. I have three sets of supplies. I am not ever supposed to take supplies from one school to the other but my budget is so low, sometimes I have to. I get less than a dollar per student per year for art supplies. What can you do for a buck? Now don't get me wrong, I get a lot of grants and I've been very fortunate but you can't those hit those same wells over and over again. It's often feast or famine. I do end up borrowing supplies from here and sharing them with my less fortunate school. I have no budget at one of them. This year is the first year that I've actually gotten faculty senate money.

6.F repeatedly expressed her gratitude for the monetary support received, but it is proof that even within the same county, all school art programs are not treated or funded equally.

In reflection to the thesis question; "How the art educators and their teaching methodologies influenced by the context of where they teach?" the role of inner-school support was discussed.

Author: $\quad$ Do you feel supported by your peers? 
F.6: One is a good country school. The teachers are very supportive of my program, but I still feel like it's about the planning time. The teachers there, I don't think they would say that, but I think when it comes down to the decision making about the program, really I'm there for the planning.

This is an on-going theme with every elementary art educator that was interviewed for this project.

F.6: This year, I've been really fighting the 30 minute art program because you can't do anything in 30 minutes. That extra 10 minutes means so much, especially because at this school I have 40 minutes of art and don't have to deal with transition time. I have time between the classes and there is no lost time.

6.F: It's just not feasible to have any more than 30 minute art periods. Even if it kills my program, I still get some really cool things done, but I feel the kids are losing. If we have a really big project or a bunch of things that have to dry, we just really can't do it. For example, yesterday, we were doing a great project that I would like the kids to paint paper and let it dry and then cut up the paper to do a collage so they can explore with texture. I have to throw the texture part out of the lesson because we just don't have time and a project often has to be slapped together and you just go. 


\section{Case Analysis}

The time allotment for elementary art education classes is one of considerable reflection. Every elementary art educator interviewed for this project spoke of the fast-paced nature of the elementary art education classroom. This requires educators to take into serious consideration, the materials they use and how they will direct setting up the lessons and cleaning up after the lessons while students transition from their classrooms. 6.F expresses a desire to go into lessons with greater depth but due to time constraints, has to prioritize which standards are possible to be covered.

A certified art educator with more than a dozen years, experience, including both, private and public school settings, 6.F describes the public school system as one that requires classroom teachers to constantly prove success in the classroom via technology and data driven education. The second traveling art teacher interviewed for this project, educator $6 \mathrm{~F}$, goes to three schools in their county, and each school has its own identity. One is rural, another urban, and the third is a new suburban school that replaced two elementary schools that were housed in outdated and deteriorating school buildings in an urban setting. This new school is operating under a new configuration of the classroom setting. Classrooms are can be open and closed to a central pod called an Exploratorium. This is a very different setting from the more traditional schools 6.F visits.

6.F works continually to bring technology to their practice as an art educator but acknowledges a loss of hands on art projects in the general classroom. 6.F relayed a story of a colleague who was retiring at their rural school. This classroom teacher brought a big box of art supplies into the art room. Thinking the supplies were great, educator 6.F asked the retiring 
educator what she used to do with those supplies in her classroom. The retiring educator told 6.F that she used to do art projects with the students in her classes but hadn't used the supplies in years because they no longer had time for it. 6.F expressed gratitude for the supply donations, they found it rather distressing that general classroom teachers could no longer provide opportunities for creating in their classrooms. Educator 6.F said it affects what can be accomplished in the art classes by using scissor skills as an example:

The push toward standardized testing over the last dozen years has only boosted the importance of science, and language arts in the curriculum, while leaving subjects like the fine arts further marginalized. The comparison between the scientific method and the artistic process made by educator 6 .F is a solid argument for the importance of art education and its relativity to the sciences.

One of the schools where educator F.6 teaches is a brand new building that incorporates collaborative learning into its physical space. Classrooms are set up as pods around a central area called an "Exploratorium". These centers include books, activities, and are designed for teachers to share.

6.F confirmed the 40 minute class-time allotment but described the classes at the rural school as 1030 -minutes class periods that are conducted back-to-back with no transition time for setting up or cleaning up between classes. 6.F said even though 40 minutes is the law, they switches with the PE teacher and there is no way to have more than 30 minutes classes.6.F said it is the same schedule at the most urban school. This is interesting as, it was explained to me by another art educator, a law was passed to ensure that all teachers have a minimum of one 40minute planning period. 
Upon examination of this class structure, 6.F points out that it is easy to see why some teachers rely on coloring sheets. 6.F says there are days where they wonder why they are going to such lengths with the lessons when so often the lessons have to be cut for monetary and time constraints. It does seem that the traveling art position can take its toll on the energy and resources of the educator. This art educator works far and above the hours many educators spend outside of class.

\section{Analysis of Figure 8}

This figure was chosen to illustrate the tone color can have on the entrance of a school. Upon each visit, as I researcher, I took into consideration the aesthetics, arrangement, and placement of art in school entryways. This elementary school is one of the newest and most progressive schools seen in this study, in the state of West Virginia. The use of color and light in the entrance of this school set the tone for what I was about to witness through the interview and observation. 


\section{Word Frequency Analysis}

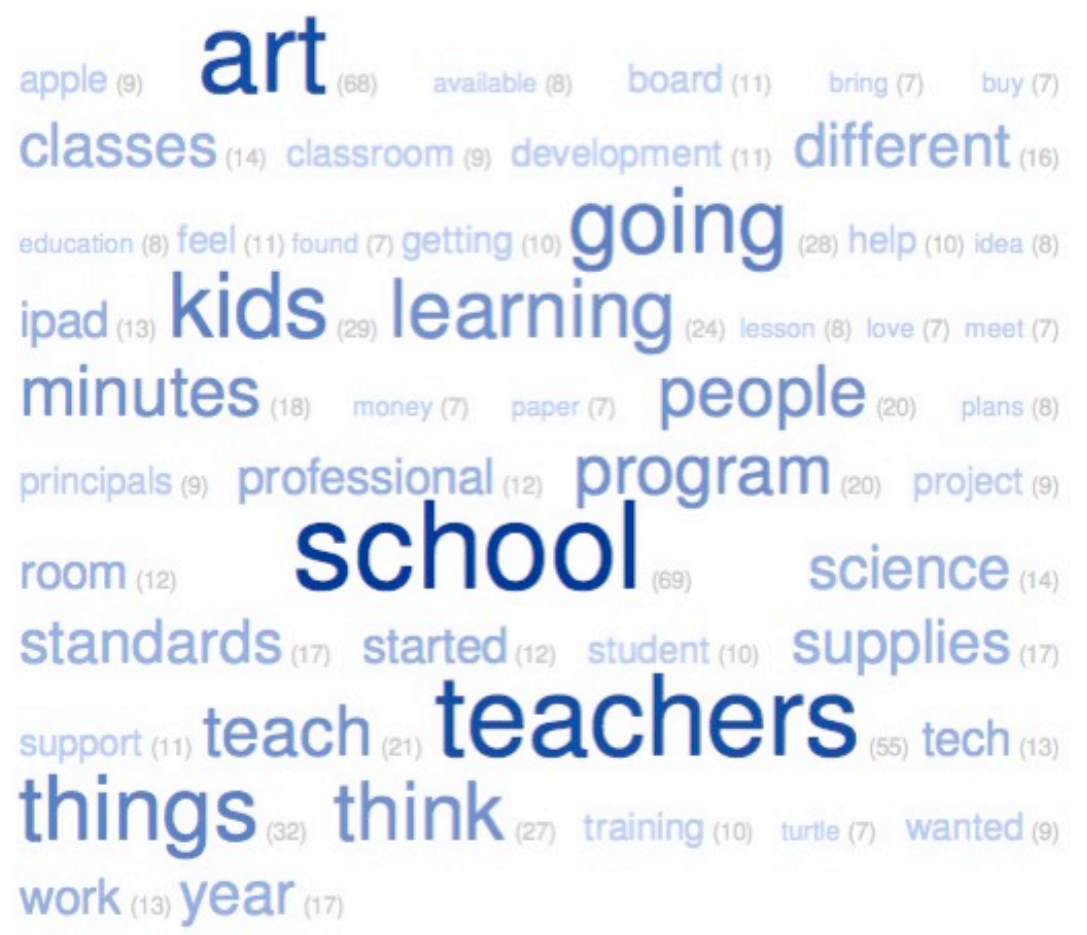

Figure 9; Word frequency analysis taken from the interview with educator 6.F, 2015. 


\section{Participant 8.H}

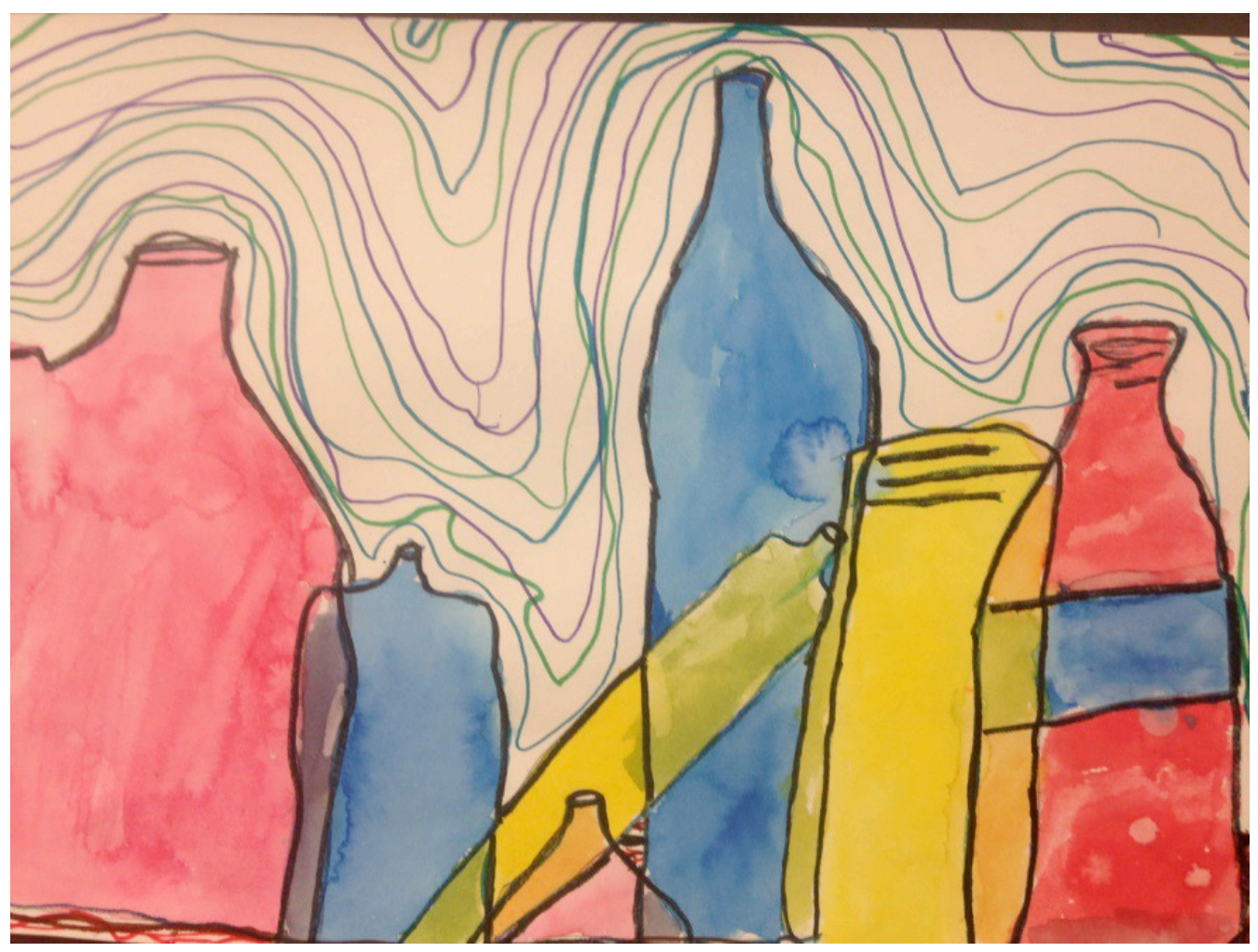

Figure 10: Color-mixing study; Elementary student work; marker and watercolors on paper, 2015

RESA IV elementary art educator. The physical approach to the school was beautiful and the view from the front of the school was of a magnificent mountain ridge. The school itself is under three years old arrival was at the end of the school day and the art educator 8.H was at bus duty so I sat in the waiting area. There was a trophy case and photographs of the previous school buildings dating back a century. $8 . \mathrm{H}$ arrived shortly and we went to the art room for the interview. This interview took place on September 24, 2015.

In response to the thesis question; "Who is teaching art in rural and urban West Virginia; what education, background and experiences do they have?" H.8 has lived in West Virginia, in the same region where they now teach, since their late elementary years. Prior to that, H.8 lived 
in an urban area of Northeast Pennsylvania. University educated in West Virginia educator 8.H holds a BFA in printmaking. H.8 worked in galleries and framing after college graduation, but upon starting a family, returned with their spouse to the area where they were both raised. It was 5 years ago that this educator returned to school to complete a Pre-K through adult certification. Living, teaching, and raising a family near where they works affords 8 .H the opportunity to work several days a week the school their children attend, volunteer for community sports activities, and scouting. The choice to settle in the state and region where they were raised is reflected in this remark; "I can turn my kids loose in the yard here in West Virginia and not worry about things. I wouldn't leave for all the money."

In reflection to the second thesis question; "What resources and support do they receive for their art programs?" Educator reported adequate resources and funding. Both of elementary art positions held by educator $8 . \mathrm{H}$ are county-funded and thus far, has not had to do any fundraisers.

8.H: I get faculty senate money at this school but I'm not, getting senate money at the other school... The majority of the money for his programs comes from a tax levy that passed by a slim margin last year. So as far as the future, that does kind have me concerned because supplies are not cheap.

8.H: This school, and in this county, they do take care of their arts, both music and visual arts. Our music program here was able to get the VHI save the music grant. We have a full band's worth of instruments.

8.H: This county is pretty blessed as far as... how I am able to fund the program. 
For the thesis question, "What methodologies do selected art teachers follow in the planning, instruction, and assessment of art in the K-12 art classroom in rural and urban West Virginia?"

Author: What benefits do you feel art education brings your students?

8.H: Everything. It brings them the world. What I do with my program is try to get kids to think about things not just differently but to think about things. So much about what they are "fed" in the school. Reading programs, math programs, everything is just little digestible segments. And it's very scripted.

8.H: Having kids think about thing things like "what comes next?" If I can get a kid to get to a place where they say "that's not going to work before they get through it, and it doesn't work, that's my goal. To have kids think. Fail even. Let them make mistakes. Let them be able to make mistakes. My goal is to get them to take chances, take risks, and try things.

8.H says they see a lot of students who are afraid to try.

8.H: to try and quantify a kid in a test score drives me insane. So you're child does well on the "smarter balance" test, but the fact is, they can't draw or write their name and have it be legible. Those gross motor/fine motor skills are being lost by not doing. You can type on a keyboard all day but if you can't write? My oldest child is in the eighth grade and his handwriting looks like a Pre-K's kid. He can't take notes, and even if he did write it down, you couldn't read it. Computers are 
great, technology is grand when it works but there is a lot of value in simply sitting down and figuring something out and creating something.

Talking at greater length about the students and the benefits of visual arts education, educator 8.H said a goal was to make sure that everyone who comes through the school sees how important what we're doing is. 8.H pointed out that some of the most talented art students are kids who have behavior and/or learning issues in other classes.

8.H: The trying kids, when they come in here, they are not the ones I have trouble with. They have something they can connect with they have something they can be happy with and proud of doing. My principal says to me, 'I think we have a lot of visual learners' and I say 'I know we do'.

Author: What is a reward to teaching art?

8.H : Watching a students in class, make something they can be proud of, and take it home to share with their family.

8.H: First grade we do all of our color theory through Monet, Seraut, and Matisse. I try to, meet CSOs for art history. I get them look at different artists, things they've done and from there, we do projects. My first graders just finished up Mondrian. So we cover our primary colors, reinforce shapes, and they make their own Mondrian-type art project. We did cut paper this year. Every year we've done paint and it is such a headache to keep the tables. You have those grids, so this time we've done it a different way. 
Combining social studies, history, and art, educator 8.H has designed an art curriculum for leading students through projects and lessons based on artists around the world. 8.H introduces them to North American Indigenous art, Australian art, African and Egyptian art and eventually brings them back to Appalachian art.

8.H: Just to let them know that a.) They do have a culture. They might not realize it, but they have a distinct culture. This helps them realize that there are a lot of things that people have done around here (regionally) that they can be proud of as well. So that's why I end with Appalachia with them.

8.H: $\quad$ My advanced art kids all have to meet grade, behavior and attendance criteria before they are allowed in. so it's an incentive for them to do well with all three of those plus it's also a way for me to get those kids that I know can do more that I can't really do with a whole class. I can get them and break things down with them in more depth and understand higher-level basics of the elements and principals.

In response to thesis question, "How the art educators and their teaching methodologies influenced by the context of where they teach?" educator 8.H Sharing future plans to design a program incorporating community involvement and collaborative, peer-based projects for students.

8.H: My goal is to have a sculptural piece completed by the advanced art class, to do as a group before they leave the school. We have that giant yard in the front. My goal is to turn that into a big sculpture garden 
so every fifth grade class will leave a sculpture in the garden and then I want to broaden into the community-based art sculpture projects where. I've already talked to...we haven't started implementing anything but we are in discussions how to logistically to work with the middle school and the high school like the middle school art club and the after school art program that's at the high school and have them work with my advanced art kids and we do a sculpture. Say we do one for here and then we go and we can find a place in town like the veterans park where we can do one. Or where we can go to each of the feeder schools and the middle schools that go into the high school and give them a chance to work with some of the students that can weld. Or some of the students at the middle school, they can do these things, and let them work with fifth graders. Collaborating and peer mentoring. That's in the works. Nothing has come about yet. We do have big plans.

Author: What are some challenges?

8.H: My challenge is mostly with me I mean schedule wise everything is kind of hectic crazy but it's nothing I can't work with. My biggest challenge is making sure that I stay on task or that I get everything done. You never know what is going to happen. You can plan for everything in the world but if half my class is not finished when I think we should move on, then we're not going to move on until we're finished. Having kids all finish different times. Having them at all different levels. Making sure that we can get things done. Just keeping the momentum but 
like I said most of my challenge is myself. Taking on more than I can handle.

Upon ending the interview 8.H said:

8.H: I'd like to let people see that if it were not for these art programs we have at these schools, the children would not get anything. There is no room in the general classroom's schedule to implement art.

\section{Case Analysis}

Basic tenants of educator 8.H's practice: global awareness, cultural awareness, art history, skills and techniques, materials, the elements of art, and the principals of design. For curriculum design, this educator looks to combine the West Virginia Content Standards for art objectives and tries to relate them to curriculum content standards in other disciplines. 8.H cited examples of where art CSOs and the CSOs in other objectives do not align but how they work to find ways to incorporate history and geography into the lessons designs. Through practice, trial and error, art educators become more adept at tailoring lessons and materials as they are most appropriate to age, grade, skill level, and physical setting.

The county where educator $8 . \mathrm{H}$ teaches provided a strong voice for the arts in this study. 8.H is working with every level of student in the school. This educator is working with Pre-K level students to directing an advanced art class where students are working on lessons in perspective using technology and digital cameras. Educator $8 . \mathrm{H}$ is the first and only art educator encountered in this study teaching an advanced elementary art class. 
Educator $8 . \mathrm{H}$ said they hope the research puts it out there that people need to value what the art program brings to students who intend to go into vocational programs. It is their belief that art programs are good for people who want a career other than a desk job. In art education classes, teachers are presented with about every learner in the school. Educator 8.H takes this into consideration and feels that art education provides success for a wide variety of learners. 8.H did report having such a variety of learners means that students finish at different rates which requires flexiblity. This is something the art educator must prepare for at every grade level. Some students will finish projects faster than others and one must be prepared to accommodate those situations.

\section{Figure Analysis}

Figure was chosen based on the number of lessons occurring within the single lesson. As educator $8 . \mathrm{H}$ explained it. These fourth grade students were working on observation and fine motor skills by drawing the still life. Then they learned the elements of color-mixing through the technical skills of painting in watercolors. Their final exercise was based on line and expressive line quality which is also engages fine motor skills. 
Word Frequency Analysis

able (f) anything (1) $\mathbf{A r t}_{\text {(2) bing (1) }}$ class (13) classroom (7) color $_{(13)}$ county (12) different (11) done $(11)$ draw (5) end (5) everything (5) fifth (12) towe (1) goal (8) grade
KidS people (10) pannino (f) pracico (5) prek o program project $_{(1)}$ really (10) (rom s) School souplure (6) shapes ${ }_{(16)}$ something (io) start (10) sudes os are of taked $m$ teachers things think (12) thid (6) together (5) WOrk $_{(21)}$ world (8) year

Figure 11; Word frequency chart taken from interview transcripts with educator 8.H, 2015. 


\section{Participant 12.L}

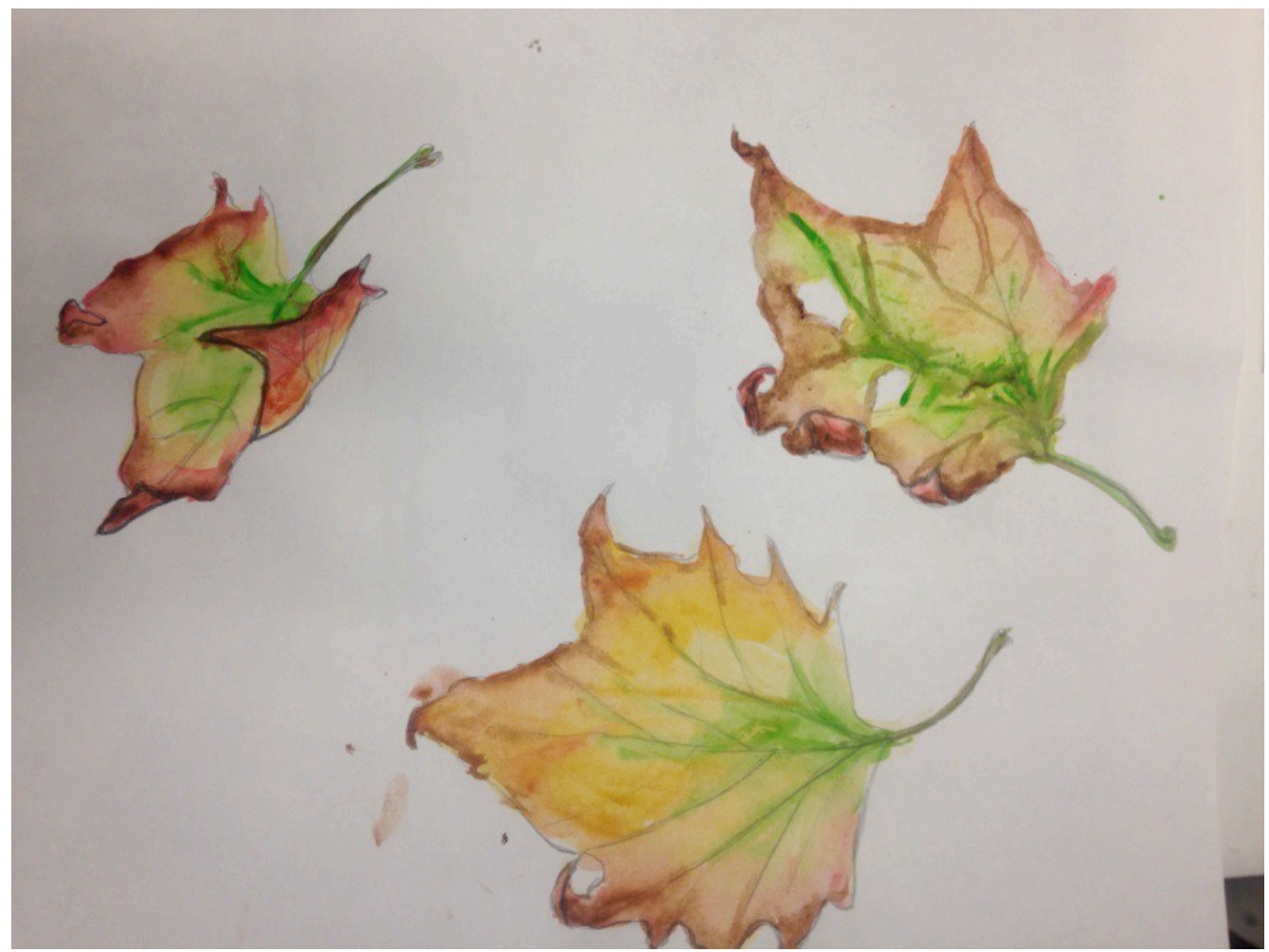

Figure 12: "Leaf studies"; watercolors and colored pencil; student work, 2015.

In response to the first thesis question; "Who is teaching art in rural and urban West Virginia; what education, background and experiences do they have?" Educator 12.L is a RESA VI Secondary art educator with 5-10 years of experience in the high school and community where they were raised and educated. Holding a degree in graphic design earned in a neighboring state, educator 12.L returned to West Virginia and finished teaching certification at a West Virginia institution also located within the same RESA as the current school where they teach.

At the time of the interview, the school was under major renovations including rewiring and a new HVAC system. Educator 12.L's classes had to be relocated to a regular sized classroom with no sink. The educator had been told it would only be for a month. In a school of 
1300, there are three art teachers at educator 12.L's school. Educator 12.L teaches all Art I classes.

Reflections and responses to interview questions as they pertain to thesis question; "What resources and support do they receive for their art programs?":

Author: How do you feel your program is perceived within the school system?

12.L: There's a wide range of opinions about our program. For the most part, I feel our administration overlooks us unless they need something done. Which is kind of disappointing. They notice more when I do something, like the last couple of years where I've done community things, when it gets the program attention or been in the paper. Otherwise its 'we're just going to tuck the art people away over here and let them do their creativity thing and then when we need posters, we're going to come for them and when we need paint we'll come to them.'

Author: Can you tell me about your program's funding support?

12.L: Okay. I usually get $\$ 1000$ from the county. And then at the Board office. I feel like we get support from the county board office. Give us more support. Our curriculum director (for the county) used to be an art teacher. So we get this thing call STEP SEVEN. You might want to pass this along to other art teachers. And now each of us art teachers get an extra $\$ 2500$ a year from step seven. I try and tell every single student teacher that I have. I try to tell other teachers. It is something that our county does and is aware of. I think it is because our 
curriculum director was an art teacher that we are even aware of this in our county.

12.L gave an account of how monies were spent:

12.L: We mostly use it for technology. Like a couple of years ago, we got tablets for research for teaching. I know the other art teachers have bought tablets as well. I was also able to acquire new digital cameras for the classroom. These are all things that we need. Last year I bought a mat cutter, so I could mat all of the art work for the show. That is so important for students to see their work presented in a professional presentation form. They don't really think about it that way until they see it matted and they get so excited. Things that I picked up while student teaching. My first year here I bought those red trying racks because I only had one for 150 students. I needed drying racks because I wanted to paint with them and wasn't any space to dry all those paintings.

In response to the thesis question; "What methodologies do selected art teachers follow in the planning, instruction, and assessment of art in the K-12 art classroom in rural and urban West Virginia Educator?

Author: How do you situate your practice and program? How do you see the role of the program?

12.L: The majority of my students are here because they need a fine art credit. For me it's mainly giving them an environment where they can be creative, where they can feel safe. They can relax for a little bit. I feel 
art should balance out those high intensity classes where they have homework all the time and where they are constantly doing worksheets. I feel art needs to be a place where they can be creative because they need that balance in their lives.

12.L: I feel like this is a place where they can come and be themselves and they can feel comfortable with themselves because I don't have super complicated expectations. I expect them to succeed in what I assign them but I don't expect them to be the next Leonardo Di Vinci. I'm only getting most of them because it's a requirement. I do get a couple here and there. And when I do it's really exciting. I'd like to get them to appreciate art a little more through this class. Because some of them do, after they have this class. I try to make it fun for them. I try to make it something that they like, by the time they're finished.

Educator12.L explained that the art teachers at her school agreed the first semester's coursework would be geared to 2Dimensional projects and to build skills. The projects would switch to a 3-Dimensional focus for the second half of the year. There is a purposeful and sequential order to the complexity of lessons taught. This is constructivist in nature.

12.L talked about some of the projects planned for the first semester:

12.L: I do try to work with as many mediums with my students as possible. This is an intro class and they need to be introduced to as many mediums as we can. So we start off with just pencil and then scratchboards. Next I'm planning to do watercolor resist but we might end up doing 
pastels since I don't have a sink right now. I also have a positive and negative shape project planned.

Author: Are there any other benefits you feel art education brings your students?

12.L: Independence. Working with them in a way that teaches them to be productive individuals. I feel like they need that. To feel like they've moved up. With the freshman now being moved up to the high school level.

In reflection to thesis question; "How the art educators and their teaching methodologies influenced by the context of where they teach?" 12 .L pointed out that a recent economic boost in the areas economy was bringing students into the schools that had varying backgrounds in art education when compared to the students from the area.

Author: Does having these students show a difference in their art education experiences?

12.L: It does a lot. and I see. we don't get whole lot of them. Maybe only one or two students a class, but I can definitely see a difference depending on what part of the country they are coming from. I had a student from New York who said..."I've already learned this. Why do I have to learn all this again?" "But you can see, you know there is a difference in education.

Author: Do your students come with the skills they need to take art? 
12.L: they really haven't retained what they should have retained. The standards they have learned up to this point aren't really evident in most of my students so I have to re-teach a lot while I'm trying to teach my lessons.

Author: Is there art education in the elementary schools in this county?

12.L: They do have art but it varies. They have two floating art teachers going to the different schools around the county. They really only see some students twice a month which is really not enough at the grade school level. To know that my son who is going to one of the grade schools is only going to get art every other week is frustrating. I definitely see a difference.

Author: What are some of the biggest challenges you face in your practice?

12.L: Well definitely the fact that the students are not getting as much art as they need to before they get to high school. They don't have the foundational skills. The students should know the elements of art by the time they get to high school and they don't even know them. Those are very basic things. Some of them are even standards at the grade school level and they are just not getting them. Some students come here and most of them will tell me that they've never heard of the elements of art and they can't name any of them. I feel like our middle school teachers here are excellent. I think they do great work but they have them for 9 weeks. The students are only required to take them for 9 weeks. 


\section{Case Analysis}

The interview uncovered, 12.L teaches Art I, six times a day. All high school students in West Virginia require a fine arts credit therefore, a school with 1300 students requires more than one art educator. In certain instances there are high school art educators who only teach the introductory high school art course known as Art I. Two high school art educators who only teach Art I in their curriculum were interviewed for this research.

Educator 12.L brings to their practice a background in graphic design which they felt added to their practice as an educator. The school provides software and the educator can use this in the classroom and as a coordinator for school clubs, events, and activities. This educator indicated they feel the Art I classes are critical to a high school student's education but they look forward to an opportunity to work with students who want to concentrate on the visual arts as a potential career.

When it came to program support, in this instance, the art educator said she felt greater support by her county's board office as much if not more than the in-school administration. This area is receiving some of the benefits and fallout of being a region seeing an influx of jobs to the economy through fracking. Tax revenues from this current trend could result in better funded art projects and higher numbers of students enrolled in local schools from other states, at least for now. The revenue coming in from the economic boost in addition to having a county representative with an art education background appears to provide this school with solid monetary support for education programs.

Educator 12.L reported their art programs as being a place for student to feel comfortable enough to express themselves as an outlet from other kinds of rigorous course-work and from the 
stresses of being a teen in this day and age. They did however, see there was a need for visual arts after getting so little in elementary and middle school. This art educator, like several other educators interviewed for this research, felt that there was a gap in the sequence of visual art education programs in the K-12 schools.

\section{Figure Analysis}

This leaf study was selected because a student asked me to include it. They were working on a scratch line drawing that they felt was not as successful. Sifting through the stack of work, the educator found this example of the student's work. It reflects a student and a teacher's connection to the importance of success in a piece a student feels. There is accomplishment and a sense of personal pride involved. The subject of this artwork is also a reflection of the leaf theme which was observed in artwork examples of by students across the state of West Virginia. This study was conducted in the fall. Autumn in West Virginia is a season where the natural colors and beauty of this state is highly celebrated. 


\section{Word Frequency Analysis}

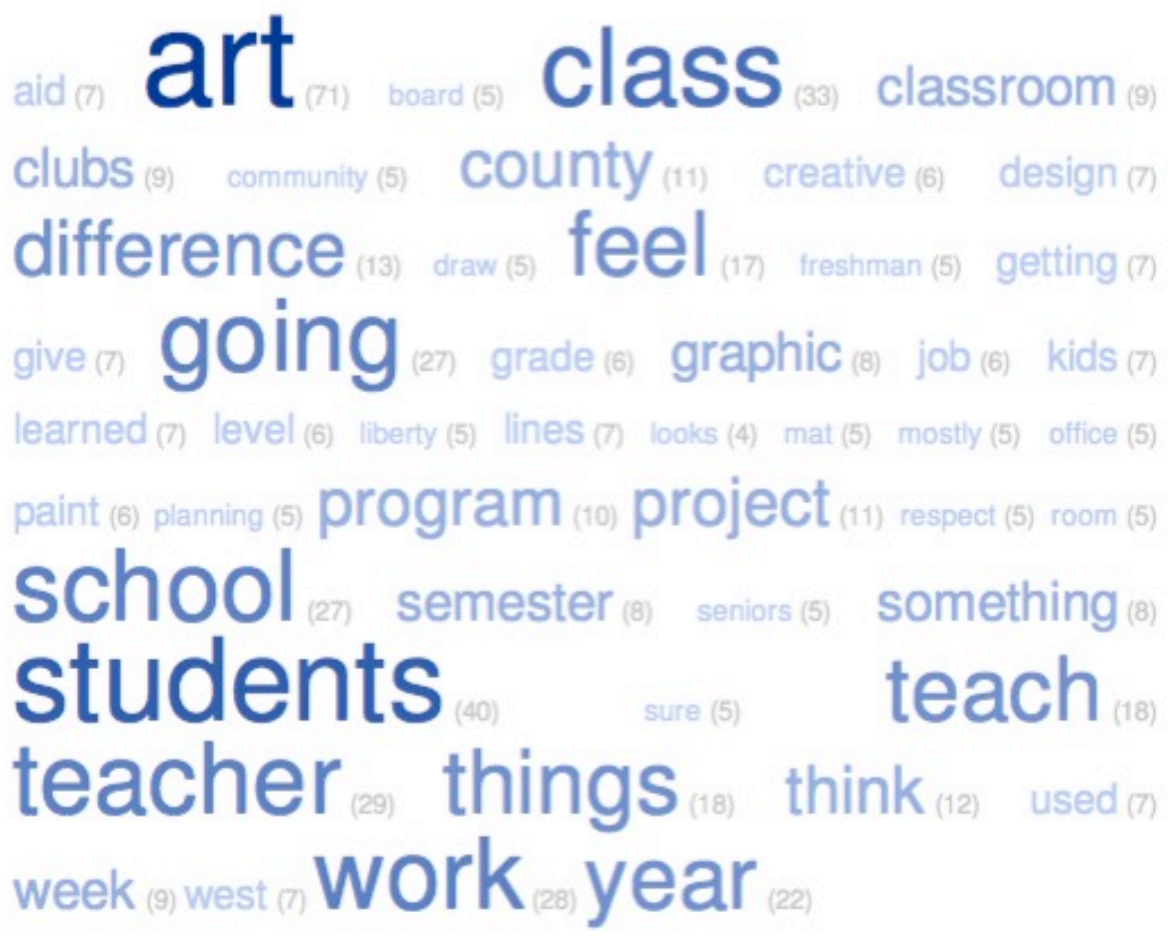

Figure 13; Word frequency chart generated from interview with educator 12.L, 2015. 


\section{Participant 14.N}

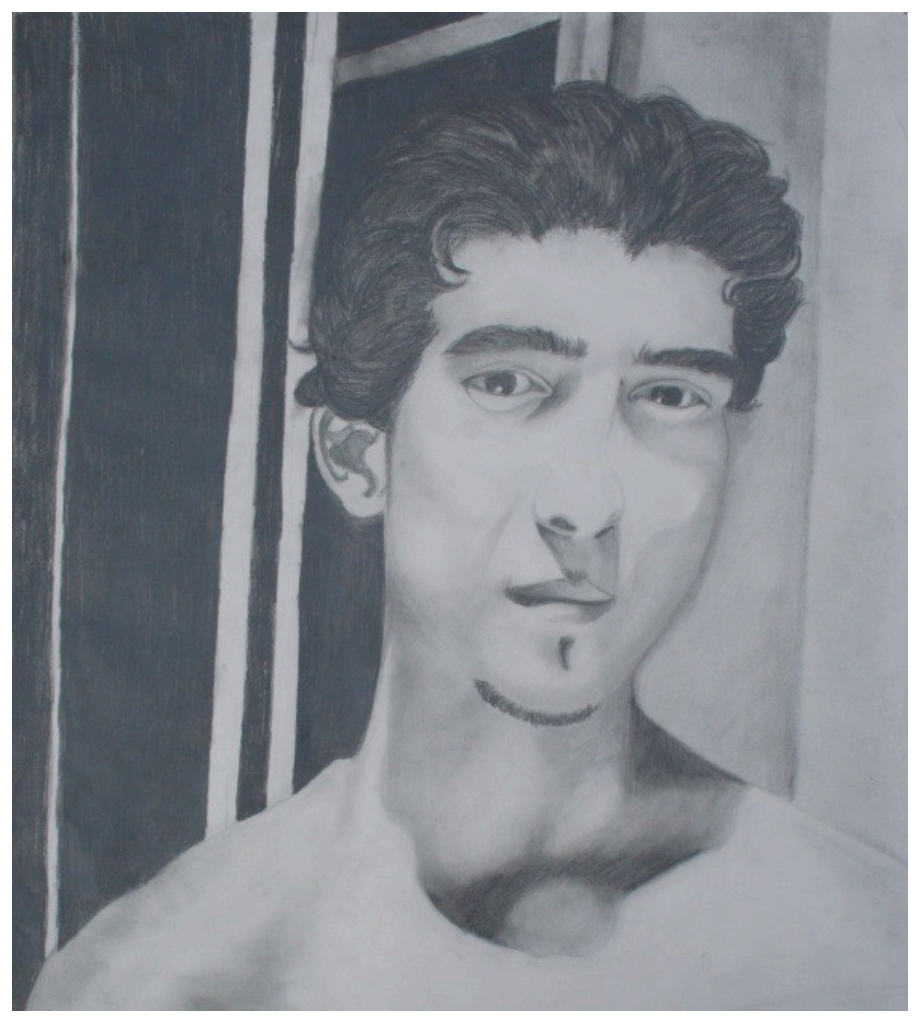

Figure 14: Self-portrait, student work; graphite on paper; Secondary RESA VII, 2015.

In response to the thesis question, "Who is teaching art in rural and urban West Virginia; what education, background and experiences do they have?" art educator 14.N, a RESA VII veteran art educator, shared they had accumulated approximately 35 years teaching experience in the region where born and raised. Educator 14.N received degrees and certification in art education within their service RESA. This educator has also worked as a mentor and cooperative teacher for pre-service educators for two neighboring universities. Recently retired, 14.N has always worked in a rural setting. This interview took place August 26, 2015 at an offsite location. 
In reflection to the second thesis question; "What resources and support do they receive for their art programs?"

14.N: It also comes down to how good a relationship you have with your administrator. During that time when I was having to push, I had a principal that really liked me. I wasn't trying to get him to like me. I think special education teachers were going in and telling him that I was doing a really good job with the special education students. I think that helped me a lot. I had a department head from another department whose daughter was in my class. She was in there pushing for me too.

14.N: I worked hard. I was putting in the hours, coming in at 6 in the morning. I'm leaving on time but I go in early. I've worked hard and it didn't matter to me whether anyone noticed what I was doing. I was doing what I had to do a good job. I kept doing it and it paid off. Hard work pays off.

14. $\mathrm{N}$ reflected on the support received as an educator in of the county where they taught:

14.N: I know that in my county the unions are big factor and a big influence. I could hear how other teachers in other counties worried but not just art teachers but other specials who worried about their jobs. We didn't have to worry so much. I think because we had strong union leadership who worked well with the county administration. They had good relationships and therefore they just made sure that laws were being obeyed. I think that helps the county because there's a lot-- I didn't have to worry about as a teacher. I saw some things going on in other counties. 
Author: Do you feel supported in your school community?

14.N: In the school community, I think it's good and very supportive. I see that when I go to faculty senate asking for money. They're like "no problem whatever you want." And the principal as a whole will say yes to about any project that I want to do, as long as I can come up with funding. If you need something that needs to be funded they try to take care of you from their end.

Author: Do you have any other thoughts about support by the administration?

14.N: Getting to the administration...I learned my second, third...years of teaching that administrators are in their own zone. If you want to get stuff done, you do it yourself. The way the school system has evolved, administrators now get upset if you don't involve them or at least tell them what you're doing. I'm used to just going and doing and setting things up for myself and arranging things. I've got a lot of successful years under my belt.

Author: With so much time and experience in the field of art education, did you ever worry about the cuts to art education programs?

14.N: A long time I never felt threatened by that and I keep hearing that from educators. I belong to a Facebook group of international art educators. You hear every once in a while, 'My job's been eliminated. My job's been eliminated.' I never felt that. I never felt that in this county. There have been times where in my school 
system and county system they have riffed teachers. I did know that one time my name was mentioned, but I was eleventh in line and the principal said, 'I doubt if we get down that far', and they didn't. I know the law says you need to be one educator per thousand and our enrollment was dropping below a thousand. Our enrollment went all the way down to 850 and they never cut me. I think it's because I was valuable to them. I was teaching graphic arts, photography. I was doing things for my graphics art class with the community. I had classes kids wanted to take. I was sometimes teaching Art I. I was sometimes teaching studio art, art history. It varied from year to year. I had that hanging over me for a while about ten to twelve years. I felt the worst that would happen to me is I would be transferred to another school.

Some might be surprised to find that indeed, art educators recruit students who show promise, to their programs.

14.N: I knew I'd have a job but I wanted to stay there and so I didn't allow myself to worry. I just worked hard and worked on keeping the numbers there and recruited students. Eventually I became the first art teacher. We've had plenty of students for two teachers. I quit worry about it. We changed the structure of the day. It was putting more students in our classroom. The problem disappeared. As long as you have demand for your classes, you really don't have to worry about it. I know about numbers. I was always conscious of that. 
In response and reflection to thesis question number three, "What methodologies do selected art teachers follow in the planning, instruction, and assessment of art in the K-12 art classroom in rural and urban West Virginia?"

Author: What are some of the benefits you feel art education provides students?

14.N: There is non-documented contributions and important things that art brings to the students. A lot of times we promote, and talk and validate our jobs with these content standards and that's all well and good. There's a lot of undocumented things like socialization, problem solving has worked its way into the objectives. And that's good. Let's face it, kids need to know how to problem solve. And kids need to learn how to improvise. Kids need to work with others. You get so much of that in the arts. The kids that need a visual arts class in particular are very confident. In that they're not afraid to try things. They also get in theatre and band. They get it in visual arts. We have an advantage in our building we have classes academy. It's where they take English and their world culture class together in hour and half block. That's why there are a lot of kids in our classes now.

Author: What other benefits do you feel art education brings your students?

14.N: That's a great contribution and a great experience for these kids. I think they just like coming to that class and not sitting in rows. They can get up and move around. They're not looking at a textbook. It's different. It's the hands and using of the motor-skills, and that's important. They need it. I 
think that's deteriorating. I try to do that as much as possible, even if it's simply cutting, pasting and gluing. I think they need to have that experience.

14.N: I've talked about socialization just the format of the basic visual art class is less formal. They are allowed to talk to each other. This happens every year, I have kids that come in and they don't know each other and they become the best of friends. I have students that come in who wouldn't ever associate with each other. Sometimes it was a class difference. Or I see kids putting boundaries on each other for being from rival towns, but they end up becoming friends through my classes.

$14 \mathrm{~N}$ : It's up to the teacher to keep the field level in the classes. That's the responsibility of any teacher is not to show that partiality and with art we're all in there struggling. Maybe? They realize this is different. It doesn't matter where I come from $\sim$ the struggle is real! They find commonalities.

In response and reflection to the final thesis question, "How the art educators and their teaching methodologies influenced by the context of where they teach?". 14.N talked about the school environment and the art education program's role in the school curriculum.

Author: What role do you feel your program, or art education programs bring to the curriculum? 
14.N: The idea of collaborating. Teachers collaborating. Teaching collaboratively. They are learning a lot in that situation. They do the Project Based Learning.

14.N: My attitude is that; 'we're already doing that in the arts'. However with visual arts there is also that opportunity to be an individual artist. Sometimes the kids do get tired of the collaborative-based learning. It's becoming part of every class they're taking. They are working in teams and dependent on teams. And there are instances where one kid doesn't want to pull his weight and brings the team down. I hear the kids fretting and worrying over their grades because of that situation. With visual art you can produce the individual piece and still be collaborating with the kids at their table. They help each other problem solve. I've seen them do it.

Author: Do you have any final thoughts?

14.N: I always thought of teaching as a service position. You're doing a service. You have a job to do. You have students to take care of. Your responsibility is "What do I have to do to make this happen?" and they're busy whining about their salary and work hours. I never thought about it that much. Yes, I knew I was working extra time and extra hours but I knew that was what I had to do. I had to do it to make things happen. There's a lot of that. You get tired of hearing about that. Maybe that's why it's time for me to leave. 


\section{Case Analysis}

West Virginia secondary art educator 14.N is recently retired from over thirty years of experience teaching secondary art education in rural RESA VII. This educator has worked as an art educator, mentor, team-leader, club sponsor, and an art education advocate at the professional level within the state. This educator hails from the region where they teach and therefore brings a certain knowledge of the region and the culture to their practice. Due to their success as an art educator for so many years, this art educator has the perspective of teaching more than one generation in a family. Several veteran art educators mentioned teaching children of their former students.

West Virginia implements a standards-focused Project Based Learning format for students to work in teams to address real-world issues and relevant challenges and present findings through well-designed projects. Project Based Learning groups are led by a teacher acting as a facilitator, mentor, and guide as the students design and implement their projects by working in team (WVDOE, 2015). Art educator taught at a school where this type of learning and teaching were part of the school's methodology. Project based learning has roots in constructivism as this type of learning is experiential in nature and student-centered where the teacher acts as a guide and a facilitator as opposed to a lecturer. Art educator 14.N was quick to point out that the arts already do this type of instruction and learning processes. $14 . \mathrm{N}$, as an example, illustrates how an art class can create cohesion in an environment that also fosters individual creativity. Students can work collaboratively and still embrace their individuality.

Art educator 14. $\mathrm{N}$ illustrated the multifaceted role an art educator can provide, and when recognized by peers, support for the art education program can rise to meet needs and 
expectations of the school community. This educator and practice reflected a recurring theme of "hard work paying off". Successful veteran teachers are understandably given greater freedom to run their programs because of a proven record.

\section{Figure Analysis}

Art educator 14.N provided this image for the research. It is a self-portrait by an upper level student. The emphasis for the lesson is the study and successful rendering of the face in pencil and graphite. Light and shadow were explored in the study. Educator 14.N felt this was an important reflection of the work they did with their students.

The initial plan was to interview and observe the art educator in the classroom, but 14.N retired over the summer of 2015. However, I did have the opportunity to observe this educator in 2013 as per required for student teaching. This art educator was an impetus for this study. They are the educator who successfully lobbied for funds to provide non-art educators' supplies for their projects so that art classroom funds and supplies were not being used for projects in other disciplines that were not being replenished. 


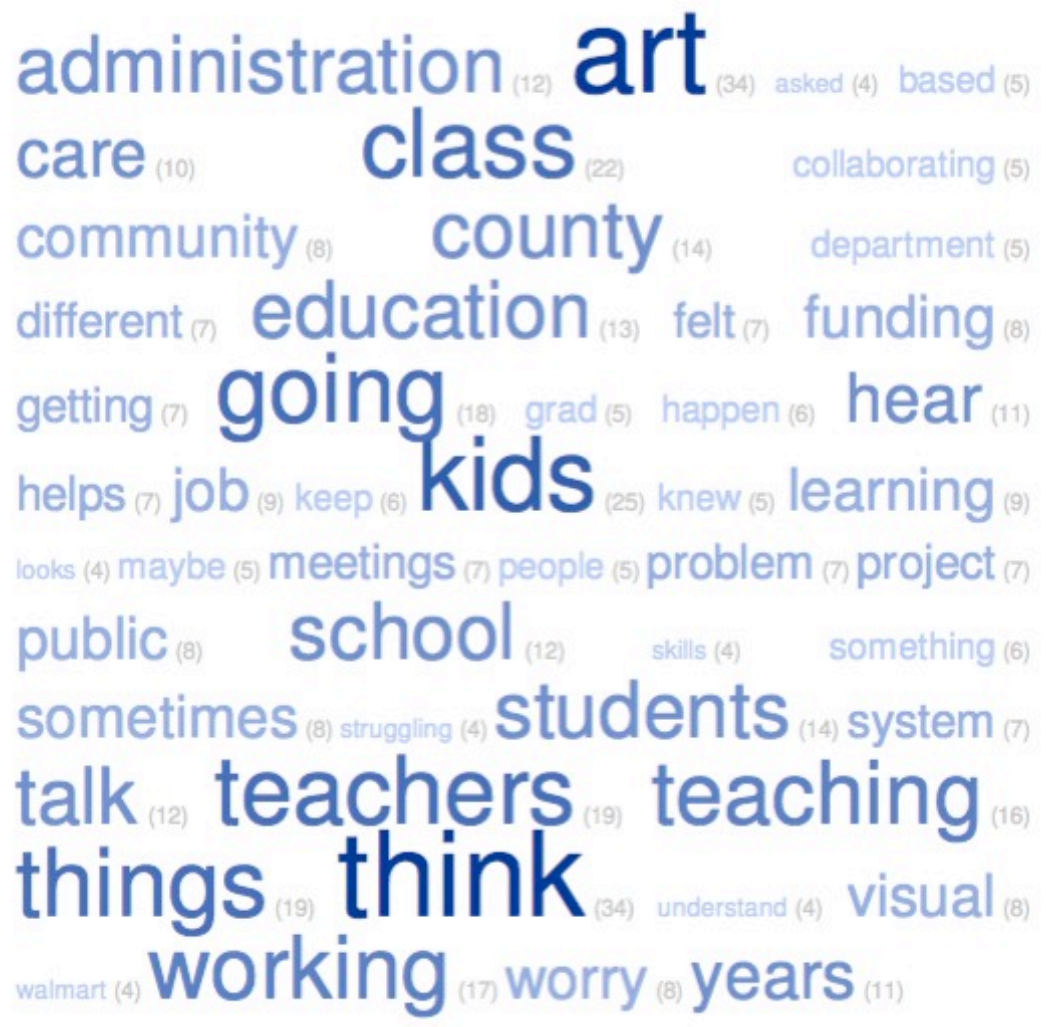

Figure 15; Word frequency analysis generated with transcripts from educator 14.N, 2015. 


\section{Participant 17.Q}

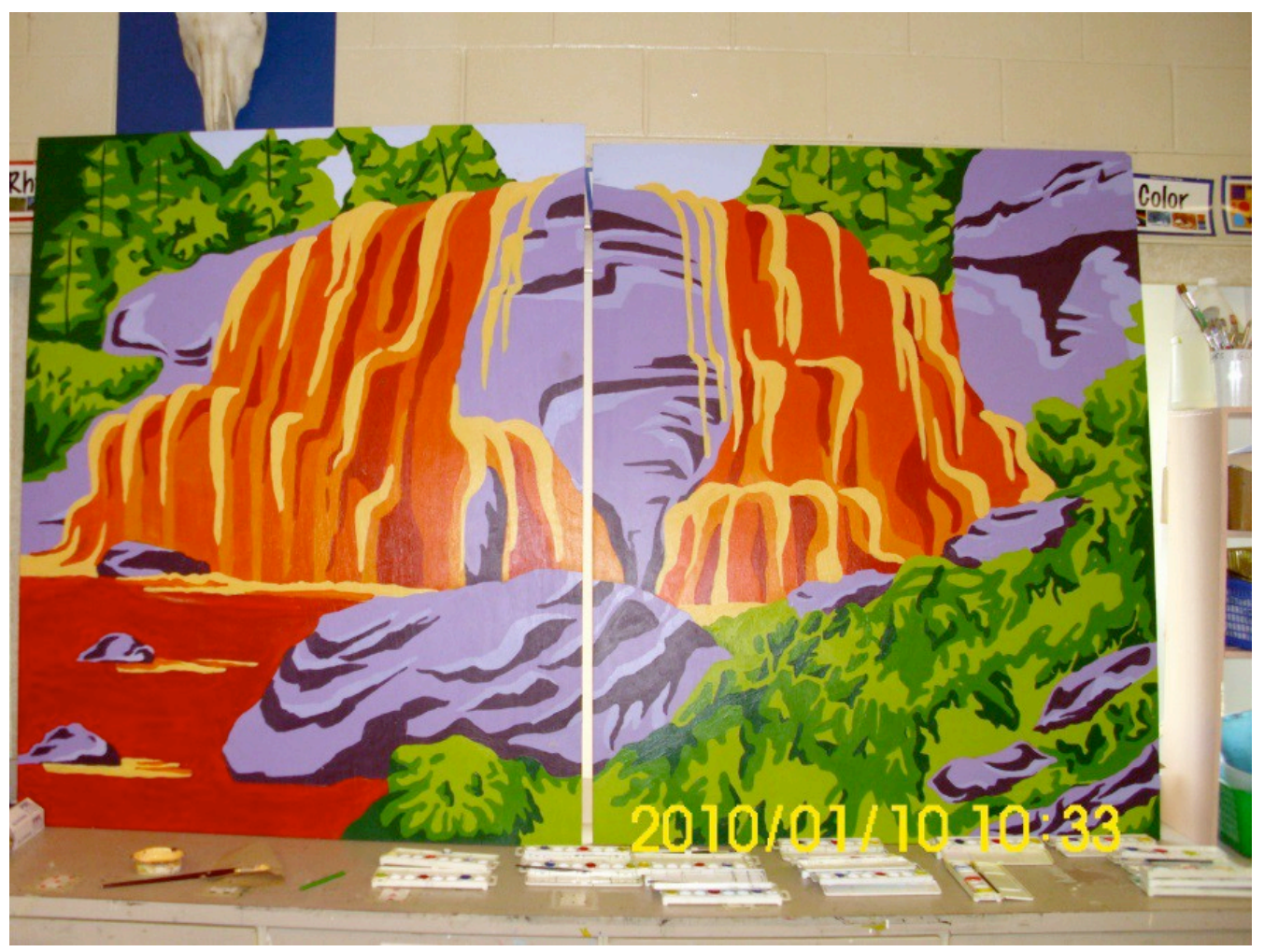

Figure 16; "Blackwater Falls"; Community mural; teacher furnished photograph, 2015.

Art educator 17.Q is currently teaching at a high school in a rural West Virginia town.

This educator brings to practice more than 25 years of experience to their teaching practice. The interview took place October 12, 2015 at an off-site location. Upon responses as they pertain to the first thesis question, "Who is teaching art in rural and urban West Virginia; what education, background and experiences do they have?" 17.Q reflected on years of service as an art educator.

Author: $\quad$ Tell me about your practice and experience as an art educator?

17.Q: I taught for a long time in RESA V. First I taught in RESA VII (rural) 10 years then I went to RESA V for over 11 years. Then I went to corrections for a year and a half. Then I went to two juvenile corrections facilities. 
Then I went back to RESA VII. So I am not a good person to say that I represent one area. But I have a real diverse feel for the state of West Virginia. Then I also worked for the state department of Education. I've been on the CSOs writing committee three times. So I know people from across the state and then I was the coordinator for arts alive. So I know art teachers all over the state.

In response and reflection to interview questions regarding the thesis question; "What resources and support do they receive for their art programs?"

Author: What role do you feel administrators play in the support of the program?

17.Q: My administrator told me; "it's just art". I go to my room and I get really mad. And then I come back and say, "were adding this bulletin board. And now we're at the board office. And now we're at Kroger. So every time he says that. I go and make sure that it's not just art. So I will... We have the tendency to get on that bandstand, to say "he or she won't let me do that". It's like 'So what. Keep going. Educate them.

17.Q: The next lesson plan is STEAM and it's due next Friday. I just got the National Art Honors society for the newspaper. And that's a checklist of what you can do to promote your arts course. I'm going to put a post-it note on there that says I'm doing all of these, except for the last one. I'm doing every single one on there just innately without even looking that list. And I want him... he just told me I needed to promote my art program. 
I'm like 'ouch'. I'm just going to take this in there and show him I've been doing everything on this promotion list.

Author: That's important.to hear your position. To show the different ways it is perceived by different entities. What are the projects you are doing?

17.Q: We support the community arts festival. Our local grocery store is Kroger and we are about to get a spot in there. They are going to give us a 16 foot mural. They have just finished remodeling and so when I saw that space, I said, "you want us."

In response and reflection to thesis question number three; "What methodologies do selected art teachers follow in the planning, instruction, and assessment of art in the K-12 art classroom in rural and urban West Virginia?

Author: What is your art education philosophy?

17.Q: I am passionate about arts education in this state. It's hard to step back from everything I did. Little monthly webinars the National Art Education Association has been doing, I've been going to that. I haven't missed one since they started. Another one tomorrow night. My county could care less. I devote all evening to this. I really care about it.

17.Q: I've taught teachers classes on arts integration some of them weren't even ready for that and arts integration is an antique. I think is what the National (NAEA) is doing is so lofty that the National Core Standards, are so lofty the real world is not ready for them. They aren't in rural 
America to understand that we aren't ready for it. Some of my peers are teaching from the 70s. People younger than I am, are coming into itare teaching such obsolete ideas. It's so frustrating listening to everything they are rolling out from the National (NAEA) and wondering how to do that in my setting because I haven't educated the parents. I haven't educated the administration. I think it would totally flip them out if I went right into to what is new.

Author: Where would you situate your practice in the school? What do you feel program provides the school?

17.Q: I've only been here two year so I'm not sure, yet. I am just feeling like I'm getting my bearings with the school. I've been here a year and a half and I have two enormous murals. We've pretty much done one every semester. My last one was a $16^{\prime}$ on the outside of a building in town.

17.Q: I think this is the first semester, since this is my forth semester. people are just now coming to me and saying "can you?" So it's taken a year and a half to build your credibility. You have to build credibility with your students too. Until they trust they can come to you. I've had more people walk in and say "can you?" just in the last month or two.

In response to the fourth and final thesis question; "How the art educators and their teaching methodologies influenced by the context of where they teach?" the interview turned to the topic of visual art's benefits to kids placed "at risk". With experience working in juvenile detention 
facilities, educator 17.Q stated, "statistics show that the arts plural help keep kids in school. It helps with the drop-out rate. It helps give kids something to look forward to in their studies."

Author: Does your county have art education in the elementary schools?

17.Q: No. We would be here another hour on that. Those that have not had elementary art versus those that have, their work is so incredibly stuck on the elementary level. I'm horrified. I am still getting faces like this. I am still getting this out of high school kids. [Draws smiley face]. They have never been taught to slow down and think. I've given them a written pretest. They can't name an artist they can't name a culture. It is discouraging. If we could prove the damage they are doing denying children an art education and how it doesn't support culture.

17.Q: I can see a decline in the local festival. If you go to a county in West Virginia that has a festival, go into the arts display and you can tell how rich their school is and how rich their arts programs are. There will be arts. But if you go to a community that is not arts supportive it is pretty lowend crafts. You can see back to the economic impact, which is back to where we started when we talked about art and the economy. They are not continuing their culture.

17.Q: Teachers aren't teaching the economy. They aren't teaching architecture. Those two are really left Out. I end every Art I with the economy of art. I call it the economy of art. How are we going to get them to go to a craft fair and buy an object local if we don't teach how it's made, how its 
priced, how its marketed? So they don't work in a bubble. So I did a whole presentation on that.

\section{Case Analysis}

This study required recruiting teachers to participate. This particular art educator came recommended by various sources. Art educator 17.Q brings more than two decades of experience to the classroom. This art educator has worked in two different RESAs and has worked and advocated on behalf of art education at the state level. This art educator has a passionate interest in art education in the state of West Virginia and believes in the artistic history of culture and craft and the potential of its powerful connection to the economy of the state. This particular vision and accomplishment was noted by peers of this art educator.

Currently teaching in the RESA where they originally taught, art educator 17.Q teaches at a high school in large town in rural West Virginia near the Monongahela National Forest. 17.Q reported the feeling that they were finally settling into the position and being asked to participate more on projects with other faculty. This educator reported some resistance to attempts to elevate art's status in school displays but was taking positive measures to overcome any obstacles.

Educator 17.Q shared an ongoing self-directed continuation of learning best practice methods as an art educator by participating in online discussions and development through the National Art Education Association. Educators of all subjects can find ways to stay current and conduct self-directed professional development. 17.Q is also an active member of the West Virginia Art Education Association and reports a positive level of support through the organization. Several participants in this research reported positive regard for the state's premier art education association. 


\section{Figure Analysis}

Educator 17.Q shared this image for research purposes. This is a mural that was created in the upper-level art classes and is to be installed in a local business not far from the image source, Blackwater Falls, West Virginia. One of West Virginia's most recognized natural land features. Several murals created by students of this educator are located in 2 counties of this educator's RESA. 17.Q feels that by doing community public art works with students, the art education program receives positive attention and which in turn, generates support for the program.

\section{Word Frequency Analysis}

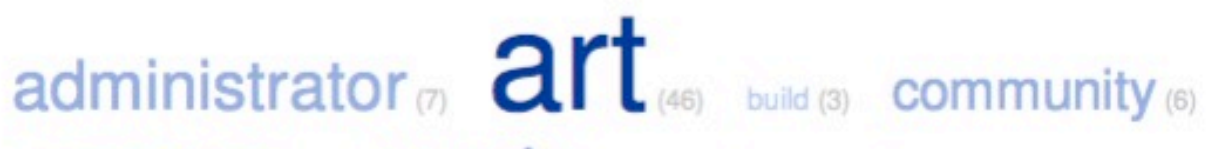
corrections (8) county (8) craft(4) culture(5) design(3) education (14) elementary (5) end (4) facing (3) feel (6) frustrating (3) getting(4) going ${ }_{(8)}$ half(4) Kids $_{(9)}$ level (4) meetings (4) national (5) people (6) professionally (3) program $_{(6)}$ promote (4) provide (3) ready (4) real (3) resa (6) room (5) School (15) something (4) started (5) state (11) satisitis (3)

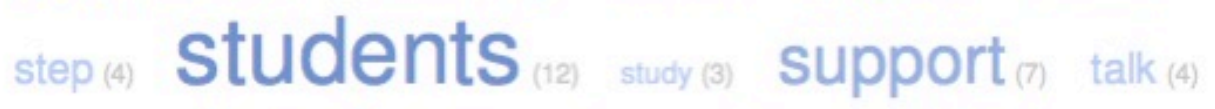
taught(4) teachers virginia ${ }_{\circledast}$ west $_{\circledast}$ work $_{\circledast}$ year

Figure 17; Word frequency analysis generated with interview transcripts from educator 17.Q, 2015. 


\section{Participant 18.R}

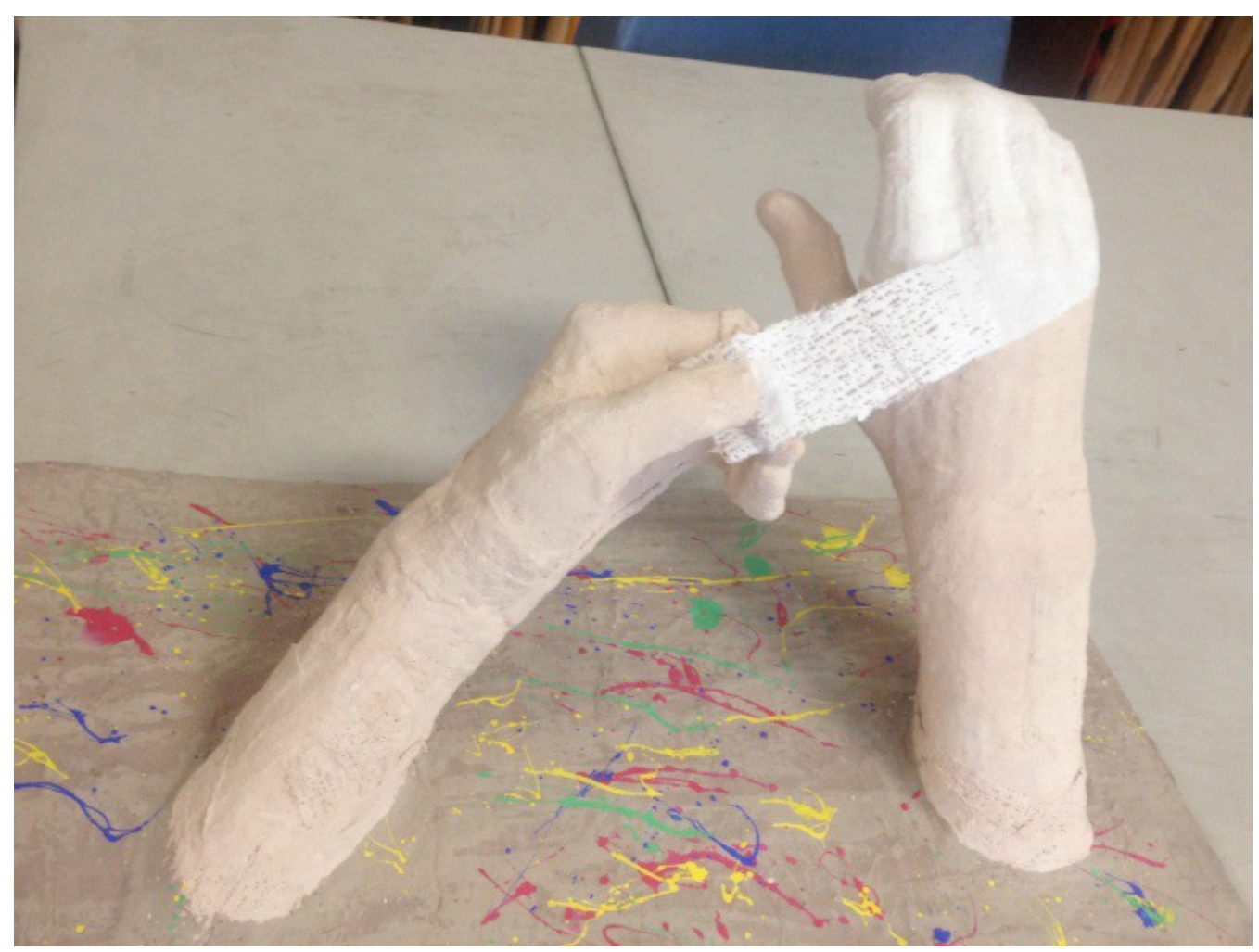

Figure 18; "3D hand sculpture"; plaster gauze and paint; High school student work, 2015.

In response to the first thesis question; "Who is teaching art in rural and urban West Virginia; what education, background and experiences do they have?" information was obtained through an interview. Art educator 18.R is a RESA VII art educator from an urban cluster region. 18.R teaches in the county where raised and educated. Teaching just under10 years, 18.R expresses clarity about their role as an art educator, the role of arts education in the schools, and the importance of art education to the development of young minds in the public education system in West Virginia. This art educator went to a West Virginia state institution to earn a BFA in painting and a certification in pre-K through 12 , visual art education. This interview took place October 1, 2015 at the school where 18.R teaches after regular class hours. 
In response to thesis question, "What resources and support do they receive for their art programs?" educator 18.R reported that the program received a lot of positive and financial support.

Author: What about funding? Yours is one of the larger schools in the state.

18.R: You've probably talked to art teachers that have trouble getting enough paper. We've done zero art fundraisers to get materials. We don't have to worry about that. (no begging) we have to be careful, There is an issue here where a teacher will want to do a project where teachers will have them color a poster in English but they don't have materials to do it so they send their kids to us, I'll have kids at my door constantly. Do you have this? I'll ask what it for and they'll tell me it's for English. We can't give them those things. It's hard for me. They don't understand. They don't understand where are money comes from and how it's used for our supplies. It's expensive and you have so many students. If we gave paper to all the kids that come ask, then we will be actually be at a loss. It's that many students asking. We had to say no across the board." Unless it's for their classes. You become the art supply store.

18R: I think we are perceived very positively. I've heard feedback just about what I'm talking about the kids who don't come in not liking art. Kids who need confidence. The other teachers see big differences in those students and their behaviors in other classes. Just based on things that happen in here, it ends up being an outlet for kids. They can create. They 
are not listening to a lecture. Or reading which they do all day long with no breaks, except for a thirty minute lunch. And it gives some time that they need to create. Some kids even have it as they're safe zone to come or I'll let them stay at lunch it is the place where people come to have a moment (whispers). Teachers recognize that with those kids.

Author: Do you feel supported in the school community?

18.R: We paint murals throughout the school. We are involved with the community any time we do sculptures we'll go show them in the library. And teachers will see that I used plaster. They like that and want to do a project with it and so we'll collaborate. I've done it with at least two teachers in the last year who liked something and then we find a way to figure out how to use it for science and social studies. I think we are seen very positively in the building.

Author: How do you feel your program is situated within the school community?

18.R: I feel like we barely fit in. they are cutting the arts everywhere this county in particular, since it's such a larger and one of the more highly funded counties. One of the highest in the state of West Virginia, the arts are doing okay. The funding at least for us in our high school, is perfectly okay. Of course there are elementary school teachers, in the county who don't get any funding the way that we do. They've cut it off they are struggling but me as a high school teacher, I'm super lucky to be in this school, specifically in this county. It's a very secure job when it comes to 
funding and everything. And also what's giving me as far ...the kids as far as high school goes. They have to have a fine arts credit to graduate. That is job security of me that means everyone needs to take an art class.

18. R: whether that be music arts drama, the easiest one or the one that comes across the easiest is going to be art one because you don't have to sing, you don't have to act in front of people, you're just in a room drawing. I teach all ART I. 6 ART I classes with an average of 30-35 kids in each one, and I'm one of four teachers here who each have the same course load with ART Is, its huge. It's a factory for fulfilling these credits for students to graduate... like the boys that were kind enough to walk you to my door. They're in my classes because they need ART I. You get to see a lot of personalities.

In response and reflection to thesis question number three, "What methodologies do selected art teachers follow in the planning, instruction, and assessment of art in the K-12 art classroom in rural and urban West Virginia?

Author: How do you situate your practice and program as an art educator?

18.R: I started teaching a couple more upper level classes for the kids that actually wanted to be in art and I got rid of them because I wanted to teach ART I again. It is so much more fun for me. I like the mix of personalities in students and if a class is too quiet and I can't even help anyone, they're 90 minute classes so it goes really slow. When there's a class of 30 kids from all different backgrounds who don't really like art, so I feel I have to 
perform and make them like it, I feel like that's better for me. I'm here because they need that fine art credit. If for some reason, they got rid of them needing a fine art credit to graduate, I don't know what would happen to the art programs.

Author: What benefits do you feel art education provides your students?

18.R: They're gaining confidence. Again I see this with the kids that come in and don't even want to be in high school. It's not like kindergarten where they think they can do anything. By the time you get to high school they are very insecure and draw and cover their paper. They don't have any confidence whatsoever. There's a huge difference between...We start to teach them the basic ways they can learn to draw. From the very bottom and then they start to gain confidence. And you have kids who are proud of their work who at one point said they hated art and they have something they are showing off and you can put it in shows.

18.R: There's kids in particular, I definitely like to work with the kids who are more troubled and really need confidence. The kids that already have that that's great and I want to keep that up but the kids that have no outlet are the kids I aim for. It's really satisfying to see them be proud of something and march it around the school, which happens all the time. And show it off in the library.

18.R: On a more technical level, people don't understand, all art is, aside from creativity which of course is integral, it's hand eye coordination and you 
need that to live your life. When it comes to writing your name or when it comes to doing anything. It doesn't have to be artistic. But it's so important to have that. Some of these kids can't even write which is crazy.

18.R: They don't realize that sitting in class and focusing on a still life and drawing what they see is helping them in those ways too. Just to become better in everything. To help their brain function. They don't understand that and I explain it to them and I try to get them to understand. You can see huge differences in everything! Like their writing. You can see their letters start to form and change throughout the year from the beginning of the year so all those different things.

In response and reflection to the final thesis question; "How the art educators and their teaching methodologies influenced by the context of where they teach?" the educator talked about the art program's role in their particular school and its curriculum.

Author: Do you feel supported by the administration?

18.R: There would be no reason, according to the people in charge, for us to really be here. Even though there are plenty of reasons and research to back up why we're here. Right now everything is STEM. It's science, engineering. We're going for STEAM to add ART in there. Our school's engineering teacher works down the hall and collaborates with us all the time. He says 'my kids are thinkers, they're engineers, they can't create they haven't had the art classes to be able to create to learn that because of the way the art programs are in the county. And everywhere. So he has to 
have them come talk to the art students. They can collaborate and help the engineers design things. They're really smart but they are so smart they can't really think outside the box. They can't be creative. They're thinking in another way.

Author: What are some of your biggest challenges?

18.R: The biggest challenge that I'm dealing with right now and have about everywhere is that you're not really set up and don't have the resources for dealing with a class of 35 maybe two of the kids are ESL. They don't have anyone to help them it's just them in your classroom and then in the same too, you might have 4 special education students who some in with one aid. I'm actually describing a class that one teacher has. Some of the special needs kids are severe. And no one ever teaches.... yeah they talk about differentiations but you need specific resources that they don't provide to you and you're just in there with them you and there's paperwork you do and the teachers talk about who is in charge of the different things but I'm dealing with a kid who needs very specific things she can't see. It has to have a lot of criteria to do her lessons and don't have the resources.

18.R Trying to figure out a way. 'How can I reach that student?' That's in all education not just art specifically. If anything it is helpful in art because it is more a creative loose environment. To kind of reach everybody. To me my biggest challenge in teaching is the class sizes are a huge issue what 
can you do in art with a class of 35 students? How are you going to do plaster with 35 students? I do and I'm not going to have them just use markers on paper. You get good at teaching because you have to find ways to organize your crap. So I don't know. The class size is a huge issue and they don't look carefully to distributes the students, they don't really look at that they can't really. They don't look at what would be the best possible situation for everyone.

Author: What do you consider the greatest reward to being an art educator?

18.R: I love working with the kids, I love being around them. All the different personalities. It's rewarding to see a kid get it. To see a kid do work that I know doesn't do work anywhere else. We can make them comfortable enough to ease into it and then give them compliments. They feel so good about themselves. Definitely one of those people. If I didn't get paid, I'd still do my job. I love it and it is so much fun. I don't care that they pay is not great. I can't imagine not being here. I love it that much. More than ANYTHING ELSE.

\section{Case Analysis}

Educator 18.R is an art educator who specializes in teaching the high school introductory art education course known as Art I. This art educator is particularly inclined to teach this introductory course in all sections. Some art educators find themselves inclined to teach the upper level visual arts courses and other educators find themselves called to work with the 
beginning levels. This particular art educator specifically chose to remain teaching the Art I courses in spite of opportunities to teach other levels.

As a high school Art I educator, 18.R said they felt they had the unique opportunity to see nearly every student in a school as each student must fulfill one fine art credit as required, for graduation. Many art educators report Art I classes as being a popular way to fulfill this fine art credit as they do not have to perform unlike theatre, music, and dance. With this responsibility comes providing students of all types of learning abilities the same opportunities to create work in the visual arts classroom.

This art educator's school is one of the largest schools in the state and therefore has a good deal of financial and administrative support. With financial and peer support comes opportunities to collaborate with other art educators, and other subject programs. Collaborations between programs provide students with valuable learning opportunities where the benefits of creative problem solving become a stable to the learning environment.

\section{Figure Analysis}

The figure shows a student's creative solution to doing a hand study for a plaster casting project. The students were required to complete a plaster gauze 3 dimensional model of their hands doing something. This particular student chose to represent their hands making the model. The teacher felt this was a clever solution to the study. Doing a 3-D plaster project for the number of students and class sizes taught by educator 18.R is an impressive feat. 


\section{Word Frequency Analysis}

county education (8) elementary (4) engineering(6) enough (5) everyone (4) everything (6) feel (9) fine (5) full (5) funding (5) getting (6) give (5) going (10) help (7) $_{\text {Gí }}$ (31) lives (4) love (4) minute (4) needs (6) particular (4) people (6) Program (10) room (6) school teachers $\boldsymbol{s}_{2 \pi}$ teaching understand ${ }_{(7)}$ ways (4) weeks (5) west (4) Work (8) $_{\text {year }}$ (10)

Figure 19; Word frequency chart generated from interview transcripts with educator 18.R, 2015. 
Participant 19.S

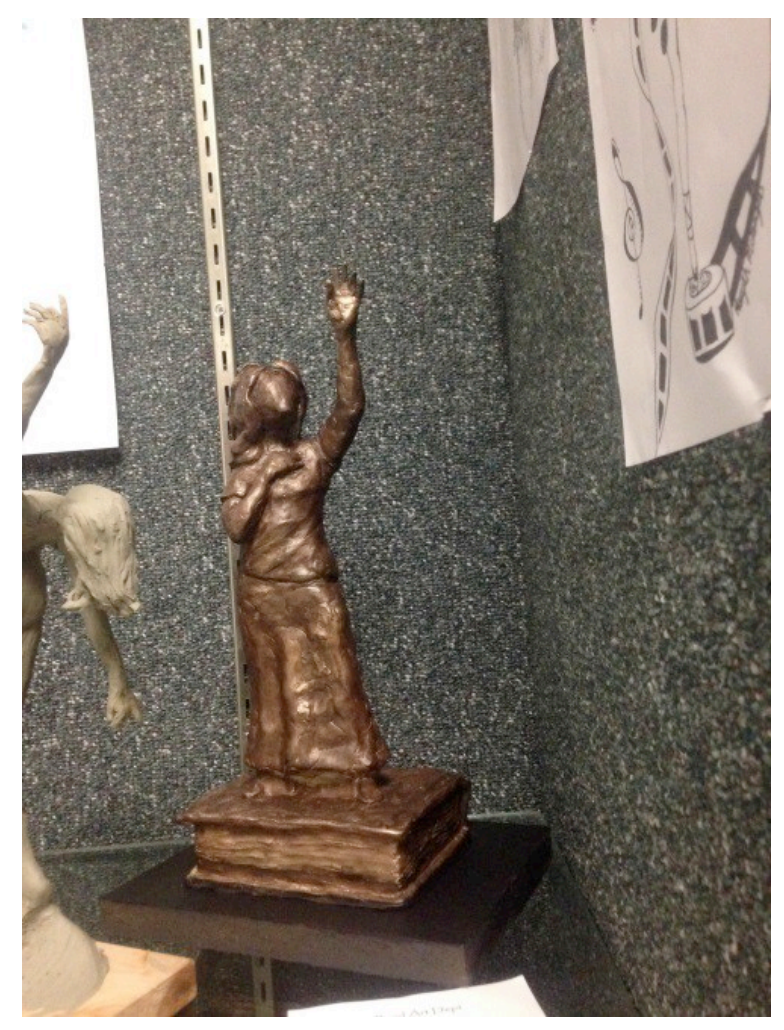

Figure 20; "Figurative Sculpture"; teacher example, 2015.

In reflection and response to the first thesis question, "Who is teaching art in rural and urban West Virginia; what education, background and experiences do they have?" 19.S is an art educator teaching in an urban cluster school that is surrounded by rural areas. Art educator teaches in the RESA where they were raised and educated. The interview took place on-site during the educator's preparation period on October 16, 2015.

Author: What led you to become an art educator?

19.S: the money and the insurance. Financial security of it. But the above and beyond stuff...I don't know. It wasn't done with me. Maybe that's why. 
Because I lived so far out and was poor if it was an after school thing I knew I want going to be able to do it. I want to give that opportunity to these kids. And open their eyes.

In response to thesis question number two; "What resources and support do they receive for their art programs?"

Author: How would you situate your program and practice within the school?

19.S: Oh my. I think it's central. All of our programs probably feel that way. If they need anything. Play sets. Anything any kind of visuals. I made stencils for the parking lot. Done silhouettes for graduation. A little bit of that give and take that you have to please. To be able to ask for things later. And to be appreciated when you don't have something in on time. They know that you're working "she does so much" Give and take. I don't think I'm the most important program. I think we're integral. I feel very respected. By the staff and the administration. Not necessarily by the students.

Author: How is the financial support for the program?

19.S: I am very blessed because we have a levy that passes in this county every time. If our community didn't support the arts and the schools. Coming up there's one. It makes me nervous. Without it, I would be a 10th of my budget. I would have to take a zero off of what I get if it were not for the levy. I try to be resourceful anyway. Try to do projects that are recycle this 
and find this. scavenge through stores and borrow. find things to use in mosaics. A broken mirror is only bad luck if it's not used in a mosaic, right?

Author: And do you feel administrative support is important?

19.S: Oh yeah that's why I left my last school. it really is. I had fifteen years in there and I thought I would retire from there. And I knew I didn't have the support. Of course this facility is awesome. This school is early 2000. It's a beautiful space.

19.S: I would like to do more traveling with them. Our county is... we're not allowed to take field trips second semester. Period. That's Arts Alive. It will have to be after school. I wanted to do more field trips this year and I need to plan them before Christmas. They like them in-state because of gas. We took a field trip last February to the glass museum and factory in Weston. And we made things. Little bubble pieces. Fused glass pieces. parents went. It was free!

19.S: I want to do stuff like that every year. I want them to have clay opportunities. I need a visiting artist to come in a make a pots. We need to reach out and pull people in. I know two murals. The city wants us to do a mural on a prominent building in town. And the board office wants us to do a mural. I'm trying to teach more about the history of this area. We think that's cool but they [the students] think there's nothing cool about the area. 
In reflection and response to the thesis question; "What methodologies do selected art teachers follow in the planning, instruction, and assessment of art in the K-12 art classroom in rural and urban West Virginia

Author: What do you feel art education brings to your students?

19.S: It's a place to belong. It's something to be good at...something to feel proud about. Express. They're all about their personal expression but they need the tools and skills to do that. Sometimes I will back them away from doing that. Their cartoons and their anime...to get some skills. They resisted a little bit. Providing the framing, and to exhibit and to push them to that. And take them to the receptions where their work is among other people. It's paramount. It should be required because it is so valuable them. Sitting around after with a table of artists eating and be in the van talking about it. It's a great outlet for them. A great way to reach kids that might not be doing anything otherwise.

In response and reflection to the fourth thesis question; "How the art educators and their teaching methodologies influenced by the context of where they teach?

Author: What are some of the challenges you face as an art educator?

19.S: Drugs is a big issue. That might be up there. I know we're the top city, in the top county, in the top state of our entire country and its drugs. That's not a nice badge to wear. Half the babies born in this county are addicted already. Half. Makes me want to cry. For them. A lot of those 
kids even if they are broken, or spoiled or over or under motivated, they come here whether they want to do my projects or not because they love me. They love being in here and having a place they can call theirs.

Author: What are your students like? Do you feel they come prepared for your arts classes?

19.S: Half and half. Who gets put in my room is not always who I want put in my room. They [the students] have had art since preschool. In this district they've had an art teacher since grade school. All elementary in my school... So I'm lucky enough that they've had some things going on but there is a disconnect somewhere. Especially with boys; in confidence, in doing anything. Their fourth grade drawings are better than their seventh grade drawings. I think that's global. Maybe America. But I think of it is confidence. My role is to be a cheerleader and to praise their efforts and coach because they need to feel they are doing worthwhile or they are not going to do it. They would rather fail than fail at what they are drawing . And put it out there. So I need give them the tools. I'm still learning. It's still a challenge.

Author: Any other challenges?

19.S: Discipline. Little more having those deadlines and not just painting whatever you want to but having guidelines and a rubric. Goals to attain for a specific project. Creative problem-solving skills 
19.S: Probably 50 percent are on free and reduced lunch. It's a different population than what I taught in the past. It's a lot more urban. Lot more discipline and apathy issues.

19.S: There's still that kind of real original thought. the girl that did the relief piece. I don't think she's had an original thought in her life. And she wants to do art with her life.

I'm thinking, 'no'. She's talented she's a technician. So you need to take the technician and give her the ideology. Or you have the kid that has the ideology but doesn't have the technique. There's a big...then you throw a lack of confidence in there, it's a struggle.

19.S: The thing that puts me over the edge is the discipline.. I have a couple of level I classes of freshmen. Like $2 / 3$ are freshman boys. Future criminals. They don't see it. Some of them are getting it. And I'm reaching but we've had ....from August to October that are still. I don't know what to do with them. I have administrative support but I can't send them out daily. Which is annoying.

19.S: Other challenges. Discipline and organization. I think of things and grab it and spread it out and inspire and inspire and then another class walks in. I need to tidy up. We all need time management skills so that we clean up at the end of every block.

Author: What rewards to you find from teaching art education? 
19.S: The faces of these kids... when I had the pieces framed and ready to go. I had some frames that were ready and I popped some pieces in and Mariah came in and I showed her and the look on her face. That pride and to see it framed like a real piece of art. Seeing them win. Seeing them push beyond what they were drawing and doing. In the whole county we've got a 96 percent pass rate on AP portfolios. Everyone does well. It's exciting.

\section{Case Analysis}

Art educator 19.S teaches in the RESA although, not the county, where they were rasied. Educated in West Virginia schools this art educator holds a BFA and certification in art education. They bring to practice, experience as a professional practicing artist, school club coordinator, and opens their classroom to student teacher from neighboring universities. 19.S has over 20 years of experience as a high school art educator and has plans to work on a Master's degree in the near future.

The methodologies employed by educator 19.S include both technical instruction as well as exploration in the expressive. The educator felt that learning the technical skills was an important component to lend itself to the expressive qualities of making art. They felt the art classroom was a safe place for students to think and work creatively regardless of their backgrounds and experience. Educator 19.S did feel there was a gap in student artistic achievements in school. They were not sure if it was the short amount of art they were getting in middle school or if it was an age or developmental gap. This educator felt the gap was more noticeable in male students. 
Educator 19.S is the only art educator in a school that serves just under a thousand students. The classroom supports work in ceramics with four wheels and a kiln, possesses a printing press, and through donation, framing equipment. This educator teaches Art I, II, III, IV and AP art and reports a high success rate for student's passing the AP portfolio exams. Because 19.S is a professional artist, they strongly encourage students to enter and participate in local and regional art competitions.

This art educator teaches in an area that is classified as an urban cluster. In their reflection regarding context, the educator reported an influx of drug abuse in the region. This educator indicated that their school is home to students from a wide variety of backgrounds. In their teaching practice, they encounter students who have had some elementary art education but not all of their students have art education in their background. They did not feel the students who had elementary art retained much of what they learned.

\section{Figure 20 Analysis}

This 3dimensional figure was created during a pre-service teaching period. The student teacher who came into this educator's classroom brought sculptural modeling skills to their practice. Due to the time frame this educator was interviewed, the preservice teacher had only recently finished their work at this school. 19.S had opened their classroom and mentored a student teacher for approximately 8 weeks allowing the student teacher to practice by taking over lessons in this veteran educator's classroom. Educator 19.S reported a positive experience when mentoring. They feel that the exchange is equal and that both the student teacher and the veteran educator learn new things from one another. 


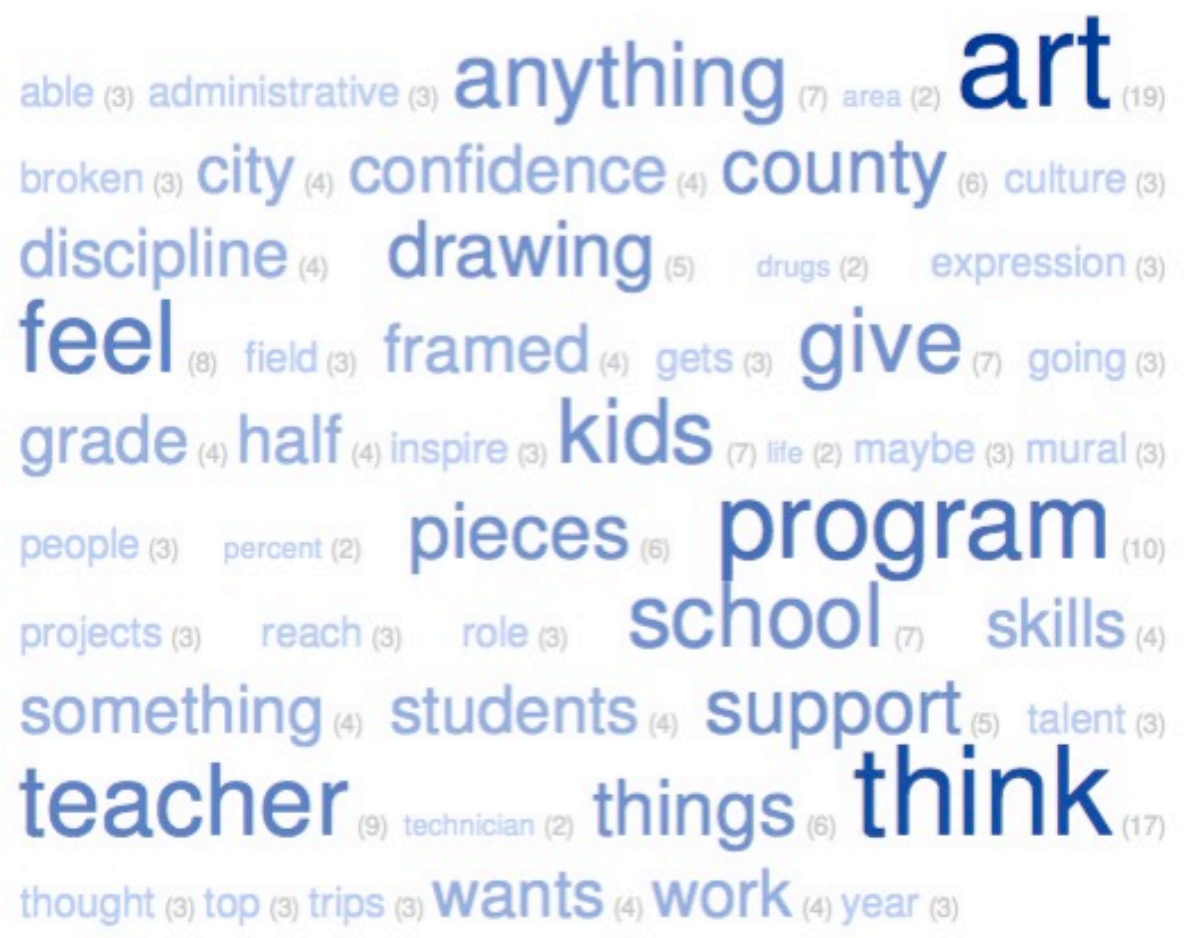

Figure 21; Word frequency chart generated from interview transcripts with 19.S, 2015.

\section{Participant 21.U}

Information was obtained to answer the first thesis question, "Who is teaching art in rural and urban West Virginia; what education, background and experiences do they have?" through an interview. This educator from RESA VIII was newly retired from an urban cluster located in historic farmland impacted by urban sprawl. 21.U is a veteran educator with more than 30 years of practice. This art educator studied in the state of West Virginia. They started off in graphic design but found themselves continually helping and teaching her classmates and went into teaching. The interview took place August 25, 2015 at an off-site location. 
Author: $\quad$ This is for my Master's thesis project.

21.U: If you look at my counties (urban cluster) or Berkeley, Jefferson, Monongalia, Kanawha, Cabell, you can get a job probably even here but if you go to the rural counties, they don't want to pay for someone with that degree.

21.U: So if you're going to go to small schools to teach, it could hurt your hire ability. If you are going to look for larger schools that's good. In our particular area that's good. Here has two high schools. And one Catholic high school.

Author: $\quad$ Yes.

In reference and response to thesis question four; "How the art educators and their teaching methodologies influenced by the context of where they teach?" $21 . U$ spoke about the unique demographics of their region of the state.

21.U: Our area has four high schools and we're busting at the seams. That shows you how this area is continually growing. Most of these people are coming out of DC. Nicer living, cheaper taxes. But that's impacting the schools tremendously.

In response and reflection to the thesis question; "What resources and support do they receive for their art programs?" the participant was asked about administrative support.

Author: What are your thoughts on the impact of administration on programs? 
21.U: They have to understand that they want to get them into this (the ARTS) as much as they want to get them in soccer, or basketball and everything else. That it's gonna take a lot of community effort to get those the people to get those kids involved.

21.U: I think that they put too much emphasis on sports and they need to bring school back to what it's supposed to be on all levels. Let's teach cursive. Let's teach them how to read, let's teach them about art, how to do math without a calculator. Let's teach them the things that give them a skill set that they will have the rest of their lives. Not when the electronics go down and they can't figure out anything. Unfortunately I see a lot of schools going way digital in art. Almost throwing away all these wonderful skills.

21.U: The biggest problem I saw when I taught 1976-1986 (10 years) then left to raise my family. Interim, taught at a college as an adjunct. When I came back to the public school. I thought! What the heck happened?? Well in that first block. I helped write the curriculum guide for 9-12. Myself and a number of others. We did from first to $12^{\text {th }}$. I had this guide... back then art was an elective. The students you got were invested in it. They wanted to express themselves. Before I left in that 10 year block. Then they switched to doing these investigative blocks where the kids would come in and learn about it. That did increase the enrollment. finding it interesting. 
21.U: This was another thing I found when I came back. Kids didn't want to keep their art. They would get their grade and throw it away. A long time ago, they wanted everything they did. Even if they just scratched on a paper, they wanted it. They kept everything. I was floored when I came back and they threw it away. Some of it was really good. Which says to me, 'I have no pride. I have no reason to be anchored...floating'. I see so many kids floating. Again, I feel art gives those kids the ability to tether themselves.

In response and reflection to the thesis question, "What resources and support do they receive for their art programs" I asked the participant what the support was like within the school.

Author: How do you feel your art education program is perceived by your peers?

21.U: there were those who would come down and think that I was a supply house... "I need tape, I need glue." Good! The store's over there. "I need a sign" if I have the students that are available...my primary objective is not to provide every teacher in that school something. I developed a reputation for "don't go there with her". I would have my national honor art students to banners, do signs, community projects. But it was the level that I could control. I can't make a sign because they're having a ham and cheese sandwich fundraiser somewhere.

21.U: We have a school store and I told the person...he said, "why do I need to order construction paper glue...?" I said, "that's going to be the first thing 
people ask me for". So when the teachers come in, I could say "oh yeah, I understand the school store sells it." And I'd get "yeah, but we thought you'd get it for us". I'd say, "guess not."

21.U: the people who respected me were the ones that were in history, some science teachers, because they got it. We would share things because we cost over. The math teachers got into it and they would want to know more about Escher. The people who were true to their craft and really wanted to teach, they understood what I was doing and I had a great deal of respect from them and to them. We helped one another. Unfortunately I see fewer entering the education field with the idea that I really want to make a difference, I really want to help students.

21.U: These days I see, "oh I get my weekends off. I get my summers.” And they're so...don't even teach. We're not teaching...we're taking cursive out of the program! Taking away cursive, you can't read the Declaration and the Constitution as it is written. Penmanship... they can't. Here I am teaching high school and they can't taught ...oh my gosh, they can't read a ruler?? Inch mark, half mark, and a quarter inch. Doesn't even know what a protractor is. Doesn't even know how to use a compass? They haven't used a compass. In response and reflection to the thesis question, "What methodologies do selected art teachers follow in the planning, instruction, and assessment of art in the K-12 art classroom in rural and urban West Virginia?" educator 21.U reflected on benefits of art education and their methodologies in the classroom. 
Author: What do you feel art education provides your students?

21.U: Well-rounded. You know you can get a lot of.... Engineers are known not to be sociable. That's sad to me. Einstein played a violin. A lot of people who were effective in life realized how important it was. Japan did a study years ago. They were losing that technology edge. They were losing their place among global competition. And they realized that it was because they took art out of the curriculum. So they put it back and they brought in exercise. They felt people had gotten too sedentary. Now they are back at the top.

21.U: It teaches you a component of education it teaches you the past makes the connections and moves you forward. And my son's an engineer also had an art teacher for a mother. So all three of my sons who are engineers all can do art and know art and appreciate art and that's why they are so good. They have to have that in their lives in some way. For them most of them it was music but they could physically draw too. And do other things. One son welds and it's a work of art. I think the public needs to be educated to understand that the ARTS aren't something to blow off. I'm talking about the visual and the performing arts.

Author: $\quad$ Tell me more about your practice as an art educator.

21.U: My classes, they all did etchings of some kind, they linoleum block, serigraphy. We did collaging, we did paint, we did hard-edge, we did realism. In my mind it was all about teaching them all these different 
mediums. Especially in the first year Then, in the second year, you weren't having to go all the way back, we worked on more of the challenging things but with more creativity, knowing the basics.

21.U: The third year, was finding your voice. What is your voice? What direction did you want to go? How can we make that even better? Working on a series. And concentrations. I've had a lot of luck with my AP kids, we never scored low. I had one kid where I had two 2s. But all my AP kids were, 4s. 5s. 6s... and that's good. That's because I'm working with a smaller group and I have the opportunity to work with them the best I can. The larger groups, I'll get some results, but not the kind of results that I'd like to see. So what I've done, helping the public education system, for me, I have always been my own advocate. So I've had in school shows, in classroom shows. I've talked to banks, and go to malls to put up shows. Enter almost every contest.

In reflection and response to the thesis question; "How the art educators and their teaching methodologies influenced by the context of where they teach?" the participant shared some personal insight and reflection on art education and policy.

21.U: When I left and came back, art was mandated. When you mandate it...you took away something. As you were at the meeting. It's all about expression. And freedom. Freedom to choose. So what's happening now in the schools, or what's happening the larger more metropolitan areas is that kids are being dumped because they have nowhere else to put them 
and then because its mandated it that they have to have that art credit. They don't look at at the other arts. Chorus, band, dance, theatre, cinematography, and shop! They follow the same CSOs interior designing, home economics they follow the same CSOs ....they don't put them there, they put them in art....

21.U: So what you have are Art I classes that are too large, un-invested, I always do a Pre-assessment and a post. The pre-assessment always shows me that maybe out of the 35 kids sitting in my class, 2 of them want to be there.

21.U: So you have this attitude that you start with in high school level which isn't good. At the grade school level, you can change that. In a high school, you can't. The post-test tells me, you've gotten through this whole year, tell me, what did you learn "well you know, I learned a lot. I've come to like it. Unfortunately it takes you three 9 weeks period to get to the point where they might allow you to teach them so consequently the kids who have this interest they won't even take the class, they know they are going to be in a room full of kids who don't want to learn.

Author: How do you feel this could be better implemented?

21.U: Being a department chair, they [the students] need me to sign off on certain things. I say, 'How come you're not in art? I see what you're drawing. I see what you're doing and they go, "I don't want to be in those big classes with all those kids." I have to go out and self-recruit and it's become very hard. It's like, guidance people don't recognize art as a 
totally different animal. They see it as a course. A course that you just put the kids in. They don't see it as specific to tap into their creative mind. If you have children that are shut down, shut off, don't want to be there. They impact the rest of the class. That's the sad part.

21.U: I see that as wrong. If you're going to make art mandated nationally it needs to be advocated better that there are other opportunities. Art does not always mean you've got to sit and do a drawing. I have kids years ago. Shop classes were once big. Kids like to make these fun projects. All kinds of school stuff. But they don't take shop because they can't fit it into their schedule. It's not available for the credits.

21.U: You're knocking out all this possibility for them to express themselves in different way that they want to do by putting these mandates. That's my pet peeve. That's my big pet peeve. Second pet peeve is the guidance counselors aren't doing their job. If they would sit down and talk to these kids and thoroughly understand they don't want to be in art class but they don't want to dance and they don't want to sing. Guidance counselors can help funnel them to the area of artistic expression that they would like.

Addressing the mixed message that the gaps sends:

21.U: It says "oh you know, it only counts as part of your grade". But they've taken away the importance of it. So they spend three years being trained that way. Then they go to high school, "look at that!" It meets every day... and it's important, and there are tests, and there's art history... and 
they can't transition. It trains them that its unimportant. It trains them it's a filler. And so when they get into high school it's another filler.

21.U: To realize that $\mathrm{G} \sim \mathrm{d}$ gives us so many talents and so many abilities, to mold ourselves to throw away the one thing that every child picks up at 18 months of age, or a little older, a crayon. Every child creates an image and every child...Viktor Lowenfeld did a study. Every child draws those same things...hrough those stages... it dies off at adolescence when every child goes to middle school. And that's when we destroy it. Most of what I have to do when they're in high school? I have to take them all the way back and try to build them back up again. Because they've lost that freedom of expression and that innocence from wanting to create. Now they have to put the right peg in the right hole. Of course I believe art education is absolutely necessary. Because if everything has an exact answer, we're not teaching abstract reasoning, we're not teaching problem solving.

21.U: If the people down in Charleston don't get it figured out, they're going to destroy one of the best products West Virginia has every produced which is art. Our culture is all about art. Cabin creek quilts, our pottery, the glass that comes out of here, you go to Missouri and it's "Blenko Glass". I mean it is our culture. Right now...they're...I don't know what. West Virginia needs to think about what is good for West Virginia. And quit trying to copy what California did ten years ago. It didn't work. My 
favorite story is open schools. California decided to have open schools. And 10 years later. West Virginia did it. After California had put walls up.

21.U: Okay, so those are my two pet peeves. Mandating and guidance. Third pet peeve, I don't know where West Virginia got this idea but they're stupid. So you have primary art, kids love it! They eat it up. They can't wait to go to art class, music class, gym class, they love it! Go to middle school, what happens? They go to a rotation class. Some counties have it for five weeks some have it for 9 . They all have these time period that they put on it. What they've done is, they've taught kids for three years, art's not in important because you're only in it for five weeks, you're only in it for seven.

Author: Do you incorporate local culture into your classes?

21.U: I always taught West Virginia artists. My kids know who Blanche Lazelle was. And Charles Jupiter Hamilton. And Duke McCowsky. I taught them about their art. And when I did that, its' like doing genealogy and you find your great-grandmother and grandfather was a horse thief. You made a connection with them they were like "oh we have artists." It's like sometimes they view their culture as "oh we're just West Virginia" but when you start showing them that these are things that you have these successful people. They start to become invested and they want to know more. So I would do that and then we would do community murals on sides of buildings we would do programs for various... like the Women's 
Club. And Christmas we'd paint things. I'd say lets. Paint something local and special Like Blakeley, Washington home.

21.U: I would take them to do field trips that were local. Like the brick plant. Let's go draw at the brick plant. And I would explain about. And the Adams Stephens home which was who Martinsburg was named after. And I would just do that stuff and try to bring in their history. When you can develop a pride for who and where they come form, you will be much more apt to create that... if that makes sense.

Author: Any reflections on retirement and teaching:

21.U: It's just I know that again. Here's my belief. I don't know if you can take a person and make them a teacher. I think it's this innate thing. It's part of who you are. It's a nurturing thing and either you have it or you don't.

Also, in response to the thesis question; "How the art educators and their teaching methodologies influenced by the context of where they teach?" participant $21 . \mathrm{U}$ also talked about her frustration with the ever growing number of duties she was to perform outside of her classroom teaching and preparatory time.

21.U: And the duties. The duties have gotten ridiculous. I am not only an art teacher, I'm a hall-patroller, a bathroom person, and I have to do the breakfast thing. Oh yeah, I have to wipe out the little kit. take the lunch count. Make sure the kid count was right. Then I had to check off the sheets. Then if a kid is wrong or called you a name or broken something. I 
can't just turn it in to the discipline officer. No I have to make at least two phone calls home. Oh okay. So when do I call? On planning period? Okay. I can't always get a parent. Then I have to call after school, I have to stay. I'm not going to call them from my personal phone.

21.U: then I have to make the calls. Then I have to document and then I have to remember. "Oh! Check the bathrooms." If they go out they have to sign this paper and then they have to sign back in, and if a kid has missed two weeks of school I have to get him caught up. It just goes on and on and on... I have to make special paperwork, projects for those who are homebound. And oh, yeah, this kid just went to transitional but came back and now you have to get them caught up. It's too much. Let me teach. Let someone else handle the discipline. It's too much. Let me do my job. Let me do what I am trained to do. That would be like asking a doctor to go into hospital and change bedpans and change the beds.

21. U: It is. They don't get it. For me the last two years...because I was on hall duty, because I had to teach from bell to bell, I had zero prep time. And because I taught 6 different disciplines in 7 different periods, it was nerve wracking. It was stressful. And I have always, always carried a full load of freshman, because I'm pretty easy going. Not these last two years. It kept growing and growing and that's when I decided to retire. 


\section{Case Analysis}

Art educator 21.U brings to their practice nearly 30 years of experience. They have taught in every grade level including as an adjunct at a nearby college and as a mentor for pre-service teachers. This educator's primary focus has been on secondary art education in the public schools. Their teaching practice responded to highest professional standards, student need, and regional context.

The educator reported inconsistencies in support for the art program. The program received monetary support but not necessarily support by administration. They felt some peers understood the role and importance of their art education program but they also saw how many teachers only relied on the program for the materials and support the visual arts program could potentially provide their project endeavors. $21 . \mathrm{U}$ also felt there was a disconnect between policy making on the state level and what is actually taking place or needed in the visual arts classroom. Like 17.Q they felt the state was not capitalizing on the benefits of art education to the workforce, economy, and cultural identity of the state of West Virginia.

The schools where this educator taught have been located in a region of West Virginia marked by growth from the Washington D.C. metro-area. This portion of RESA VIII is unique to most of the rest of the state as people from the urban areas are moving out of the cities and into a rural landscape. This is having an impact on the schools as noted by art educator 21.U. In spite of the shifting demographics, this educator brings local culture and history into the classroom. With so much experience, educator $21 . \mathrm{U}$ is able to teach all levels of the visual arts and can provide students with opportunities to work with a wide array of materials and projects. 
Due to all of this experience, educator 21.U has seen many changes in the role and purpose of art education programs across several decades. This educator feels that the current direction of the mandating of an art credit when there are gaps in the sequence of curriculum in the K-12 visual arts programs, leaves students in a poor position to be successful in the arts. This art educator feels that with a lack of other types of classes, too many students are crowding into the Art I courses and forcing out the students who want to be there but do not find the environment conducive to learning.

\section{Figure Analysis}

There is no figure to analyze as this educator had retired unexpectedly (to the interviewer) before the meeting. Attempts have been made to acquire a recent image from their last year of teaching but to no avail. However, due to this educator's experience and knowledge of the field, their interview was included in this report.

\section{Word Frequency Analysis}




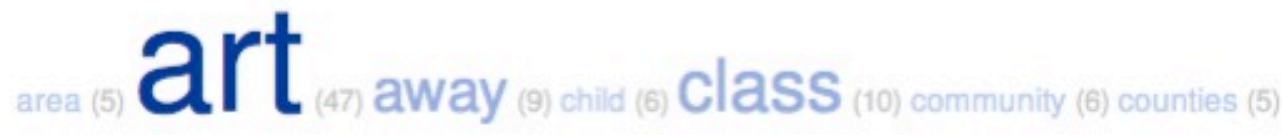

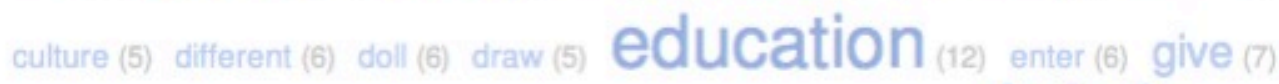

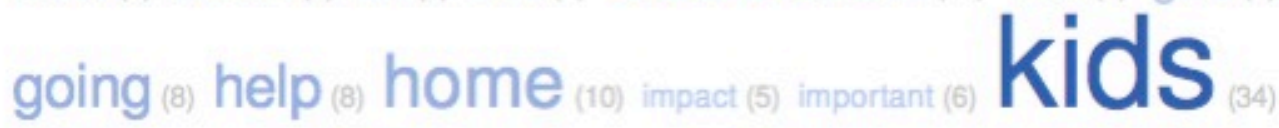
learn (8) lets (6) $\operatorname{lot}_{(10) \text { mandated (5) }}$ Oh (12) okay (5) people propram (6) pubicic) realized (s) really (10) School

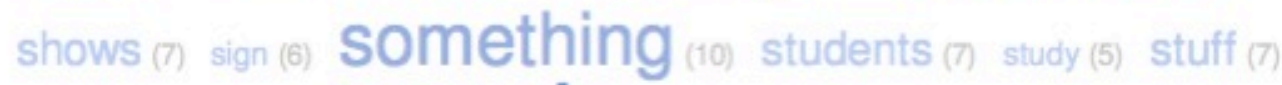

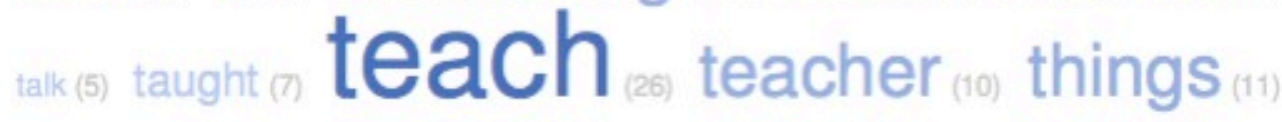
think (12) thought $_{(12)}$ virginia (1) wanted (8) west (1) work $^{(12)}$ years

Figure 22; Word frequency chart generated from interview transcripts with educator 21.U, 2015. 


\section{Participant 22.V}

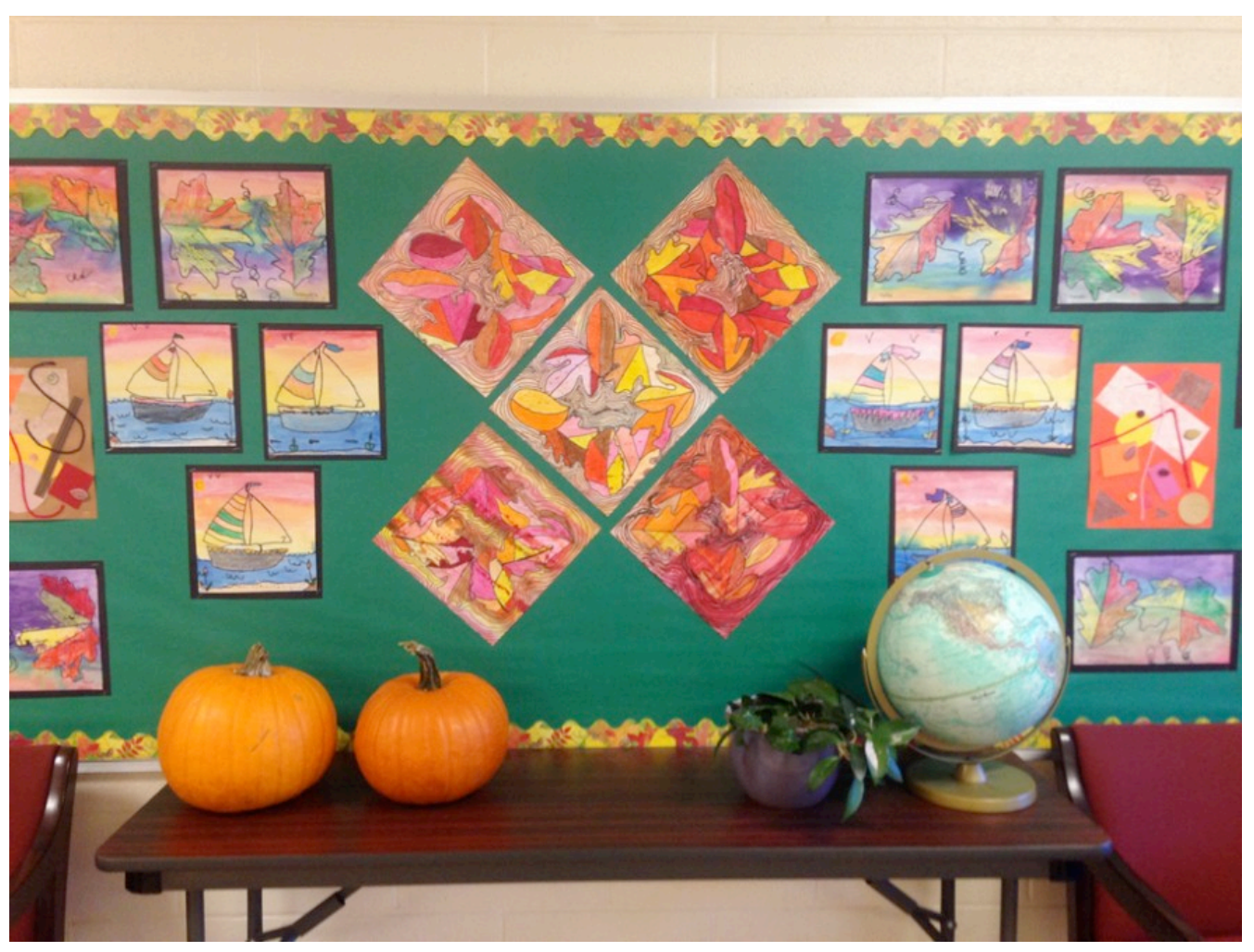

Figure 23; Entryway of a RESA VIII elementary school; Student work, 2015.

In response to the first thesis question; "Who is teaching art in rural and urban West Virginia; what education, background and experiences do they have?" educator 22.V is a RESA VIII elementary art educator in a rural region, somewhat near urban cluster. Some urban sprawl from the Washington D.C. is spreading into this educator's service area.

22.V has 35 years of experience as an elementary art educator. This educator was born and educated in the upper reaches of the Northeastern United States. Once earning a Fulbright scholarship to Japan, 22.V has worked primarily within elementary schools and does a great deal of work in the community arts realm. Supplementary to their practice as an art educator in RESA VIII, 22.V has provided many years teaching and direction for summer arts programs in her 
teacher area. The interview took place, on-site before the start of the school day on October 15, 2016.

Author: What is your background as an art educator?

22.V: I was trained "art on a cart" style. But that's how I was trained. On a cart. I was trained to teach at two schools. Trained to teach art from a cart. I never had a classroom. I've taught in a cafeteria, so that someone could be in here. It has made me very organized and efficient. I don't waste time.

22.V: I came in 1979 and for 19 years, I was at two elementary schools. Each year I would go before the Board with a letter and read it and a $\mathrm{PhD}$ from the local college would go with me. First they put in music teachers, then they put in librarians, then they did nurses, and then they made us art educators full time. The two schools where I taught were identical, right down to the closet.

In response and reflection to the thesis question; "What resources and support do they receive for their art programs?"

Author: What is the support like for your program?

22.V: It's kind of up to the individual school. So what i did was write a grant to the arts council of Jefferson county and I've been awarded it for almost $\$ 500 \ldots 10$ years. 
Author: Do you make a point to make the arts program and important part of the community?

22.V: It's really important in order to get funding from the principal, you have to make it...what's it going to benefit? I've worked with the PTO and done two projects for them to raise money with student art work.They can call it a magnet program. I did the one called "my art" every child had a picture framed hanging in the cafeteria for gallery night. And the parents could buy them totally framed. If they didn't we had to un-frame them and the frames went back. Only once we did that. They were just pop-in frames. It was costly. $\$ 35$ framed it was a good fundraiser. I got the TV that way.

V.22: Here is one of the wood projects the kids did when Charley Jupiter Hamilton was here.

Author: Where did you come up with the scraps?

22.V: Parents are great here. They are wonderful. You ask, and all the sudden you have boxes. My goal is to use up what we have here and a lot of this before I go. There's a lot of stuff here that's mine and will probably end up at the community art space where I also work.

22.V: My principal is so generous. If I'm maybe doing a printmaking project, tell him I'm kinda short. And I do not use tempera. I use printing ink. And I tell the kids and they're going to get a real piece of watercolor paper. I tell them what this is and respect the material and I'm getting you something good. That gives it some value. They are very good about it. 
22.V: There are some money constraints and it is going to be tough. I'm very conservative. The kids know that it goes into the scrap box if it's usable. We re-use it. All the yarn was donated. I make sure I have enough and a little bit extra.

22.V: We'll be $50 \%$ cut next year and only get $\$ 500$. That's not even a dollar a kid. So if a teacher is getting \$250? It's a good thing I'm easing out. I buy a lot myself to. If the levy passes, it should be okay. If it fails, they can do it one more time. Part of it is the racetrack (economy) the funds aren't there because they've opened other racetracks. And the governor just did another $1 \%$ budget cut.

In reflection and response to thesis question; “ What methodologies do selected art teachers follow in the planning, instruction, and assessment of art in the K-12 art classroom in rural and urban West Virginia?” art educator 22.V discussed various lessons and philosophies behind their art education program and practice.

Author: $\quad$ Do you follow a specific art education pedagogy?

22.V: Mine. It's mine. It's a flow that goes from one thing to the other. We write a newsletter as teachers in the school. We are responsible for it and it goes to them monthly. So I tell the parents what to look for and what we're learning.

22.V: We just finished color and shape. K-5 and I start with Elements and then I bring the principles in and I keep developing. Like this, we're 
talking about rhythm. When they come in they are going to tell me the difference between Project A on this side and Project B on this side. And they're going to have to figure out if they choose A, they're going to have to tell me how they're going to do it, and list the steps. So they both include painting. One has less. Some kids don’t like watercolors. This way they can choose.

Author: What do you feel your program offers and art education in general provides your students?

22.V: So many things. Right now our math goal for the year... I didn't realize how much math I teach until they pointed it out.

22.V: When we went to Craftworks in-service we did STEAM. It was wonderful! It all connected in our heads and we went out of there all excited. So I'm using the terms that they have identified that they want to use as vocabulary.

22.V: When they leave here, these kids know color theory. The guy at the middle school wrote me a note. "I don't have to teach it! They've got it!"

22.V: We have a dedicated theme at our school each year. We've done outer space. We've done oceans. We've done wildlife...continents. Last year was dedicated to me, it was ARTS MAKE AN IMPRESSION. 
In response to the thesis question, "How the art educators and their teaching methodologies influenced by the context of where they teach?" art educator $22 . \mathrm{V}$ reflected on the region.

Author: In this region, do good teachers get pulled out of state because of better pay?

22.V: Yes. But if you're raising your kids here, a lot of them will stay. New ones come in, get their wings here, and we mentor them, and off they go. We train them well.

Author: What do you feel might be the biggest challenge to being an art teacher in West Virginia?

22.V: The time element. We're used as a planning period. That's all we're considered. You've probably heard that a million times. That's like when the first grade went on a field trip yesterday to the pumpkin patch. They [the teachers] said, "Oh we'll be back. Some of them might go with parents. We might be fifteen minutes late for your class." So I said "keep them" they didn't like the sound of that. "We need a break." I'm wondering if they ever consider that we need breaks too. The bus was late so we didn't have them. I had cut and prepared all of the materials. They didn't even tell us they were going until the day before. "Oh we just remembered!"

Author: Do you feel this portion of the state gets left out of what happens on the state level? Do you feel it gets treated differently? 
22.V: It does. For example the conference [WVAEA]. Now I've done two conferences here at Shepherd for the WVAEA. We brought them over here. Attendance isn't so great. I was RESA 8 rep for years and finally I said, "I cannot make it to your meeting in February in Panera in Summerville." At that time of the year? Can't do it. I've been as far as Marshall, and Parkersburg. It's tough to stay connected. The people here don't go into the organization. It's like you get to Morgantown. The college is there.

22.V: I think we have it good over here. We have the culture of the arts here. Harpers Ferry. Being close to Washington and the museums. I like to go to the Phillips Gallery.

Author: Do you ever get to take students over?

22.V: When we had $6^{\text {th }}$ grade. I would go with the $6^{\text {th }}$ grade. I had an art club then and I would go with the art club. They would go with me to the galleries. It's too difficult. They make field trips so hard. A bus is $\$ 900$. Then you have to get a substitute. Don't want to cancel my class somebody might miss their break.

Author: We always think this part of the state would have such easy access but its not that easy.

22.V: No 


\section{Case Analysis}

For 35 years art educator $22 . \mathrm{V}$ has brought a steady and consistent program to the student and community in their service area. Identifying as an art educator who was trained "art on a cart", this educator has developed the skills and flexibility of taking the art lessons to students in regular classrooms as opposed to having a stationary art classroom. This art educator was raised and educated outside of West Virginia but has lived in state over 30 years. They have taught as a classroom teacher, a mentor to pre-service teachers, as a summer arts program coordinator and as a coordinator for educator professional development. Educator 22.V reports this to be their last year teaching for the public school system but they intend to stay connected to the community arts scene in their district.

Educator 22.V reports positive monetary and administrative support for their program. They also have many years of experience writing grants and acquiring monies for technology and extra supplies. Educator 22.V identifies examples of positive rapport and support from administration and peer educators but also sees the art education program used as a planning period for other educators without the due respect for the work that art educators do to implement their projects and programs.

Educator 22.V brought a multitude of cultural both local and global to their lessons. Projects also incorporated the necessary goals required to be taught to specific ages and stages of the elementary school curriculum. This educator presented carefully executed teacher examples for each lesson as well as step-by-step models. Materials, tools, examples, and works in progress were neatly organized throughout the classroom and artwork was displayed throughout the school. 
Figure 23 Analysis

There were numerous examples of works that could have been chosen but this photograph of the display at the entryway of 22.V's school showed a number of examples at once and exemplified the importance of student art work. The two pumpkins displayed on the table were grown in on the school grounds, used for drawing projects in the art classroom, and then put on display with student work. The colors reflect the seasons, their placement reflects the importance and aesthetic addition of student work to a school setting, and the variety of work and arrangement of the display board are a reflection of an art educator's careful work.

\section{Word Frequency Analysis}

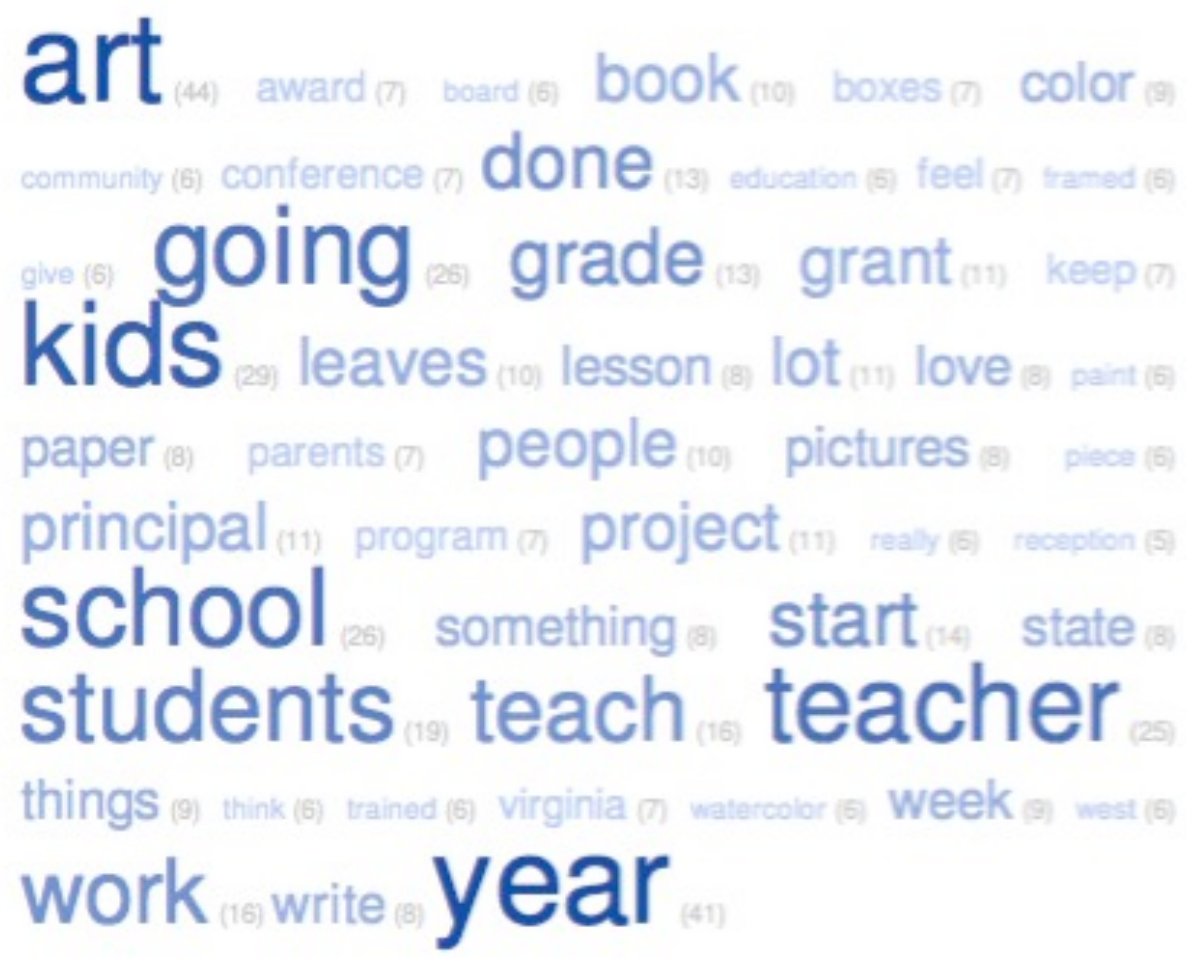

Figure 24; Word frequency chart generated from interview transcripts with educator 22.V, 2015. 


\section{Data Analysis}

The purpose of this proposed study is to examine art educators in West Virginia. The following research questions were addressed in this study:

1. Who is teaching art in rural and urban West Virginia; what education, background and experiences do they have?

2. What resources and support do they receive for their art programs?

3. What methodologies do selected art teachers follow in the planning, instruction, and assessment of art in the K-12 art classroom in rural and urban West Virginia;

4. How the art educators and their teaching methodologies influenced by the context of where they teach?

Each of these thesis questions was addressed through a semi-structured interview format. In eight of the twelve cases represented in this paper, a site, or school visit occurred. In four of the twelve cases represented in this paper, interviews were conducted outside of the classroom. For the in school visits, photographs were taken but for the off-site interviews, teachers were relied upon to provide an example. Two of the teachers who met me off-site have invited me to visit their classrooms. The other two are retired.

Information was collected through interviews, observations, and a survey. Interviews were recorded for accuracy and notes and photographs were collected on site. Collected data was broken into themes and analyzed by hand based on theme categories as they pertained to the research questions. Through this method of analysis, the collected data identified similarities or 
differences of phrases and categorized these findings into themes (Glaser \& Strauss, 2011;

Robson, 2002).

The following matrix shows the participants who are represented in this paper.

Table 1: The Participant Matrix

\begin{tabular}{|c|c|c|c|c|c|c|c|c|}
\hline Educator & RESA & $\begin{array}{l}\text { Grade } \\
\text { Level } \\
\end{array}$ & $\begin{array}{l}\text { Years } \\
\text { Teaching } \\
\end{array}$ & $\begin{array}{l}\text { Off } \\
\text { Site } \\
\end{array}$ & $\begin{array}{l}\text { In } \\
\text { School }\end{array}$ & Rural & $\overline{\text { Urban }}$ & $\begin{array}{l}\text { Urban } \\
\text { Cluster }\end{array}$ \\
\hline $1 . \mathrm{A}$ & I & Secondary & $35+$ & & $\mathrm{X}$ & & & $\mathrm{X}$ \\
\hline 2.B & I & Elementary & $11-20$ & & X & $\mathrm{X}$ & & \\
\hline 3.C & II & Secondary & $11-20$ & X & & $\mathrm{X}$ & & \\
\hline 5.E & III & Secondary & $25-30$ & & $X$ & & & $X$ \\
\hline 6.F & III & Elementary & $11-20$ & & $\mathrm{X}$ & & X & \\
\hline 8.H & IV & Elementary & $0-5$ & & $\mathrm{X}$ & $X$ & & \\
\hline 12.L & VI & Secondary & $5-10$ & & $\mathrm{X}$ & & & \\
\hline $14 . \mathrm{N}$ & VII & Secondary & $30+$ & X & & $\mathrm{X}$ & & \\
\hline $17 . Q$ & VII & Secondary & $20-25$ & $\mathrm{X}$ & & $\mathrm{X}$ & & \\
\hline $18 . \mathrm{R}$ & VII & Secondary & $5-10$ & & $\mathrm{X}$ & & & $\mathrm{X}$ \\
\hline 19.S & VII & Secondary & $20-25$ & & $\mathrm{X}$ & & & $\mathrm{X}$ \\
\hline 21.U & VIII & Secondary & $25-30$ & $X$ & & & & $X$ \\
\hline $22 . \mathrm{V}$ & VIII & Elementary & $35+$ & & $\mathrm{X}$ & $\mathrm{X}$ & & \\
\hline
\end{tabular}

For this research, attempts were made to extend a survey and invitation to be interviewed through contacts via email to all 55 counties in the state of West Virginia. Through this method and word-of-mouth, 18 interviews were conducted. 16 of which had useable data collected and 12 of which are represented within this paper. Time constraints and overrepresentation from a particular RESA and gaps in data collection helped narrow down this selection.

Of the twelve represented in this paper only one is male and the other female. There were two males interviewed total. A third agreed to an interview but never returned a confirmation and there was no longer an opportunity to meet. The survey results report, of 50 survey responses, 3 
did not specify gender and of the remaining 47,39 identified as female and 8 as male. $83 \%$ of respondents identified as female and $17 \%$ identified as male.

I discovered that many of our art educators are teaching near or at least in the state where they were raised and educated. This brings to the students in their classroom a person that understands the region and local culture. Educator 1.A, 2.B, 5.E, 6.F, 8.H, 12.L, 14.N, 18.R, 19.S, and 21.U are all teaching in the RESA where they were raised and educated. Educators 3.C, and 17.Q are natives of West Virginia but teaching in different RESAs than where they were raised. $22 . \mathrm{V}$ is the only art educator represented in the interviews who was not born, raised and educated in West Virginia. This is a testament to these educators dedication for bringing the arts to the students of their regions and communities.

The length of experiences from educators ranged with the least number of years teaching was 7 years' experience. The longest number of years reported was 35 years by educator 22.V. Educators 1.A and 14.N had just under 35 years and educator had been in the field for more than 35 years but had taken almost 10 years off to raise children. The survey results reported only 1 participant of 50 gave no number of years dedicated to the teaching of art. See table below.

Table 2:

Survey Question: Indicate the number of years dedicated to teaching art:

\begin{tabular}{lll}
\hline Answer Choices & Response \% & \# of responses \\
\hline 0-5 years & $24.49 \%$ & 12 \\
6-10 years & $18.37 \%$ & 9 \\
11-20 years & $26.53 \%$ & 13 \\
21-30 years & $18.37 \%$ & 9 \\
31+ years & $12.24 \%$ & 6 \\
Total: & & 49 \\
\hline
\end{tabular}


The Art educator survey results from 50 respondents indicated that exactly $25 \%$ of the respondents had 1-5 years of experience in the classroom. Another $25 \%$ of respondents had experience in the 11-20 years of experience range. $18.75 \%$ of respondents indicated 6-10 years of experience in the classroom and another $18.75 \%$ of respondents reported $21-30$ years of experience. The lowest percentage represented in the survey was $12.50 \%$ with $31+$ years of experience in the classroom.

\section{Methods of Instruction and Strategies}

For the third question, many strategies and philosophies were uncovered but the core mission of these educators was to give their students the best art education experience possible. Every single educator represented in this thesis provided examples of ways that they were contributing their personal time and money into the what they provide their students. Many provided examples of ways they were going above and beyond their classroom hours to design lessons, attend to works in progress, arranging materials and supplies in the classroom, preparing artwork for display, setting up exhibits and disassembling exhibits, and self-directed professional development. Every single educator represented in this interview expressed work they do in their service community as artists. These examples present evidence of the valuable contribution art educators make to their communities as whole.

Educators 2.B, 6.F, and 8.H, all elementary art educators, felt the testing-based education system was taking from the student's abilities to think creatively. They felt art classes gave elementary students' an opportunity to think creatively, to problem solve, and to express themselves in ways their general classroom curriculum no longer supported. Each of the three

felt that data driving education and assessment based education was reducing student's fine and 
gross motor skills. They talked the impact it is having on handwriting, drawing, and the ability to use simple tools such as scissors.

Educators at the secondary level also talked about the impact of data driven education on gross and fine motor skills. Educators 1.A, 3.C, 5.E, 12.L, 14.N, 17.Q, 18.R, 19.S, and 21.U all discuss their students' lack of abilities in fine motor skills. Several felt the loss of handwriting in the elementary schools was contributing to this decline. They talked about gaps in student's art education, as so many students in West Virginia get no specialized art education in the elementary schools. The limited segment of art education in the middle schools was also seen as creating a deficit in the fine motor skills necessary to draw and create with multiple mediums in their art education courses.

Educators 1.A, 17.Q, and 19.S specifically discussed how students were coming to high school level I visual art courses still drawing exactly as one would expect a primary student might draw. Educator 1.A said there was only art education taught in 2 of the 19 elementary schools in the county. 17.Q also said there was limited to no specialized art education taught in the elementary schools in their service county. Educator 19.S said there was elementary art education in two of the four elementary schools that fed their service high school but didn't feel the ones that had it retained much of what they might have learned.

All of the art educators suggested the limited exposure in middle school attributed to deficits. Educator 21.U felt that it was a great disservice to give students such little exposure in middle school and then mandate a full year in high school where they arrived unprepared for the year long course work required for meeting the criteria of their fine arts credit. This educator felt 
the gap created an attitude where visual art classes were deemed less than important, which led to levels of apathy when they reached high school.

The art educators in the interview portion of the study talked about bringing both local and global cultures into their classroom. Educators 6.F, 8.H, 21.U, and 22.V specifically talked about designing lessons revolving around global cultures and that they felt these lessons contributed to global awareness. They discussed consulting the standards as part of their process for structuring lessons around culture. Educators 1.A, 2.B, 6.F, 8.H, 17.Q, 19.S, 21.U, and 22.V expressed specific lessons and ways they brought local culture into their classroom lessons. Several said that students' had trouble recognizing their local culture or seeing it as important. Educator 21.V provided several examples including having students design a seal for the county in which the school was located. Educator 17.Q cited local festivals as an indicator of the level of investment a region put into arts education programs. They suggested a distinct link saying that the crafts exhibited at festivals where communities supported school arts programs were much better crafted than those found in communities where the arts had been marginalized in the curriculum, lamenting the loss of West Virginia craft and culture.

Science, Technology, Engineering, Art, and Math (S.T.E.A.M), is a movement that is taking hold in art education curriculums across the county. Science, Technology, Engineering, and Math (STEM) is a widely popular initiative to bolster science and math education in the United States. STEAM is an answer to STEM as it incorporates creative thinking, design thinking, and language into the STEM curriculum. Multiple teachers expressed great interest and excitement regarding this new movement. Educators like 6.F, 18.R, 17.Q, 21.U, and 22.V all spoke with enthusiasm regarding the impact of S.T.E.A.M. thinking had in their curriculum and instruction. 
Educator 18.R's program is physically situated and works in close proximity to the engineering program at the high school where they teach. It was the only high school observed where a 3D printer was in use for both programs. 18.R's school collaborated lessons between the engineering and the art programs in order to foster better creative and design thinking among the students. This interrelating of the visual arts, design, and aesthetics with science, math, and engineering fosters multiple perspectives and ways of problem solving which can better prepare learners for a 21 st century global economy.

As art educators discussed their experiences as art educators in West Virginia, the "planning period" came up in numerous interviews. All mentioned that the regular classroom teachers' planning period affected the time length of their own art classes. Teachers reported on several occasions that their peers indicated in some way that the art classes were important to them because it gave them a planning period. In one instance, 2.B, reported that the impetus for the creation of the art educator positon in their school was due to the county's implementation of a 40-minute planning period.

\section{Support for Art Education programs}

Art educators in both the survey, and through interviews, reported relying on multiple sources for equipment, supplies, and materials for their programs. This study reports that every art educator interviewed had at least 2 sources of financial and material support for their program. The following chart is derived from the data gathered through the survey conducted for this research. 
Table 3

Survey Question: "What kind of funding does your program receive? Check all that apply."

\begin{tabular}{lll}
\hline Funding Sources & \# of Answers & Total \% of support \\
\hline Private donations & 12 & $25.53 \%$ \\
Federal funds & 6 & $12.77 \%$ \\
State allocated & 20 & $42.55 \%$ \\
County funds & 36 & $76.60 \%$ \\
Parent Teacher Associations & 8 & $17.02 \%$ \\
Grants & 20 & $42.55 \%$ \\
$\begin{array}{l}\text { Other (i.e. out of personal } \\
\text { funds) }\end{array}$ & 14 & $29.79 \%$ \\
\hline
\end{tabular}

This table represents 47 total answers out of the 50 participants from the survey. Three participants chose not to answer the question.

Art educators reported being conservative and resourceful with their materials and supply money. Several reported concerns about the potential drop in support if county education tax levies were not passed. These results indicate a variety of different ways art educators must explore for financial support for their programs. One educator in RESA I only received monies from grants and donations for art supplies, equipment, and materials.

\section{Art Education and Context}

Art educators interviewed for this research had lived in West Virginia most of their lives. Only two represented in the paper were not born in West Virginia but both had lived in-state for more than 25 years. All of the teachers taught within 30 miles of their schools. Two teachers 
interviewed for this paper, 3.C and 17.Q live outside the county where they taught but both live in a neighboring county to their school. The people who are teaching visual arts courses in West Virginia have many years of experience and connection to the people and communities in which they serve bring to practice a genuine understanding of the culture, economy, and geography of the region. They are an integral part of the education system and culture of their environment.

The majority of educators representative of the research live in rural or urban cluster regions. Educator 6.F and 5.E from RESA III teach in the most populated area with 18.R and 21.U being in the next most populated areas. 3.C represents a rural area to the western side of the state and 17.Q teaches in a rural mountain region. Educators 1.A, 2.B and 8.H, represent the southern rural quadrant of the state however, 1.A reported in the interview and was observed teaching a more diverse and urban cluster population than might be expected for the region.

Educators 1.A, 2.B, 3.C, 6.F, 12.L, 14.N, 17.Q, 18.R, 19.S specifically address issues of poverty affecting their students. 1.A and 3.C specifically talked about the difficulty some students face in getting their basic needs, food, clothing and shelter, met on a daily basis. 19.S addressed drugs as an issue in their school and 12.L reported a movement among students within their school to combat drug abuse among teens. 17.Q has taught in two different RESAs and therefore has worked with students from the a wide variety of backgrounds and has also taught incarcerated youth. 2.B reported teaching students from every background from affluence to severe poverty. 18. R also reported teaching students from every socio-economic background. 18.R was the only educator who reported language obstacles with students who are learning English as their second language. 21.U and 22.V saw a range of socio-economic backgrounds among their student population. They also saw an influx of students from the Washington DC metropolitan area spreading into their area which is very different from the rest of the state. 12.L 
is also seeing an influx of people from other states and countries due to the economic boom brought about by fracking.

Culture and community were acknowledged within every interview. Educators $14 . \mathrm{N}$ and 19.S didn't specify local cultural influence. Educator 14.N felt only it varied as to whether culture played a role in the perceptions and methodologies of the art education classroom. Educators 6.F and 8.H stated that their students didn't understand the importance of their culture or their student's culture had been marginalized. 19.S also reported students having no sense of their local history or culture. 21.U and 22.V talked about specific lessons where local culture and history were incorporated and $6 . \mathrm{H}$ was in progress with students as they use Apple IPads to create an online history book about the history of their urban neighborhood. Both 17.Q and 21.U felt the marginalizing of arts education courses was directly attributing to a loss of culture and loss of pride in the culture and crafts of the region. 


\section{CHAPTER 5}

\section{Discussion/Conclusion}

The visual arts are considered a core subject on the federal level but how visual arts curriculum and programs are implemented is largely dependent on state policy for

implementation. The West Virginia Board of Education includes the visual arts in their standards for curriculum and instruction in the visual arts for the pre-K through 12 grade levels in the public school system. However, it does appear, through this research, the implementation of visual art programs varies significantly from school to school and county to county across the public education system of West Virginia.

\section{Art education is a recognized component of the West Virginia public school curriculum and is implemented using content standards and objectives.}

The art educators in West Virginia who participated in this study reported using the state's standards as found on the West Virginia Department of Education website, to design their lessons. These standards are part of the $21^{\text {st }}$ century common core standards and are clearly defined in a specific sequence for optimal learning in the visual arts at each grade level. The content standards objectives for the visual arts from pre-K to the $12^{\text {th }}$ grade are available and accessible through the West Virginia Department of Education's website. These objectives serve as guideposts for the West Virginia art educator to design their curriculum and lessons. Educators reported consistently using these objectives in the designing of lesson plans. 


\section{$21^{\text {st }}$ century technology is being utilized in visual arts classes in the K-12 public school system in West Virginia.}

The findings of this study indicate technology is being utilized in the visual arts classrooms in West Virginia. Computer animation, 3D design and printing, and digital photography were some of the art mediums influenced by technology in the classroom. During this research process, IPads were being distributed to all of the students in the high school of a participating art educator.

This study suggests West Virginia art educators are gaining access to programs and applications of technology for improving the education and classroom experience for their visual arts students. Programs like STEAM (Science Technology Engineering Art and Math) were reported by educators to be a new and positive way to integrate the arts with the other academic discipline. Immersion into technology and the implementation of programs like STEAM in the visual arts, is an important part of keeping West Virginia students prepared for success in a global economy.

\section{Differentiation of instruction is an integral part of the lesson planning and classroom environment in visual art programs across West Virginia.}

Differentiation in instruction was also reported as a regular part of instruction design. The findings suggest art educators in West Virginia operate programs that are considered optimal for a variety of learners. Educators reported having the full spectrum of learners and therefore designed lessons with this variety of students in mind. West Virginia art educators saw the visual arts as providing an avenue of learning and expression that ensured success for most students of all levels. 
Art educators must persevere in a high-stakes testing atmosphere that marginalizes the arts as a core subject.

As there are no previous studies of art educators in West Virginia, this study uncovered evidence of the dedication of service by West Virginia art educators in the midst of a hierarchal order of importance with respect to curriculum that can have the tendency to marginalize the visual arts as a core and supported subject in the public education system. Art education is not always provided the same status as math science and language arts. As one art educator noted, “art has its own language". This research indicates many West Virginia art educators feel they must continually prove the value of visual arts programs in an atmosphere that does not always value the arts. Educators in this study also reported programs such as STEAM have the ability to both enhance their student's learning and provide much needed validation for the value of visual arts programs as it connects to all subjects and disciplines in the curriculum.

Many art educators participating in this study felt that their programs provided opportunities in knowledge acquisition often overlooked by administration and peers. For example, art educators in this study underscored the structure of art education classes as already being what current models of education are striving to be. Project based learning (PBL) is gaining traction as a method of education in the West Virginia public education system (WVDOE, 2015). PBL is constructivist in nature and design as it the role of the educator is to present the problem or project and serve as a guide through the process. Students are to conduct their own learning situations and through teamwork as they creatively problem-solve, or construct the project. Art educators in West Virginia felt visual arts courses were already implementing these processes of learning in their classes. 


\section{Context does have an impact on visual arts educators and their programs.}

It is the West Virginia art educator who is given the task of implementing art education programs for the students of the public education system. West Virginia art educators operate their programs under a variety of conditions and contexts. Art educators in West Virginia teach students from a wide variety of social and economic backgrounds. The majority of educators teach in rural areas or within urban cluster regions that are surrounded by large tracks of rural land. West Virginia does have some urban areas but is also one of two states in the country that lost population last year. West Virginia also faces a higher rate of poverty in the United States with approximately one-third of school age children living below the poverty line. Some educators represented in this research reported higher numbers of poverty among their student population, as well as homelessness, and hunger. Art educators reported they felt visual arts classes provided an outlet for students facing difficulties in their personal lives.

West Virginia is diverse in its geography and socio-economic populations. Geography plays a role in arts programs, as so much of West Virginia is rural. Educators report trips to museums and galleries require substantial funding that is not available in their areas. This study indicates these factors vary and impact how art educators implement their programs. In spite of these variances, art educators report providing a necessary means and avenue of knowledge that is critical to the cognitive, social, and emotional wellbeing of the students of West Virginia's public schools.

Art educators in this study reported time constraints, monetary support, local economy, and general attitudes toward the visual arts influence how they design and operate their art education programs. This study found policy-making on the state and federal level impacts what 
West Virginia art educators teach in the visual arts programs they direct. The participating art educators provided specific examples of the impact of these factors on the lessons they teach.

The art educators who participated in this research project were made up of people who were from West Virginia or who have been dedicated to living and teaching in the state for the majority of their lifetimes. This suggests the people teaching art education in West Virginia have a genuine sense of their communities and the students they teach. It appears they understand the backgrounds of the culture, economy, and geography of their service areas. Their dedication to their programs and the students of West Virginia indicates these educators are invested in their work, their communities, and what a visual arts education can bring to the students they teach.

\section{The access to art is not equal.}

Data collected from this research shows that not every county receives support for visual arts educators and visual arts programs equally. This study revealed that elementary art education programs are not available in all 55 counties. Some counties had elementary art education in all elementary schools, other counties had visual arts in only a few elementary schools. Many art educators reported little to no elementary art education in several counties across West Virginia.

In the counties where elementary art education was taught in every elementary school, the research indicated art educators have to travel to more than one school. Participating educators from counties with art education in all elementary school, RESA VII and RESA III, reported art educators visiting as many as five and six schools in one week. In these instances, as well as those elementary schools with on-site art educators, indicated students are receiving one visual arts class every two weeks that is between $30-40$ minutes in duration, and that is including transition time between students, classes, and materials. 
The research indicated art educators participating in this study, celebrated their role and what the visual arts bring to student learning. Many of the educators who participated would like to see more consistent and equal access to funding, support, and outside classroom art activities such as museum and gallery visits at every level.

Time constraints and limited access to visual arts programs create gaps in student knowledge.

This study shows that not all elementary students have access to visual arts classes. Research also indicated some middle schools did not have visual art classes taught by a certified visual art educator. However, most counties and educators reported middle school arts classes were 6-9 weeks in rotation. Most middle school students in West Virginia attend a maximum of 9 weeks in a visual arts class throughout their entire middle school education. These findings suggest that the visual arts are taught but at a minimum time length. This brief experience with the visual arts may not be providing the skills necessary for student preparedness for taking visual arts courses in high school. As every high school in West Virginia has an arts course requirement for graduation, the minimal exposure in middle school appears to be creating a gap in basic visual arts skills and knowledge.

\section{Lack of a background in the visual arts is having an impact on what high school art educators are able to teach.}

The findings of this study indicate there is a wide variance in the implementation of art education programs in West Virginia. The results show differences in how much visual arts education students are exposed to from school to school and county to county. The research also indicates there are gaps in the sequence of programs offered to the students of West Virginia's public schools. Because so many students do not receive specialized art education in elementary 
school and limited exposure in the middle schools, high school art educators have to go back and re-teach basic art knowledge and skills.

Art educators represented in this study expressed concern over the loss of handwriting and fine motor skills of students moving through the elementary schools today. Educators on the high school level reported a lack of basic fine motor skills to do even simple cutting and pasting. This study found that many of these art educators felt that the loss of fine motor skills started with the loss of handwriting and impacted the way they taught their lessons.

\section{Support for art education programs varies and is expressed in many forms.}

High school art education is a graduation requirement and therefore the programs in the secondary schools were supported with some monies collected through levies and from faculty senate monies. Every art educator participating this study, reported applying and receiving grant money or receiving donations from local entities such as parents, business, neighbors, and extra allowances provided by school administration if they were able to secure money for the program. Most educators reported supplementing equipment, supplies, and materials from their own pockets. Many educators reported connecting with community venues as a source of support for student art exhibitions.

\section{School administration has a vital role in the levels of support and implementation of visual} arts programs.

Administrative support by school faculty and principals was a major theme among educators. Most reported that a positive rapport was critical for receiving school support for programs. The level of support offered by school administration was described as critical and more than one educator said that it affected their choices regarding further employment with the 
school. Many felt that by doing work outside of their classroom curriculum played a role in they support they received in return. Administration does indeed, have an important part in the support of a visual arts education program. The more an administrator understands what a visual arts program can provide students and the school community, the better environment an art educator has for directing a successful visual arts program. It is important to note that art educators can still direct successful programs without direct support from a school administrator.

High school art education is a graduation requirement and therefore the programs in the secondary schools were supported with some monies collected through levies and from faculty senate monies. Every art educator reported applying and receiving grant money or receiving donations from local entities such as parents, business, neighbors, and extra allowances provided by school administration if they were able to secure money for the program. Most educators reported supplementing equipment, supplies, and materials from their own pockets. Many educators reported connecting with community venues as a source of support for student art exhibitions.

\section{Recommendations}

There is a tremendous need to better understand the impact of the arts, namely visual arts, have on students receiving a public education in the West Virginia school system. This study indicates art education provides important learning opportunities for the intellectual, emotional, and social growth of students in West Virginia.

A more in depth study of which counties and populations in West Virginia receiving arts education in the elementary schools versus those regions and populations who do not receive any specialized visual arts education in the elementary schools is needed and could illuminate the 
vital role of the visual arts in West Virginia's public schools and why we must work to keep them. 
APPENDICIES

APPENDIX A:

West Virginia RESA Map

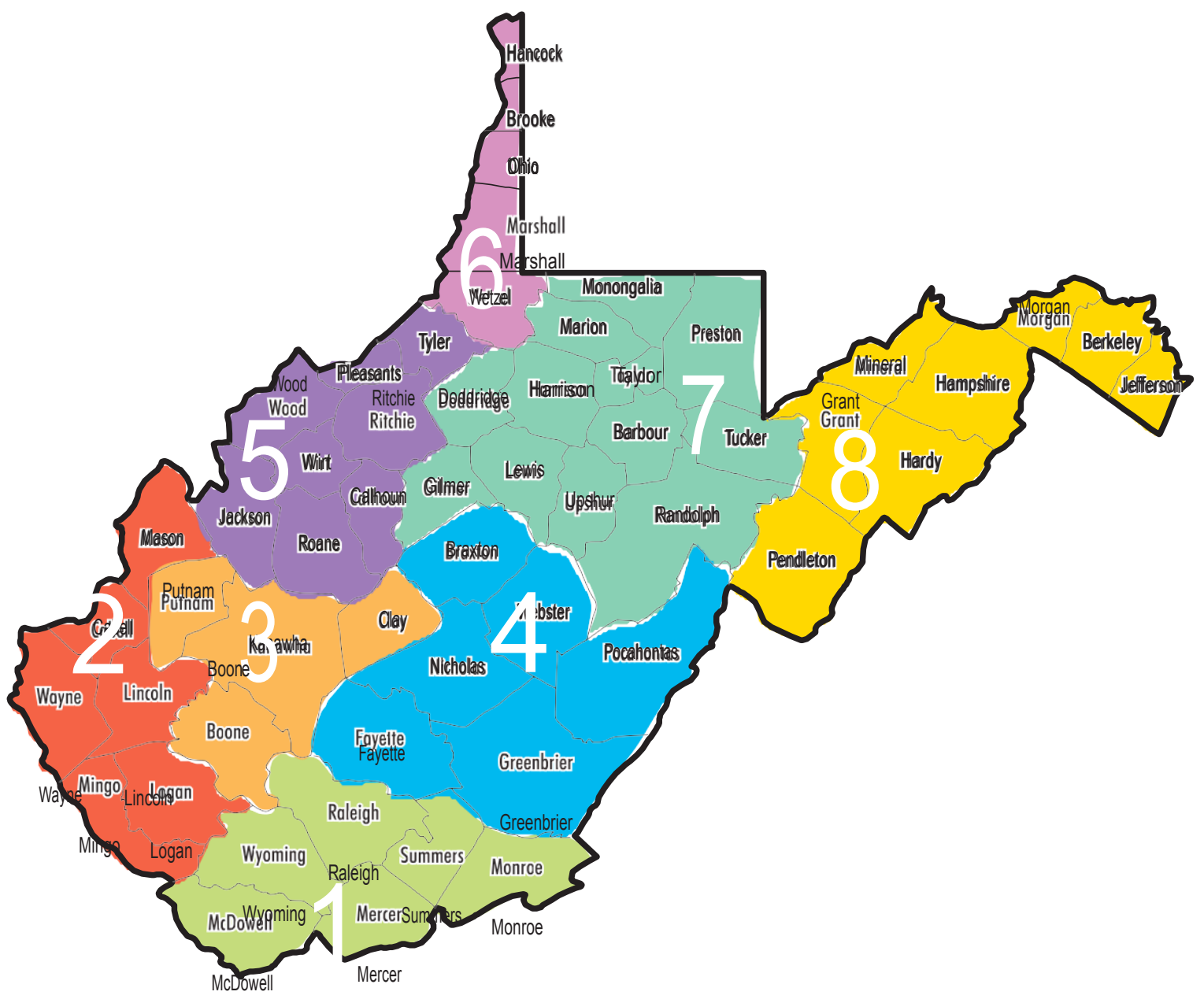




\section{APPENDIX B:}

WV Rural and Urban Map

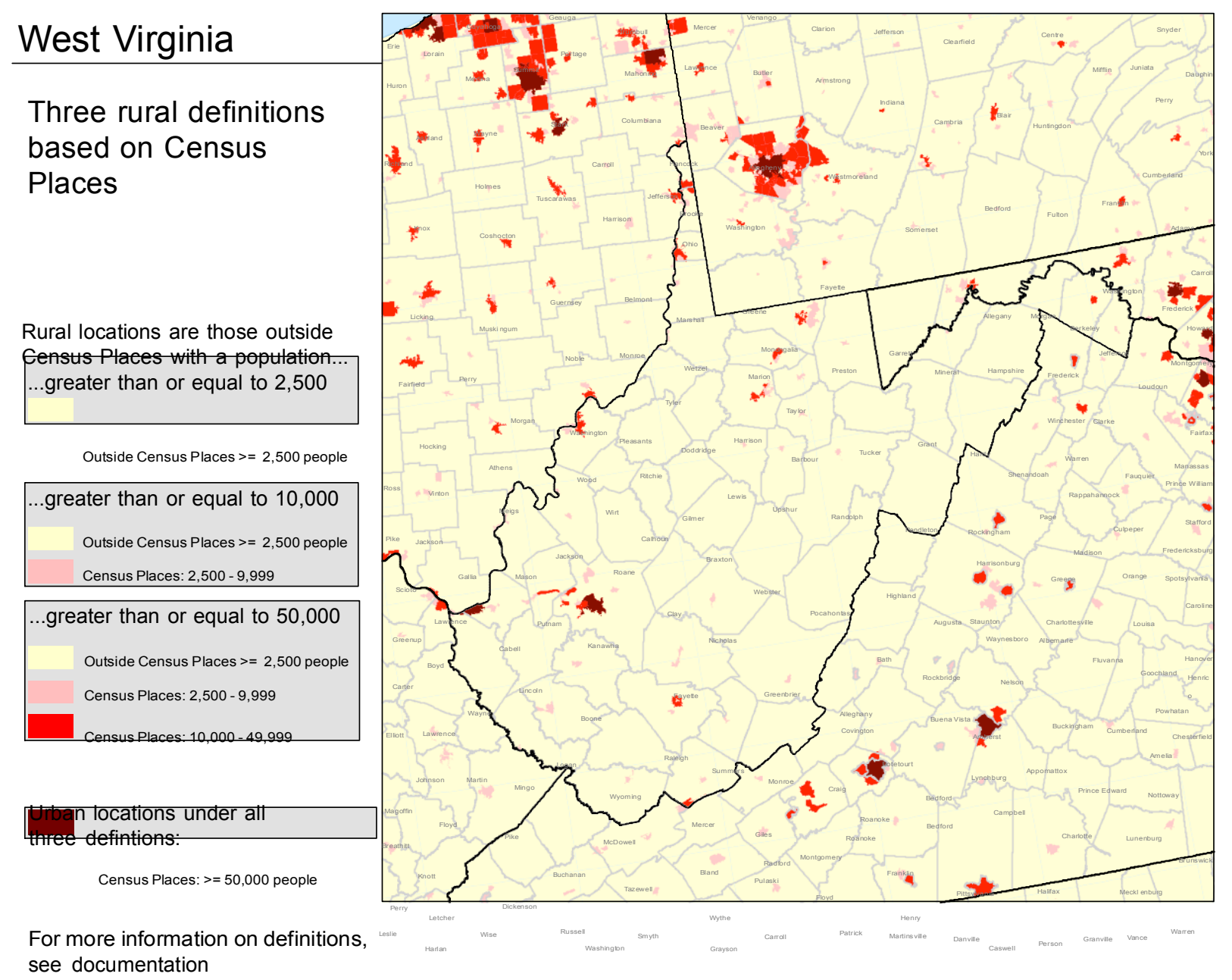




\section{REFERENCES}

Arts Education Partnership, (2014, March). A Snapshot of StatePolicies for Arts Education. Washington, DC: Author.

Bates, J. (2000).Becoming an art teacher. Belmont, CA: Wadsworth/Thomson Learning.

Boehm, M. (2011, April 14). Federal cultural-grants agencies to lose $11.2 \%$ of their funding under budget deal. L.A. Times.

Bogdan, R. C., \& Biklen, S. K. (2003). Qualitative research for education: An introduction to theories and methods. Boston: Allyn \& Bacon.

Brens, M., \& Hickman, R. (2011). Engagement in the arts and self-efficacy of adolescent women. Visual Inquiry, 1(1), 9-19.

Brady, K. P., Thomas, J. Y. (2005). The Elementary and Secondary Education Act at 40: Equity, Accountability, and the Evolving Federal Role in Public Education. Review of Research in Education, 29, 51-67. Retrieved from http://www.jstor.org/stable/3568119

Bureau of Business \& Economic Research. West Virginia University College of Business and Economics (2014). West Virginia Economic Outlook 2014. Retrieved from: http://www.be.wvu.edu/bber/outlook_pdfs/WV-Economic-Outlook-2014.pdf

Clark, G., Zimmerman, E., Educational Resources Information Center (U.S.), \& United States. Office of Educational Research and Improvement. (1997). Project ARTS: Art for rural teachers and students : Javits gifted and talented students education program : Identification, curriculum, evaluation. Washington, DC; Bloomington, Ind: Indiana University.

Congdon, K. (2004). Community art in action. Worcester, Mass.: Davis Publications.

Crotty, M. (1998). The foundations of social research: Meaning and perspective in the research process. London: Sage Publications.

Crouch, R. (2007, November 15- updated 2012, May). The United States of education: The changing demographics of the United States and their schools. Retrieved November 20, 2014.

Denzin, N. K., \& Lincoln, Y. S. (2003). Strategies of qualitative inquiry (2nd ed.). Thousand Oaks, CA: Sage.

Dewey, J. (1934). Art as experience (18th ed.). New York: Minton, Balch \& Company.

DeYoung, A. J., \& Howley, C. B.. (1990). The Political Economy of Rural School Consolidation. Peabody Journal of Education, 67(4), 63-89. Retrieved from http://www.jstor.org/stable/1492681

Efland, A. (2002). Art and cognition integrating the visual arts in the curriculum. New York: Teachers College Press. 
Efland, A. (1990). A history of art education: Intellectual and social currents in teaching the visual arts. New York: Teachers College Press

Eisner, E. (2002). The arts and the creation of mind. New Haven: Yale University Press.

Eisner, E. (1991). The Enlightened Eye: Qualitative inquiry and the enhancement of educational practice. New York, N.Y.: Toronto.

Eisner, E. (2004). Handbook of research and policy in art education. Mahwah, N.J.: National Art Education Association.

Eller, R. (2008). Uneven ground Appalachia since 1945. Lexington, Ky.: Univ. Press of Kentucky.

Emerson, R. M., Fretz, R. I., \& Shaw, L. L. (1995). Writing ethnographic fieldnotes.

Greene, M. (1978). Landscapes of learning. New York: Teachers College Press.

Greene, M. (1995). Releasing the imagination: Essays on education, the arts, and social change. San Francisco: Jossey-Bass.

Gutman, David. (2015, March 26). W.Va. losing population faster than any other state. The Charleston Gazette. Online.

Hetland L., Winner E., Veenema S., Sheridan K. (2007). Studio thinking: The real benefits of visual art education. New York, New York: Teachers College Press.

Hoyle, R. H., Harris, M. J., \& Judd, C. M. (2002). Research methods in social relations. Fort Worth, TX: Wadsworth.

Kvale, S. (1996). Interviews: An introduction to qualitative research interviewing. Thousand Oaks, CA: Sage Publications.

Liepolt, L., \& Rodriguez, M. (2004). What is Constructivism? Retrieved, from http://www.thirteen.org/edlnlineconcept2class/constructivism/

Lowenfeld, V., \& Brittain, W. (1964, 1987). Creative and mental growth (4th ed.). New York: Macmillan.

Mathis, W. J. (2003). Equity and adequacy challenges in rural schools and communities Retrieved from http://search.ebscohost.com/login.aspx?direct=true\&db=eric\&AN=ED478057\&st $\mathrm{e}=$ ehost-live

Mertens, D. (2005). Research and evaluation in education and psychology: Integrating diversity with quantitative, qualitative, and mixed methods (2nd ed.). Thousand Oaks, Calif.: Sage Publications. 
Miles, M., Huberman, A., \& Saldana, J. (2013). Qualitative data analysis a methods sourcebook (Third ed.). Los Angeles, California: Sage Publications.

Moorefield-Lang, H., \& Heather M Moorefield-Lang. (2010). Arts voices: Middle school students and the relationships of the arts to their motivation and self-efficacy. Qualitative Report, 15(1), 1.

Moran, J. D. (2015).Summary of federal Every Student Succeeds Act, the reauthorization the Elementary and Secondary Education Act (United States, Department of Education).

Newman, T., Curtis, K., \& Stephens, J. (2003). Do community-based arts projects result in social gains? A review of the literature. Community Development Journal, $38(4)$, 310-22. Retrieved from:

http://search.ebscohost.com/login.aspx?direct=true\&db=eric\&AN=EJ677781\&sit $\mathrm{e}=$ ehost-live

National Coalition for Core Arts Standards, (12 Feb. 2014). National Core Arts Standards: A Conceptual Framework for Arts Learning (2014): n.p. Nationalartsstandards.org.

No Child Left Behind Act (NCLB) Act of 2001, Pub. L. No. 107-110, § 115, Stat. 1425 (2002). http://www2.ed.gov/policy/elsec/leg/esea02/107-110.pdf

Noss, A. (2014). Household income. American Community Survey Briefs. doi: $10.1787 / 888932966276$

Robson, C. (2011). Real world research: A resource for users of social research methods in applied settings (3rd ed.). Chichester, West Sussex: Wiley.

Ruppert, Sandra. (2010) Art Education Partnership. Creativity, Innovation, and Arts Learning; Preparing all students for success in Global Economy. February 3, 2010.

Sabol, F. R. (2013). Seismic Shifts in the Education Landscape: What Do They Mean for Arts Education and Arts Education Policy? Arts Education Policy Review, 114(1), 33-45. doi:10.1080/10632913.2013.744250

Spohn, C. (2008). Teacher Perspectives on No Child Left Behind and Arts Education: A Case Study. Arts Education Policy Review, 109(4), 3-12. doi:10.3200/aepr.109.4.3-12

United States, Census Bureau, Geography. (2010). United States Census Bureau. Retrieved from https://www.census.gov/geo/reference/urban-rural.html

United States Census Bureau, Small Area Income and Poverty Estimates (SAIPE): 2012 Highlights, U.S. Government Printing Office, Washington, DC, 2013.

United States. Dept. of Education., \& United States. Dept. of Education. Office of Planning, E. (2010). A blueprint for reform: The Reauthorization of the Elementary and Secondary Education Act. Washington, D.C.: U.S. Dept. of Education, Office of Planning, Evaluation and Policy Development. 
Walker, T. (2014, September 02). The Testing Obsession and the Disappearing Curriculum NEA Today. Retrieved from http://neatoday.org/2014/09/02/the-testing-obsession-andthe-disappearing-curriculum-2/

West Virginia Department of Education (2015). Content Standards and Objectives. Visual Art Policy 2520.12 https://wvde.state.wv.us/policies/csos.html

West Virginia Department of Education (2015). Vision for 21st Century Visual Arts. Retrieved from:https://wvde.state.wv.us/instruction/fine arts.html

West Virginia Department of Education. (2008). 21St Century Visual Art Content Standards And Objectives For West Virginia Schools (2520.12). Retrieved from http://wvde.state.wv.us/policies/p2520.12.pdf

West Virginia Department of Education (2015). Mission and Goals. Retrieved from: http://wvde.state.wv.us/boardgoals/

West Virginia Division of Culture and History (2015). West Virginia Commission on the Arts: Arts in Education Program. http://www.wvculture.org/arts/grantbook/artsined.htm

West Virginia Legislature. (2015). WV Code 5. Retrieved from http://www.legis.state.wv.us/wvcode/ChapterEntire.cfm?chap=18\&art=5A §ion=5

Whitehead, T. L., Ph.D. (2005, July 17). Ethnographically Informed Community And Cultural Assessment Research Systems (EICCARS) Working Paper; Basic Classical Ethnographic Research Methods, Secondary Data Analysis, Fieldwork, Observation/Participant Observation, and Informal and Semi structured Interviewing [Scholarly project]. In Http://www.cusag.umd.edu/documents/workingpapers/classicalethnomethods.pdf.

Yakima, G. (2015). About STEAM; FAQ. Retrieved from http://steamedu.com/about-us/faqs/

Yin, R. (2011). Qualitative research from start to finish. New York, New York: The Guilford Press.

Zhao, G. (2014, June). Art as Alterity in Education. Educational Theory, 64(3), 245-259. doi:10.1111/edth.12060 
